This work is licensed under a Creative Commons Attribution 3.0 License.

\author{
Monograph \\ urn:1sid:zoobank.org:pub:BC89C4DA-4346-4B84-8A54-976F9741636B
}

\title{
Revision, phylogeny, and microhabitat shifts in the Southeast Asian spider genus Aetana (Araneae, Pholcidae)
}

\author{
Bernhard A. HUBER ${ }^{1}$, Olga M. NUÑEZA ${ }^{2} \&$ Charles LEH MOI UNG ${ }^{3}$ \\ ${ }^{1}$ Alexander Koenig Research Museum of Zoology, Adenauerallee 160, 53113 Bonn, Germany. \\ ${ }^{2}$ Department of Biological Sciences, Mindanao State University - \\ Iligan Institute of Technology, Tibanga, Iligan City 9200, Philippines. \\ ${ }^{3}$ Sarawak Museum, Jalan Tun Abang Haji Openg, 93566 Kuching, Sarawak, Malaysia. \\ *Corresponding author: b.huber@zfmk.de \\ ${ }^{2}$ Email: olgamnuneza@yahoo.com \\ ${ }^{3}$ Email: charllmu@sarawak.gov.my \\ ${ }^{1}$ urn:lsid:zoobank.org:author:33607F65-19BF-4DC9-94FD-4BB88CED455F \\ ${ }^{2}$ urn:lsid:zoobank.org:author:6D14FCCC-F148-4293-9F23-0EB5A4119305 \\ ${ }^{3}$ urn:lsid:zoobank.org:author:8738F336-D1CC-4AD3-97E4-82BC1729A123
}

\begin{abstract}
The previously poorly known Southeast Asian spider genus Aetana Huber, 2005 is revised. Fifteen species are newly described, and the first SEM data and a first phylogenetic analysis of the genus are presented. Four species groups are well supported, one restricted to Borneo, two restricted to the Philippines, and one ranging from the Philippines to Fiji. The cladistic analysis and field observations suggest that the ancestor of Aetana built its web close to the ground, in confined spaces among and under rocks and logs. In at least two cases, evolutionary shifts of microhabitat resulted in species being adapted to life in higher forest strata, with correlated morphological and behavioral changes (lighter coloration; longer abdomen; additional sheet in web or more strongly domed web). The following species are newly described: A. abadae Huber, sp. nov., A. baganihan Huber, sp. nov., A. banahaw Huber, sp. nov., A. kiukoki Huber, sp. nov., A. libjo Huber, sp. nov., A. loboc Huber, sp. nov., A. lozadae Huber, sp. nov., A. manansalai Huber, sp. nov., A. ocampoi Huber, sp. nov., A. paragua Huber, sp. nov. and A. pasambai Huber, sp. nov. from the Philippines; A. gaya Huber, sp. nov., A. indah Huber, sp. nov., A. lambir Huber, sp. nov. and A. poring Huber, sp. nov. from northern Borneo. The female of $A$. kinabalu Huber, 2005 is newly described. A potential case of female genital dimorphism is documented in A. ocampoi Huber, sp. nov.
\end{abstract}

Keywords. Pholcidae, Aetana, Southeast Asia, cladistic analysis, microhabitat shift.

Huber B.A., Nuñeza O.M. \& Leh Moi Ung C. 2015. Revision, phylogeny, and microhabitat shifts in the Southeast Asian spider genus Aetana (Araneae, Pholcidae). European Journal of Taxonomy 162: 1-78. http://dx.doi. org/10.5852/ejt.2015.162 


\section{Introduction}

The genus Aetana Huber, 2005 was originally created in the context of a major effort to resolve the taxonomic chaos of small six-eyed pholcine spiders (e.g., Huber 2003a,b,c, 2005a,b). Previously, these pholcids were mostly subsumed in the wastebasket genus Spermophora Hentz, 1841. Most species originally described in Spermophora have been removed, either to other 'old' genera like Pholcus Walckenaer, 1805; Belisana Thorell, 1898; Metagonia Simon, 1893; Anopsicus Chamberlin \& Ivie, 1938; Paramicromerys Millot, 1946; Panjange Deeleman-Reinhold \& Deeleman, 1983; and Spermophorides Wunderlich, 1992; or to newly created genera like Buitinga Huber, 2003; Zatavua Huber, 2003; and Savarna Huber, 2005. However, despite these improvements, Spermophora and its relatives continue to be problematic. This is at least partly due to the poor knowledge of some of the groups involved. The genus Aetana Huber, 2005 is symptomatic of this.

When Aetana was created, only three species were known, based on a total of 19 adult specimens. They originated from a cave on Luzon (A. omayan Huber, 2005; 1 J, 2 우), a forest in Sabah (A. kinabalu

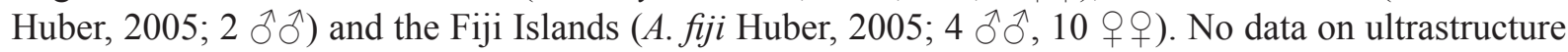
were available; nothing was known about their natural history beyond basic locality information on labels; none of the material available was suitable for molecular work; and relationships to other pholcine genera remained obscure. The present paper focuses mainly on improving this situation. It is based on almost 500 newly collected specimens representing 17 species; we provide first SEM data on several species representing different species groups; we performed the first formal cladistic analysis of relationships within the genus and to other pholcine genera; and we provide the first natural history data. An analysis of molecular data of most species will be presented in the context of a molecular phylogeny of the entire family (A. Valdez-Mondragón, D. Dimitrov, B.A. Huber, unpublished data).

A secondary focus of this paper relates to microhabitat shifts in Pholcidae and ultimately to the question of whether such shifts are causally related with species diversification. Multiple convergent shifts among microhabitats may allow the testing of correlation between ecological diversification and species diversification. A fundamental problem of such studies is the usually low sample size. Only if an ecological shift has occurred multiple times independently is a test possible for a correlation between shift and diversification (e.g., phytophagy in insects: Mitter et al. 1988). Pholcidae may provide such an opportunity. Shifts among microhabitats appear to have occurred multiple times convergently in different directions: leaf litter $\leftrightarrow$ large protected spaces $\leftrightarrow$ among low vegetation $\leftrightarrow$ green leaves. The latest molecular phylogeny of Pholcidae (Dimitrov et al. 2013) supports several such shifts, but morphological data suggest that many more cases exist (B.A. Huber, unpubl. data). In Aetana, for example, the dark coloration and short abdomen of $A$. omayan suggested a microhabitat near the ground while the light coloration and long abdomen of $A$. kinabalu suggested a different microhabitat, higher among the vegetation. We tested these assumptions in the field and combined them with a phylogenetic analysis, thus providing one more piece in the mosaic of pholcid diversification.

\section{Material and methods}

Most of the material studied herein was collected during recent expeditions to the Philippines (Feb.Mar. 2014) and northern Borneo (July-Aug. 2014). Further specimens came from student projects at Mindanao State University - Iligan Institute of Technology dealing with ecological aspects of pholcid diversity in the Philippines. The material is currently deposited at the Zoologisches Forschungsmuseum Alexander Koenig, Bonn (ZFMK), Mindanao State University - Iligan Institute of Technology, Iligan (MSU-IIT), and Sarawak Museum, Kuching (SMK). Further material came from the California Academy of Sciences, San Francisco (CAS) and the Netherlands Centre for Biodiversity Naturalis, Leiden (RMNH). 


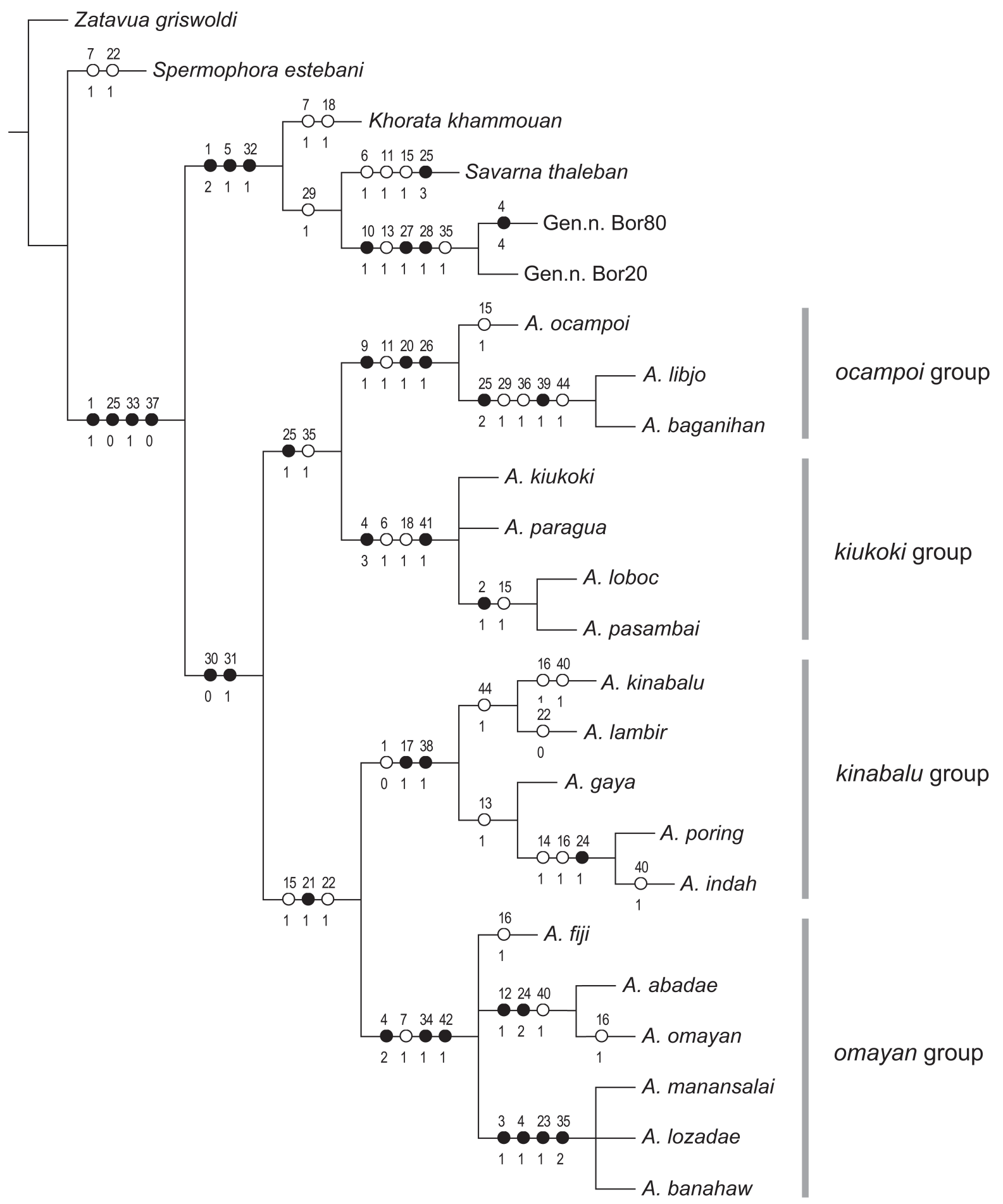

Fig. 1. Single most parsimonious cladogram resulting from analyses of the matrix in Appendix 1. For characters and character states see Appendix 3. Only unambiguous character changes are shown. See Cladistic analysis section for further details. 
Species descriptions are ordered as in the cladogram in Fig. 1. Methods and terminology used are as in recent revisions (Huber 2011, 2013). Measurements are in mm unless otherwise specified. Eye measurements are $\pm 5 \mu \mathrm{m}$. Epigyna were cleared in a warm $\mathrm{NaOH}$ solution and stained with chlorazol black. For SEM photos, specimens were dried in HMDS (Brown 1993), and photographed with a Hitachi S-2460 scanning electron microscope. SEM data are presented within the descriptions but are not based on the holotype specimens described. The distribution maps were generated with ArcMap 10.0.

The following abbreviations are used in the text:

ALE $=$ anterior lateral eyes

$\mathrm{ALS}=$ anterior lateral spinnerets

$\mathrm{AME}=$ anterior median eyes

a.s.l. $\quad=$ above sea level

$\mathrm{L} / \mathrm{d}=$ length $/$ diameter

N.P. $=$ National Park

$\mathrm{PME}=$ posterior median eyes

PMS $=$ posterior median spinnerets

Further abbreviations used only in figures are explained directly in the figure legends.

The numerical cladistic analyses were done using NONA, version 2 (Goloboff 1993), Pee-Wee, version 2.8 (Goloboff 1997), and TNT, version 1.1 (Goloboff et al. 2004, 2008). The matrix is shown in Appendix 1; terminal taxa and characters scored are given in Appendices 2 and 3. Of the 44 characters, 39 are binary; four non-binary characters are treated as non-additive (char. 4, 24, 25, 35). One character is treated as additive (char. 1). The final matrix can be downloaded at http://www.pholcidae.de/matrices. $\underline{\mathrm{html}}$. Cladogram analysis was done with Winclada, version 1.00 .08 (Nixon 2002). See Cladistic analysis section below for details of the analyses.

\section{Results}

Class Arachnida Cuvier, 1812

Order Araneae Clerck, 1757

Family Pholcidae C.L. Koch, 1851

Genus Aetana Huber, 2005

\section{Cladistic analysis}

Using NONA with hold/100, mult*200 (or hold/10; mult*10.000), and amb- for the matrix in Appendix 1 and equal character weights resulted in a single most parsimonious cladogram with a length of 80 $(C I=67 ; \mathrm{RI}=84)($ Fig. 1$)$. All other analyses resulted in the same cladogram: TNT using the implicit enumeration algorithm; successive weighting in NONA (with the consistency index as weighting function); and implied weighting in Pee-Wee (which resolves character conflict in favor of the characters that have less homoplasy).

\section{Taxonomy}

Aetana Huber, 2005

Aetana Huber, 2005a: 72-73. Type species: A. omayan Huber, 2005. 


\section{Diagnosis}

Even though the cladistic analysis identifies only two synapomorphies for Aetana, the genus is fairly easily distinguished from the putatively closest relatives by the following characters: retrolateral trichobothrium on leg 1 very proximal (at $<5 \%$ of tibia length) and presence of curved hairs on tibiae and / or metatarsi (both in contrast to Spermophora, Khorata Huber, 2005, Savarna, and an undescribed genus from Sarawak, below called 'Gen.n. Borneo'); sternum not dark, retrolateral trichobothrium on male palpal tibia in very distal position, and presence of epiandrous spigots (all in contrast to Khorata, Savarna, and 'Gen.n. Borneo'); male legs without spines and male palpal coxa unmodified (both in contrast to 'Gen.n. Borneo'); ALS with only two spigots, epigynal plate without external pair of pockets, and female genitalia without unpaired posterior pocket (all in contrast to Spermophora). Most characters previously thought to be diagnostic (Huber 2005a) are rendered invalid due to the newly described species.

\section{Description}

\section{Male}

MeasuREMEnTs. Total body length $\sim 2.5-4.5$ (smallest species in A. kinabalu group; largest species in A. omayan group); carapace width $0.9-1.8$; leg 1 length $\sim 27-44$; tibia 1 length $\sim 6.0-11.0$; tibia 2 /tibia 4 length $0.92-1.08$; tibia $1 \mathrm{~L} / \mathrm{d} \sim 55-95$ (the largest species, $A$. omayan, has the relatively thickest legs; the smallest species, A. gaya, has the relatively thinnest legs).

CoLOR. In life mostly ochre-gray with brown and black marks (e.g., Figs 51-56, 105-110), only A. libjo Huber, sp. nov. and A. baganihan Huber, sp. nov. with light brown to orange prosoma and palps (Figs 8-12); sternum never dark; legs usually with indistinct darker rings on femora (subdistally) and tibiae (proximally and subdistally); darker rings missing in A. libjo Huber, sp. nov. and A. baganihan Huber, sp. nov.

Body. Carapace either with shallow median furrow restricted to frontal part (Figs 63-64, 198) or without furrow (Figs 118, 130); ocular area raised, eye triads on short stalks directed toward lateral, in some species with median process (Figs 77, 96) or with pair of processes arising from near ALE (Figs 221, 226). AME absent. Clypeus high, either unmodified, with small paired processes (Fig. 191), with large median process (Figs 59, 77), or with indistinct lateral ridges (Figs 221, 226). Abdomen from slightly longer than high (Figs 51-56) to almost cylindrical (Figs 8, 102), pointed at spinnerets. Male gonopore with four epiandrous spigots in all species examined with SEM (e.g., Figs 37, 143, 162); each ALS with large widened spigot and pointed spigot, without further cylindrically shaped spigots (Figs 68, 210); PMS with two spigots each.

Chelicerae. Very variable, distal apophyses ranging from short processes in frontal position (Figs 15, 40) to long processes in lateral position (Figs 191, 226), absent in A. kiukoki group; proximal apophyses usually present, large in A. kiukoki group (Fig. 66), absent in A. ocampoi group (Figs 15, 40); chelicerae without modified hairs; without stridulatory ridges.

PALPS. Coxa unmodified; trochanter usually with one retrolateral to ventral process, sometimes provided with scales or teeth (Fig. 158), in A. ocampoi group fused to femur (Figs 14, 27); trochanter in some species with additional prolateral apophysis (Fig. 189); femur rarely simple (Fig. 27), usually with one or more processes, in A. kinabalu group with complex set of up to four processes (e.g., Figs 150-151); patella either triangular in lateral view or ventral side longer than usual (e.g., Figs 14, 58); tibia either of usual shape (e.g., Figs 14, 127) or rather small and slender (A. kiukoki group; e.g., Fig. 58), with retrolateral trichobothrium in very distal position (close to tibia-tarsus joint; Figs 27, 114); palpal tarsus small, usually with capsular tarsal organ (Figs 134, 203), exposed in A. libjo Huber, sp. nov. (Fig. 35) (not clear in A. ocampoi Huber, sp. nov. and A. baganihan Huber, sp. nov.); procursus usually complex with proximal 
and distal parts connected by membranous hinge; procursus in A. kiukoki group unusually long (Figs 58, 76), in A. ocampoi group reduced to simple semi-transparent process (Figs 14, 27); bulb either with weakly sclerotized embolus as only process (Figs 114, 159), in A. kiukoki group with additional short membranous process (Figs 58, 75), in A. ocampoi group with additional novel processes (Figs 13-14, 26-27).

LEGS. Without spines; with curved hairs on tibiae and/or metatarsi (Fig. 133); usually without or with few vertical hairs, only in A. libjo Huber, sp. nov. and A. baganihan Huber, sp. nov. with one dense row retrolatero-dorsally on each tibia; retrolateral trichobothrium on tibia 1 very proximal (at $2-4 \%$ of tibia length), prolateral trichobothrium absent on tibia 1, present on other tibiae. Tarsus 1 usually with $\sim 25-30$ pseudosegments, fairly distinct distally; tarsus 4 with single row of ventral comb-hairs of a modified Belisana-type (cf. Huber \& Fleckenstein 2008; Figs 32, 69, 82, 209).

\section{Female}

Similar to male but eye triads on lower humps (Figs 64, 80, 119) and closer together than in male (sexual dimorphism low in A. ocampoi group; in other groups, eye triads in females often less than half as wide apart as in males); clypeus and chelicerae unmodified; legs slightly shorter than in males (tibia $1 \sim 4.0-9.0$ ). Females in A. omayan group with stridulatory apparatus between prosoma (elongate median plate on carapace posteriorly; Figs 186-188) against abdomen (indistinct hairless area frontally). Epigynum weakly to heavily sclerotized, sometimes with scape of variable length and shape (Figs 28, 60 ), never with external pair of pockets in anterior epigynal plate but in A. kinabalu and A. omayan groups sometimes with internal sclerotized pockets originating from ventral wall of uterus externus (Figs 111, 192-194), and in A. omayan group with pair of membranous external pockets in posterior epigynal area (Figs 192, 194, 222). Internal genitalia with pair of pore plates, in A. libjo Huber, sp. nov. and $A$. baganihan Huber, sp. nov. with unique median membranous structure (Figs 29, 44); in A. kiukoki group with distinctive serrated ridges (Figs 61, 73, 79).

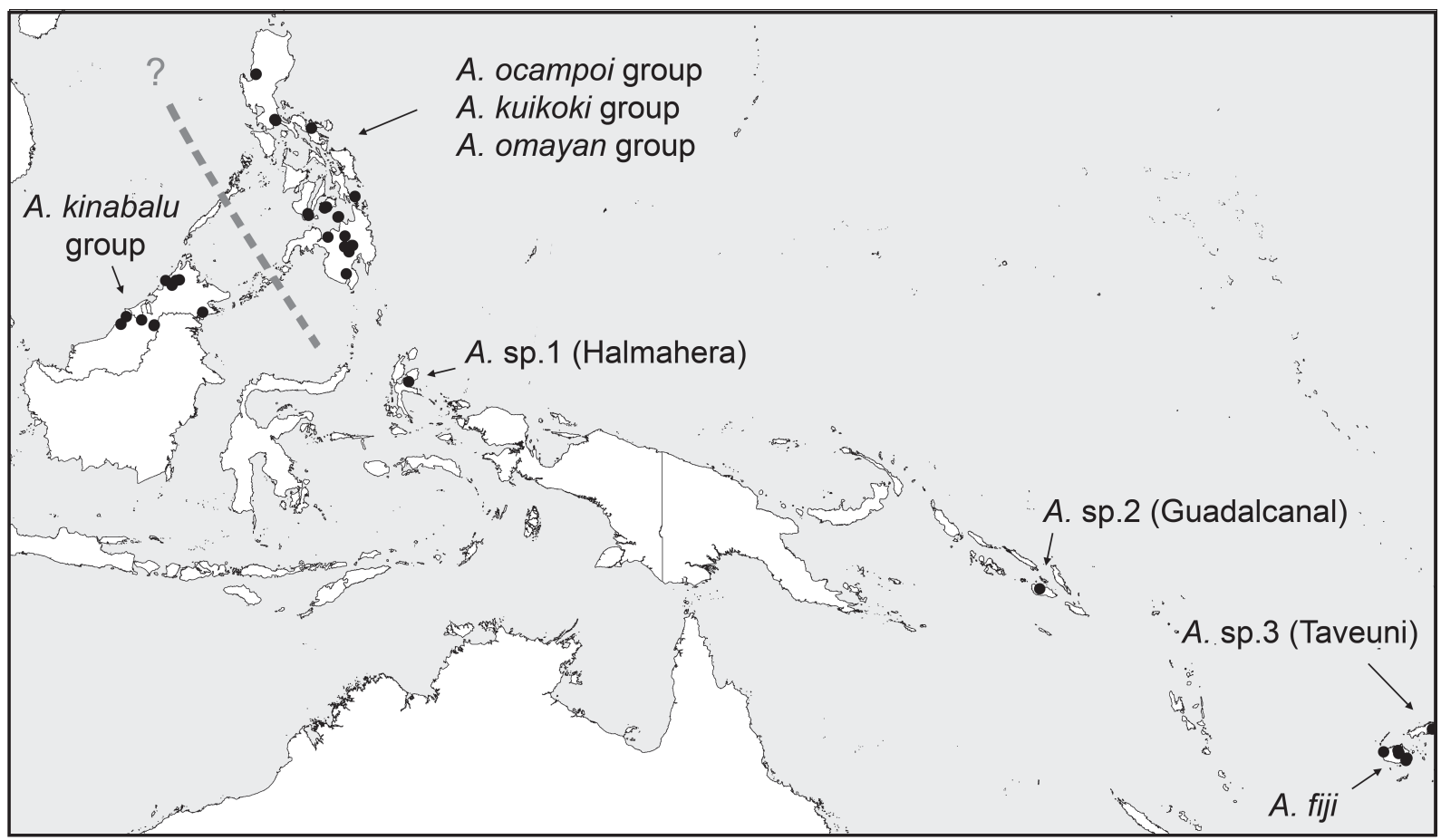

Fig. 2. Known distribution of Aetana. Shown are also three undescribed species that are known from poorly preserved specimens only. 


\section{Monophyly and relationships}

Morphologically, the monophyly of Aetana appears weakly supported. Only two characters support this node (Fig. 1), both of them without homoplasy within the taxa included in the matrix but with considerable homoplasy among more distant Pholcinae relatives: (1) the very proximal position of the retrolateral trichobothrium on the leg tibiae (char. 30); and (2) the presence of curved hairs on leg tibiae and/or metatarsi (char. 31). However, preliminary analyses of molecular data (including many more potential close relatives) (A. Valdez-Mondragón, D. Dimitrov, B.A. Huber, unpubl. data) consistently support the monophyly of Aetana with high support values.

The sister group of Aetana appears much better supported by morphology. Four characters suggest that three genera together (Khorata, Savarna, and 'Gen.n. Borneo') are sister to Aetana. This, however, is in conflict with our preliminary molecular data that suggest a closer relationship between Aetana and East Asian Spermophora (incl. S. estebani) than between Aetana and Khorata, Savarna, and 'Gen.n. Borneo'. Such a close relationship with East Asian Spermophora was actually proposed in the original description (Huber 2005a), at that time without a formal cladistic analysis.
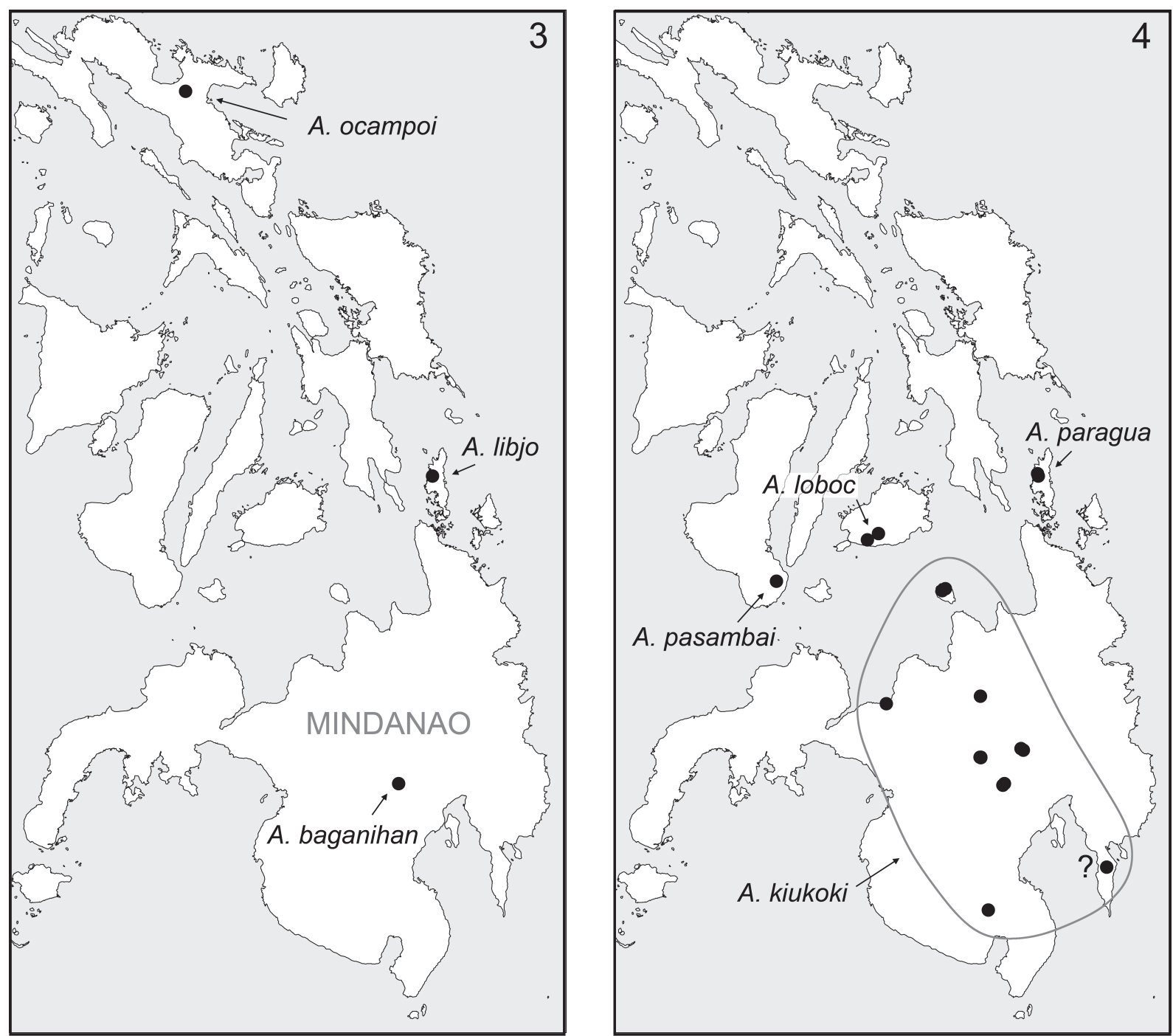

Figs 3-4. Known distributions of the Aetana ocampoi (3) and A. kiukoki (4) groups. The question mark denotes a female specimen assigned tentatively to $A$. kiukoki. 
Within Aetana, four species groups receive strong support both from the morphological analysis herein (Fig. 1) and from our preliminary molecular data. Conflict exists regarding relationships among these groups. The present analysis supports a sister group relationship between the Aetana kinabalu and A. omayan groups, and at least one of the three characters supporting this node is a unique feature (the long retrolateral membranous process on the procursus; char. 21). Our preliminary molecular data do not strongly support any sister group relationships among the four species groups within Aetana.

\section{Natural history}

Most species were collected in forests, from well protected spaces close to the ground, under rocks and logs, in small holes and cavities. Few species occur higher in the vegetation, even in places directly

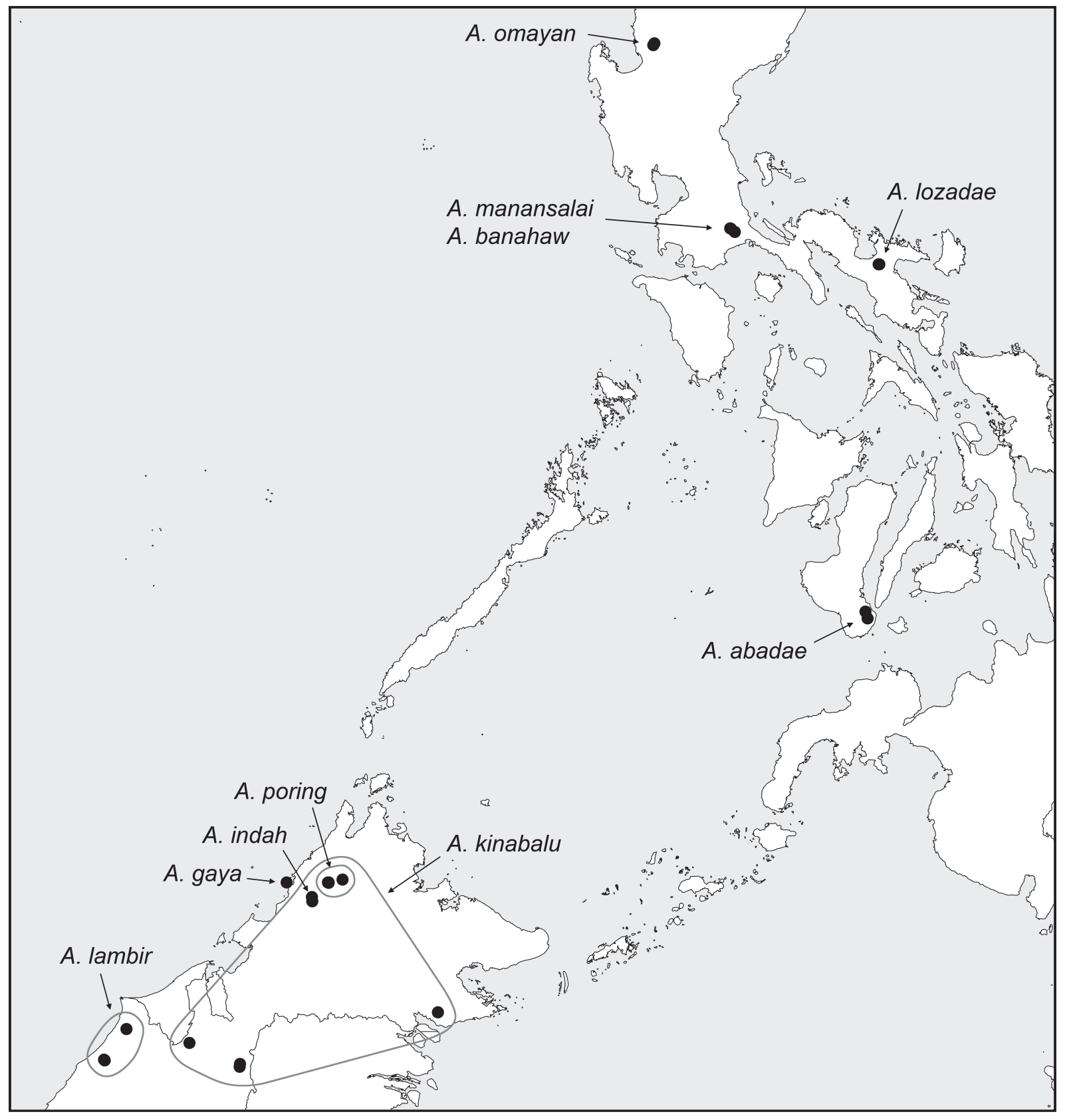

Fig. 5. Known distributions of the Aetana kinabalu (Borneo) and A. omayan (Philippines) groups. 
reached by the sun, most notably the closely related $A$. libjo Huber, sp. nov. and A. baganihan Huber, sp. nov. and the putatively close relatives $A$. kinabalu and $A$. lambir Huber, sp. nov. An exception is the type species A. omayan, which was mainly collected in a cave but also among rocks in a treeless ravine.

All species seem to build simple domed sheet webs (like most other pholcids studied), but the sheets are unusually strongly domed in A. libjo Huber, sp. nov. and A. baganihan Huber, sp. nov., and in A. kinabalu and A. lambir Huber, sp. nov. a second sheet occurs a few $\mathrm{cm}$ under the main sheet.

In six cases, two species were found to share a locality, sometimes in different microhabitats (e.g., at Baganihan: A. kiukoki Huber, sp. nov. near the ground; A. baganihan Huber, sp. nov. among vegetation), sometimes in what seemed to be identical microhabitats (e.g., at Mt. Banahaw: A. manansalai Huber, sp. nov. and A. banahaw Huber, sp. nov., both close to the ground).

In most species, males and females were often found together sharing a web. This was never observed in A. libjo Huber, sp. nov. and A. baganihan Huber, sp. nov., where males and females were sometimes observed very close to each other but in separate webs.

When disturbed, Aetana spiders tend to run toward the periphery of the web rather than to vibrate in the 'typical' pholcid way. Some do then vibrate vigorously for a very short time before becoming motionless and pressing their body against the substrate; others stop vibrating and start to gently move the abdomen in circles (A. libjo Huber, sp. nov. and A. baganihan Huber, sp. nov.). The closely related A. poring Huber, sp. nov. and $A$. indah Huber, sp. nov. barely reacted to disturbance.

\section{Composition}

The genus now includes 18 described species. The high species turnover in the Philippines and in northern Borneo, together with the wide distribution of one species group (A. omayan group; Philippines to Fiji Islands) and the huge sampling gaps in eastern Indonesia, New Guinea, and east to Fiji suggest that at least several dozen further species are likely to exist.

\section{Distribution}

Ranging from northern Borneo and the Philippines to Fiji (Fig. 2). Most gaps and missing records are probably due to lack of adequate sampling, but the absence of records from two areas might reflect real absence. First, our intensive collecting in western Sarawak (at seven localities ranging from the Pueh foothills in the west to Niah in the east) did not result in a single specimen of Aetana, while many specimens were collected at all eight localities in eastern Sarawak (east of Niah) and Sabah. Second, northern Australia is relatively well sampled, but a revision of all the material available in collections (Huber 2001) did not reveal any Aetana.

Aetana ocampoi Huber, sp. nov. urn:1sid:zoobank.org:act:85B2FF02-FB08-48B3-91E9-0AB54D7866F5

Figs 6-7, 13-25

\section{Diagnosis}

Easily distinguished from closest known relatives (A. libjo Huber, sp. nov.; A. baganihan Huber, sp. nov.) by dark coloration (Figs 6-7) and by several details of the male palp (Figs 13-14; long cylindrical bulb; ventral process on femur), male chelicerae (Fig. 15; more proximal position of apophyses), and epigynum (Figs 16-19; short triangular scape). 

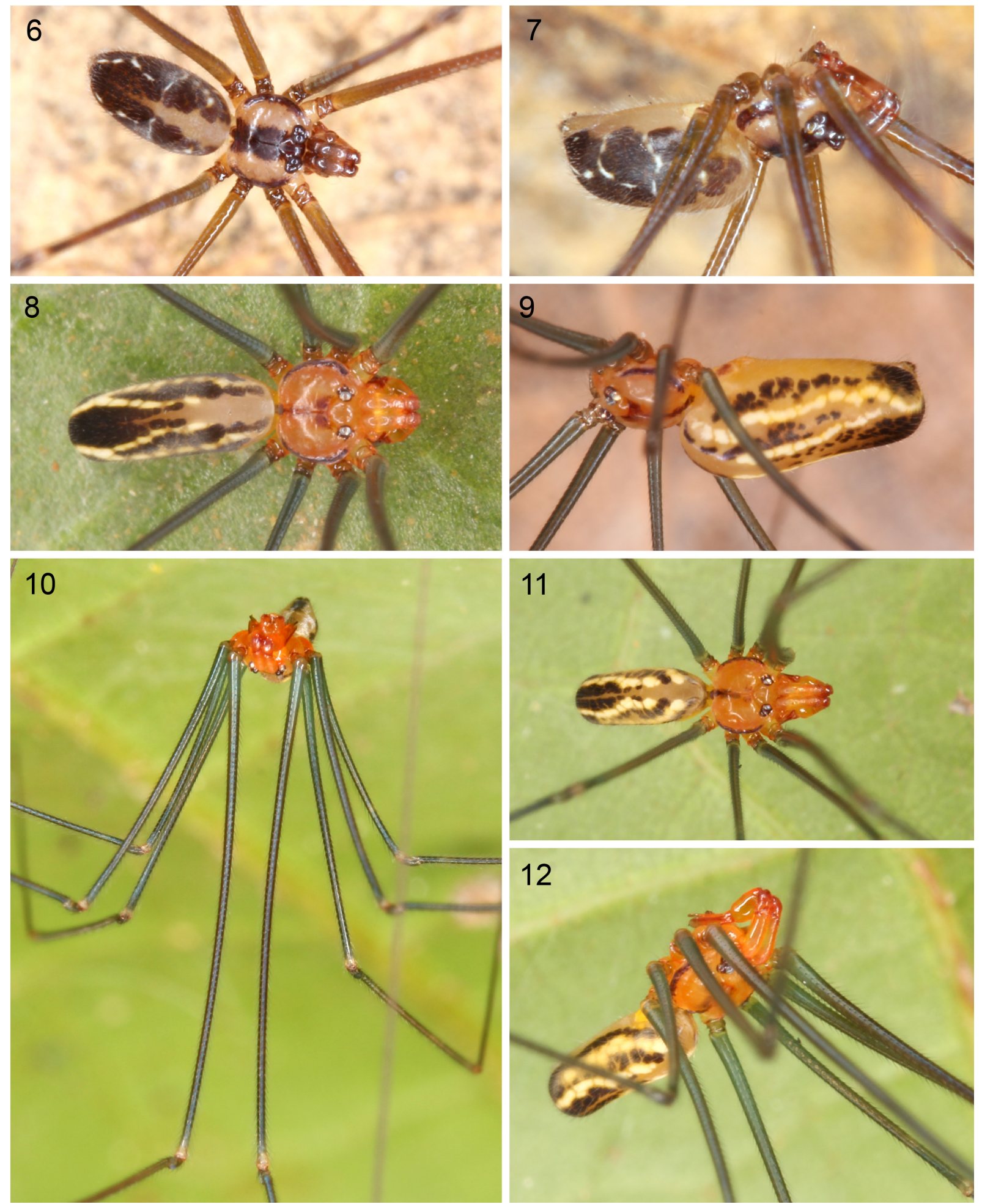

Figs 6-12. Live specimens. Aetana ocampoi group. 6-7. A. ocampoi Huber, sp. nov., $\widehat{o}$ from Mt. Isarog, Luzon. 8-9. A. libjo Huber, sp. nov., $\sigma^{\widehat{T}}$ and $q$ from Dinagat Island, Mindanao. 10-12. A. baganihan Huber, sp. nov., ô $\widehat{\jmath}$ from Baganighan, Mindanao. 


\section{Etymology}

Named for the Filipino artist Hernando Ruiz Ocampo (1911-1978), famous for his work reflecting the harsh realities of his country after the Second World War, but also for his interest in depicting Philippine flora and fauna.

\section{Material examined}

\section{Holotype}

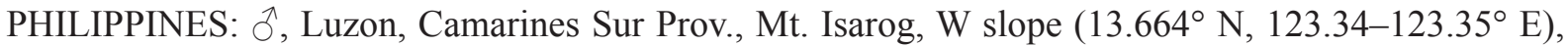
$\sim 600-900$ m a.s.l., forest, near ground, 23 Feb. 2014 (B.A. Huber), ZFMK (Ar 13927).

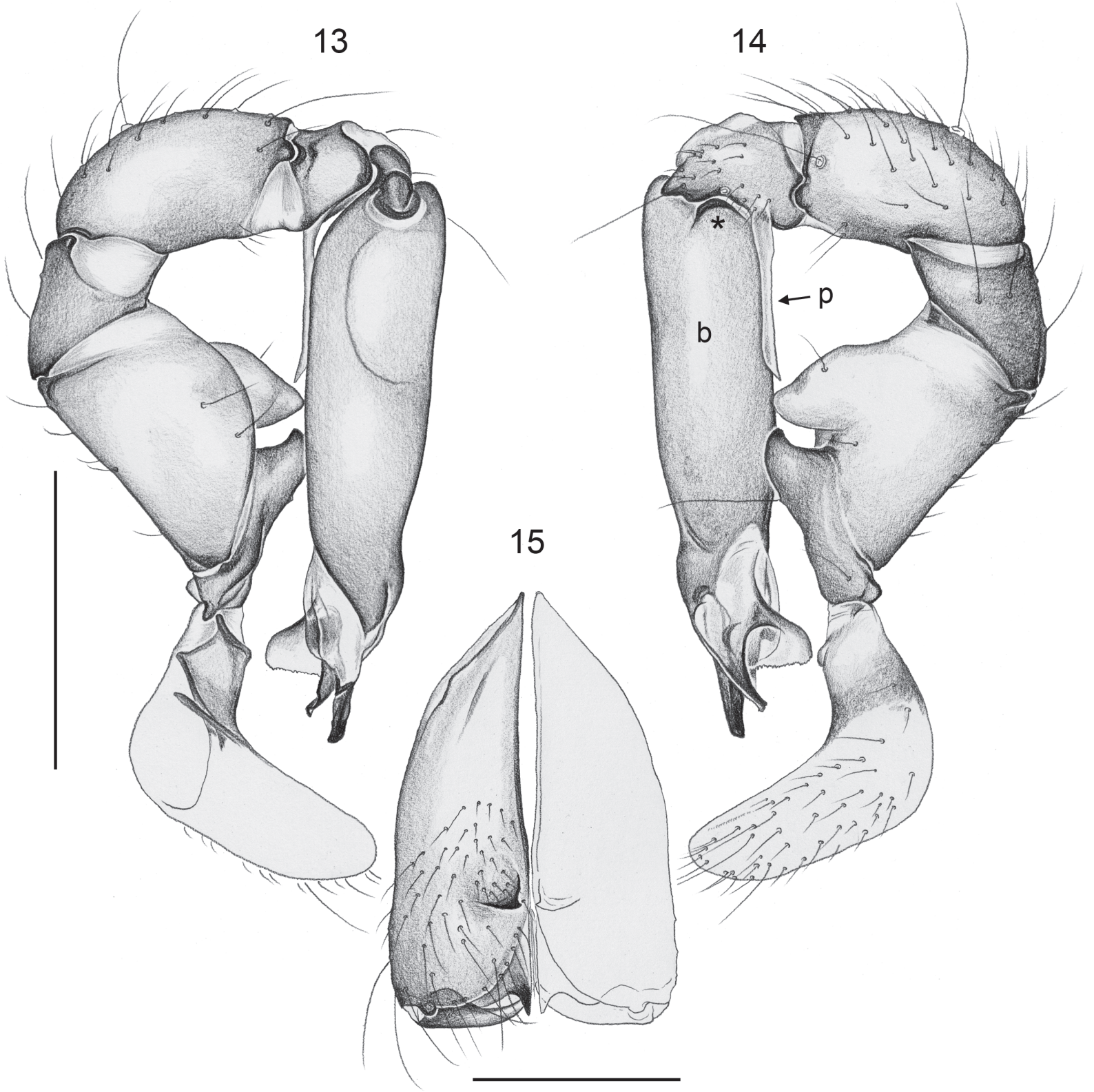

Figs 13-15. Aetana ocampoi Huber, sp. nov. 13-14. Left male palp, prolateral and retrolateral views (asterisk: retrolateral process of bulb). 15. Male chelicerae, frontal view. $b=$ genital bulb; $p=$ procursus. Scale lines: $13-14=0.5 \mathrm{~mm} ; 15=0.2 \mathrm{~mm}$. 


\section{Other material}

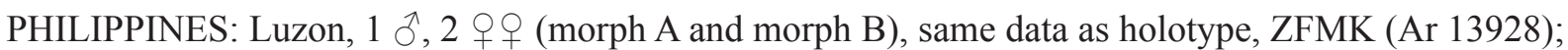
3 우 (2우 morph A, 1 을

\section{Description}

Male (holotype)

MeAsurements. Total body length 2.7 , carapace width 1.1 . Leg $1: 28.3(6.7+0.4+6.6+11.8+2.8)$, tibia 2: 3.9, tibia 3: 2.7, tibia 4: 4.0; tibia $1 \mathrm{~L} / \mathrm{d}$ : 59. Distance PME-PME $185 \mu \mathrm{m}$, diameter PME $125 \times 120 \mu \mathrm{m}$, distance PME-ALE $20 \mu \mathrm{m}$; AME absent.

CoLor. Carapace pale ochre with wide median dark band including ocular area and narrower lateral black margins; clypeus pale ochre, distal half light brown; sternum pale ochre, medially light brown; legs light brown, with dark rings subdistally on femora and proximally on tibiae (incl. patellae); abdomen dorsally densely covered with dark marks and some white marks, ventrally gray, small dark mark behind gonopore, larger dark mark in front of spinnerets.
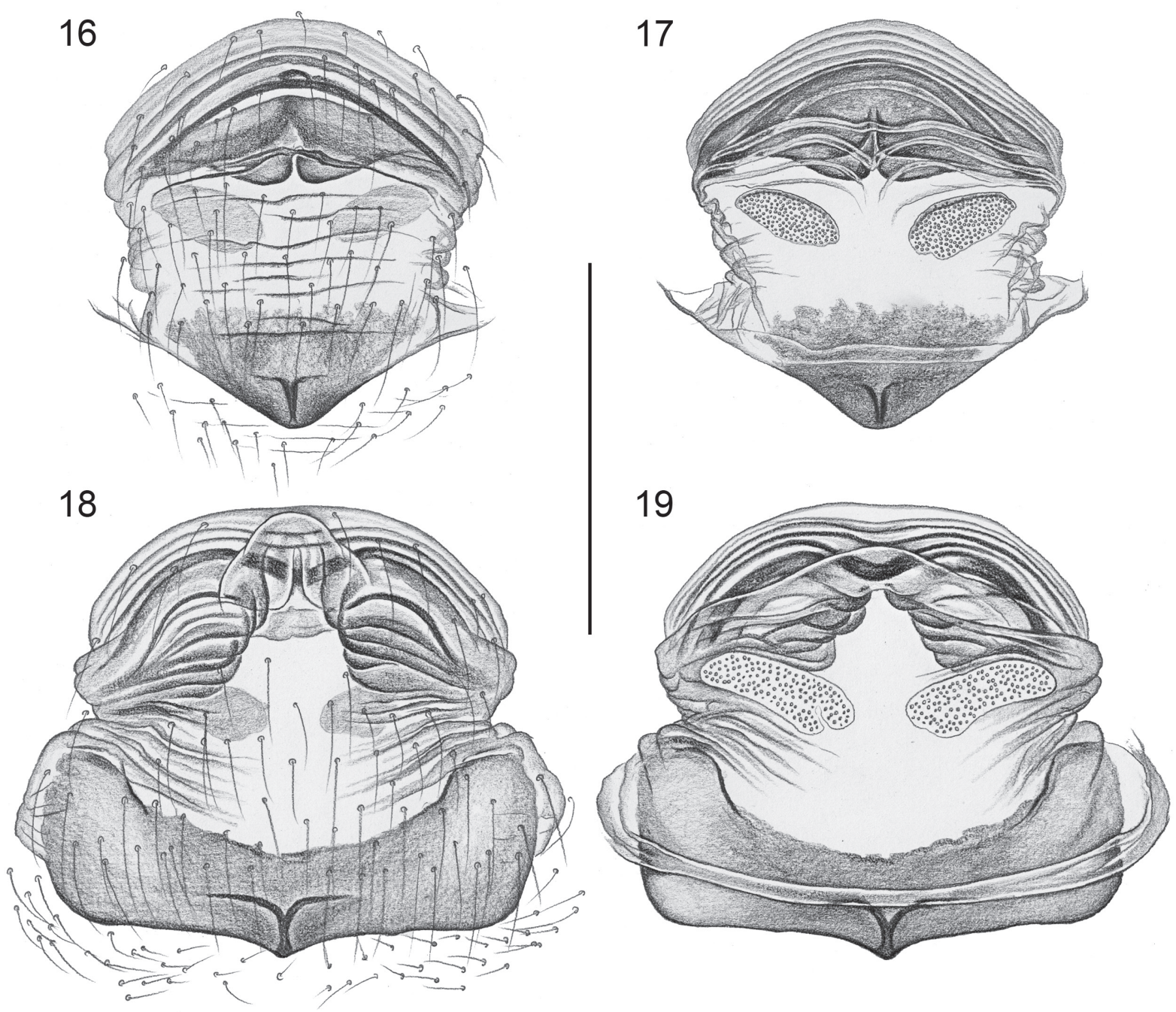

Figs 16-19. Aetana ocampoi Huber, sp. nov. Cleared female genitalia of morph A (16-17) and morph B (18-19), in ventral (left) and dorsal (right) views. Scale line: $0.5 \mathrm{~mm}$ (all at same scale). 
BoDy. Habitus as in Figs 6-7; ocular area slightly raised, each triad on low hump; carapace only anteriorly with very shallow and narrow median furrow (rather just a dark line); clypeus unmodified; sternum wider than long $(0.60 / 0.55)$, unmodified.

Chelicerae. As in Fig. 15, with pair of frontal apophyses near median line, without proximal lateral apophyses; without modified hairs; without stridulatory ridges.

PALPS. As in Figs 13-14, coxa unmodified, trochanter on retrolatero-ventral side with large apophysis fused to femur; femur with large retrolatero-ventral process; retrolateral trichobothrium on tibia very distal; tarsus with semitransparent simple procursus; genital bulb large, cylindrical, with retrolateral apophysis proximally and two distinctive processes distally: dorsal process with sclerotized black tip; ventral process with semitransparent flap.

Legs. Without spines, with curved hairs on tibiae 1 and metatarsi $1-4$, few vertical hairs; retrolateral trichobothrium on tibia 1 at $3 \%$; prolateral trichobothrium absent on tibia 1, present on other tibiae. Tarsus 1 with $\sim 25$ pseudosegments, distally distinct.

Male (variation)

Tibia 1 in other male: 7.2; this male paler but otherwise identical.
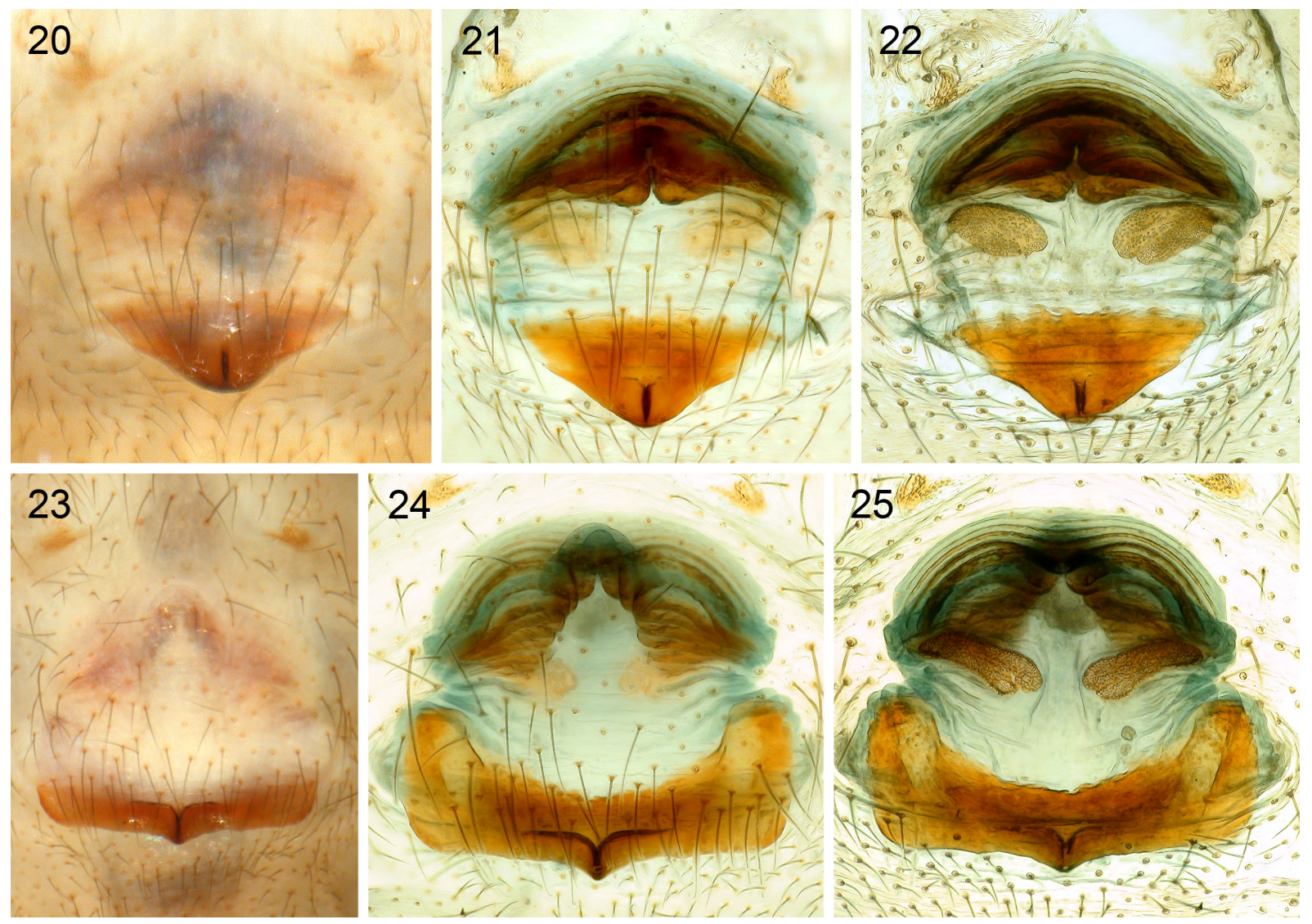

Figs 20-25. Aetana ocampoi Huber, sp. nov. Female genitalia of morph A (20-22) and morph B (2325); untreated in ventral view, cleared in ventral and dorsal views. 
Female

In general similar to male; eye triads closer together (distance PME-PME $140 \mu \mathrm{m}$ ); tibia 1 in 2 females: 5.5, 5.7. Epigynum apparently dimorphic: three females with small triangular sclerotized scape (Figs 16, 20; morph A), two females with much wider sclerotized area of epigynum (Figs 18, 23; morph B); internal genitalia also different, as in Figs 17, 19, 22, 25.

\section{Natural history}

The spiders were found close to the ground, apparently more deeply hidden under rocks and logs than the sympatric $A$. lozadae Huber, sp. nov.

\section{Distribution}

Known from type locality only (Fig. 3).

Aetana libjo Huber, sp. nov. urn:1sid:zoobank.org:act:91DA8483-221E-4FBB-8CD8-453CFD23B90F

Figs 8-9, 26-40, 45-47

\section{Diagnosis}

Distinguished from the very similar $A$. baganihan Huber, sp. nov. by shapes of bulbal processes (compare Figs 38-39 and 41-42), by shorter male palpal tibia (2.1-2.4 $\times$ longer than wide vs. 2.9-3.2 in A. baganihan Huber, sp. nov.), and by shorter epigynum and wider scape (compare Figs 28 and 43 ). Distinguished from next closest known relative (A. ocampoi Huber, sp. nov.) by light coloration and several details of male palp and epigynum (especially shapes of bulb and scape; Figs 26-28). From all other congeners by simple procursus and complex bulbal processes (Figs 26-27) and by narrow epigynal scape.

\section{Etymology}

Named for the type locality; noun in apposition.

\section{Material examined}

\section{Holotype}

PHILIPPINES: ô, Dinagat Isl., near Libjo, Paragua Forest, 'site 1' $\left(10.222^{\circ} \mathrm{N}, 125.553^{\circ} \mathrm{E}\right), 130 \mathrm{~m}$ a.s.1., forest at brook, among low vegetation, 20 Feb. 2014 (B.A. Huber), ZFMK (Ar 13929).

\section{Other material}

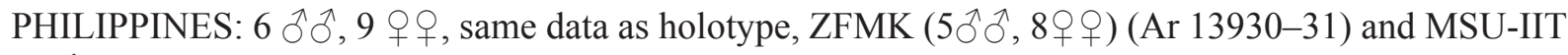
(1 $\hat{O}, 1$ 穴); 3 juveniles in pure ethanol, same data, ZFMK (Phi 231).

\section{Description}

Male (holotype)

MEAsurements. Total body length 3.1, carapace width 1.1. Leg 1: $37.4(9.0+0.5+8.8+16.2+2.9)$, tibia 2: 5.1, tibia 3: 3.3, tibia 4: 4.8; tibia $1 \mathrm{~L} / \mathrm{d}$ : 74. Distance PME-PME $270 \mu \mathrm{m}$, diameter PME $125 \times 95$ $\mu \mathrm{m}$, distance PME-ALE $20 \mu \mathrm{m}$; AME absent.

Color. Carapace ochre-yellow with black lateral margins, dark mark behind ocular area and dark median mark on posterior rim; ocular area and clypeus pale ochre; sternum bright orange; leg coxae ochre-yellow, other leg segments greenish-ochre (especially femora) to light brown (distal segments); abdomen grey with distinct dorsal and lateral pattern of black marks, ventrally with brown band between gonopore and spinnerets (mid-section indistinct). 

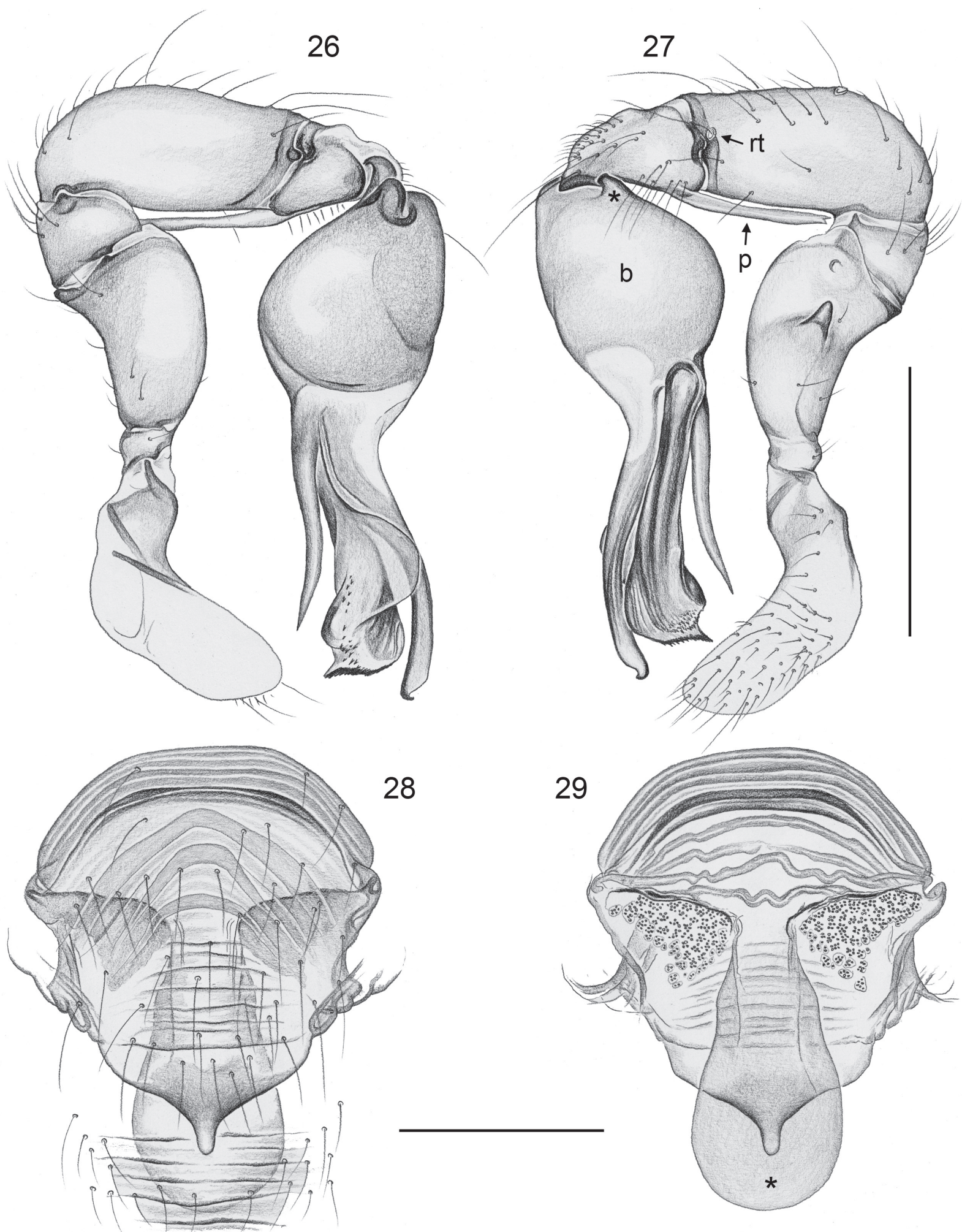

Figs 26-29. Aetana libjo Huber, sp. nov. 26-27. Left male palp, prolateral and retrolateral views (asterisk: retrolateral process of bulb). 28-29. Cleared female genitalia, ventral and dorsal views (asterisk: median membranous structure). $\mathrm{b}=$ genital bulb; $\mathrm{p}=$ procursus; $\mathrm{rt}=$ retrolateral trichobothrium. Scale lines: $26-27=0.5 \mathrm{~mm} ; 28-29=0.3 \mathrm{~mm}$. 

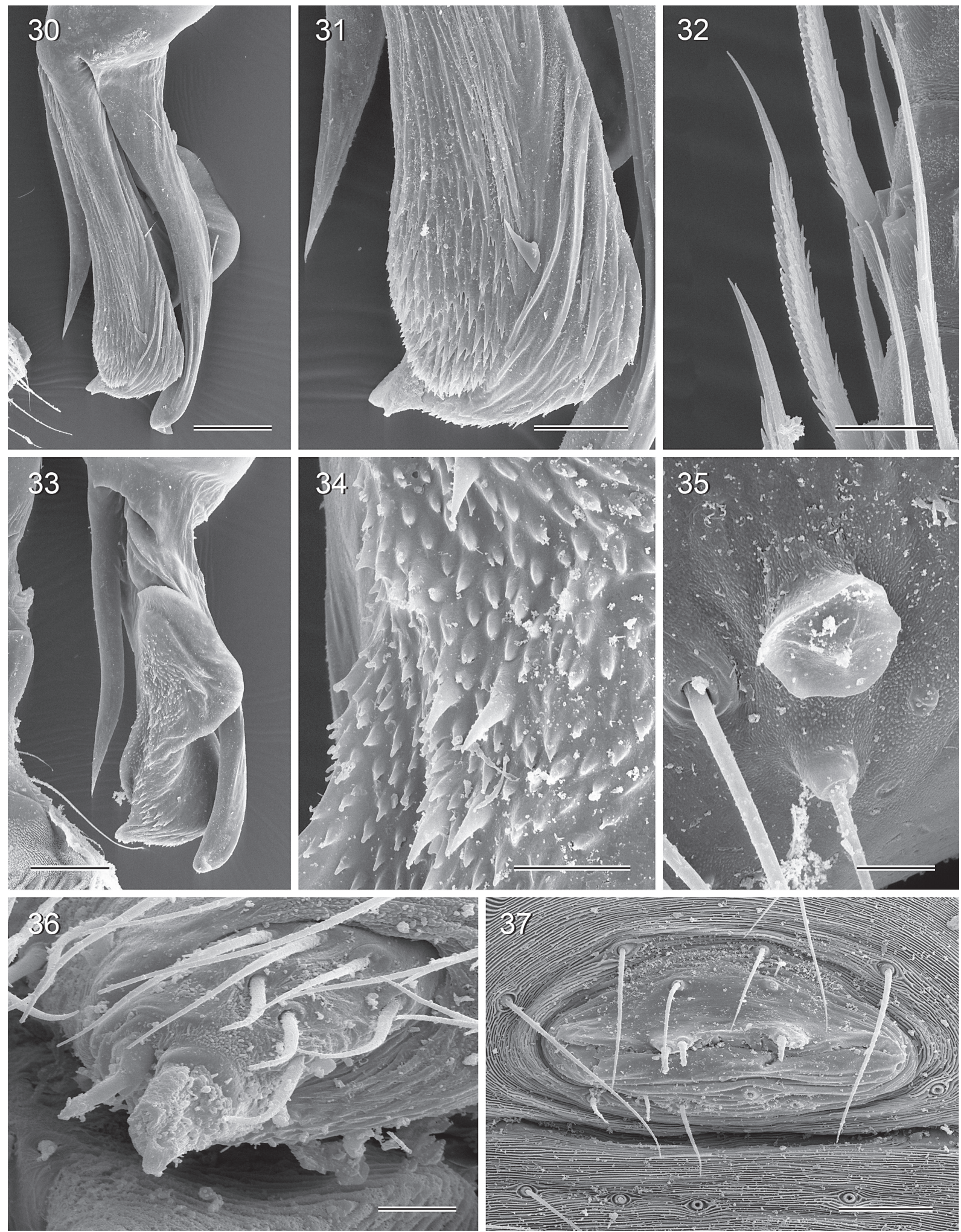

Figs 30-37. Aetana libjo Huber, sp. nov. 30. Processes of right genital bulb, retrolateral view. 31. Detail of preceding. 32. Comb-hairs on female tarsus 4. 33. Processes of left genital bulb, prolateral view. 34. Detail of preceding. 35. Male palpal tarsal organ. 36. Female ALS. 37. Male gonopore. Scale lines: $30,33=100 \mu \mathrm{m} ; 31,37=40 \mu \mathrm{m} ; 32,34=20 \mu \mathrm{m} ; 35-36=10 \mu \mathrm{m}$. 
BoDy. Habitus as in Fig. 8; ocular area slightly raised, each triad on low hump directed toward lateral; carapace only anteriorly with very shallow and narrow median furrow; clypeus barely modified, indistinct median process near rim provided with some slightly stronger hairs; sternum wider than long $(0.70 / 0.55)$, unmodified. Gonopore with four epiandrous spigots in two pairs (Fig. 37). ALS as in female (cf. Fig. 36).
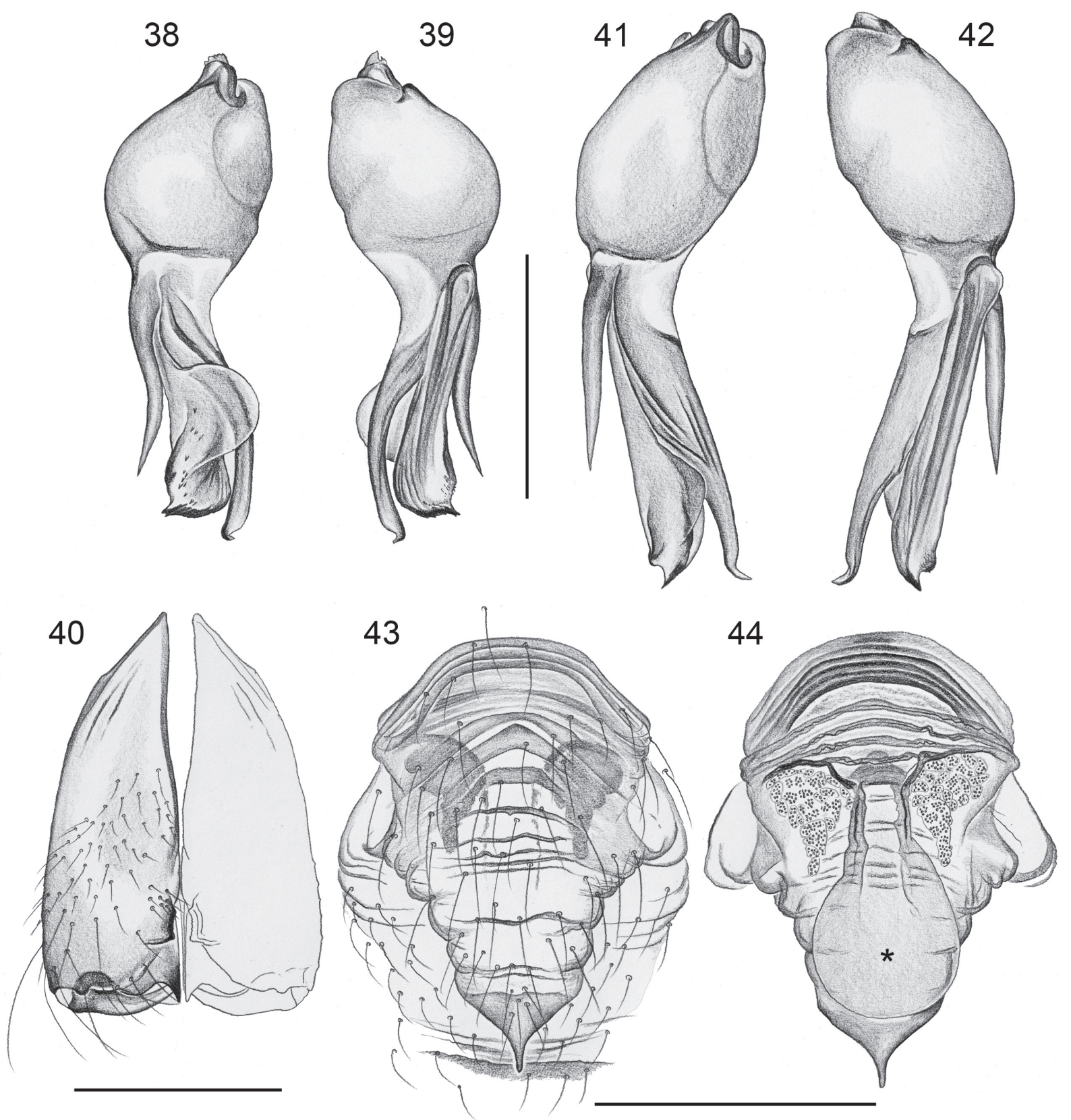

Figs 38-44. - 38-40. Aetana libjo Huber, sp. nov. 38-39. Left genital bulb in prolateral and retrolateral views. 40. Male chelicerae, frontal view. - 41-44. Aetana baganihan Huber, sp. nov. 41-42. Left genital bulb in prolateral and retrolateral views. 43-44. Cleared female genitalia, ventral and dorsal views (asterisk: median membranous structure). Scale lines: $38-39,41-44=0.5 \mathrm{~mm} ; 40=0.3 \mathrm{~mm}$. 
Chelicerae. As in Fig. 40, with pair of ridge-shaped apophyses distally near median line, without proximal lateral apophyses; without modified hairs; without stridulatory ridges.

PaLPS. As in Figs 26-27, coxa unmodified, trochanter on retrolateral side with large apophysis fused to femur; femur with small retrolateral process distally; tibia length/width: $0.50 / 0.22$; retrolateral trichobothrium on tibia very distal; tarsus with semitransparent simple procursus directed toward patella; tarsal organ exposed (Fig. 35); genital bulb large, with small retrolateral process proximally and three distinctive processes distally (Figs 30-31, 33, 38-39): dorsal process with distal hook; central hinged process with large prolateral flap and complex tip; ventral hinged process with simple pointed tip. Location of sperm duct opening unknown.

LEGs. Without spines, with curved hairs on metatarsi, with vertical hairs in higher than usual density in one retrolatero-dorsal row on each tibia; retrolateral trichobothrium on tibia 1 at $2 \%$; prolateral trichobothrium absent on tibia 1, present on other tibiae. Tarsus 1 with $\sim 30$ pseudosegments, distally distinct. Tarsus 4 comb-hairs with very dense tines (Fig. 32).
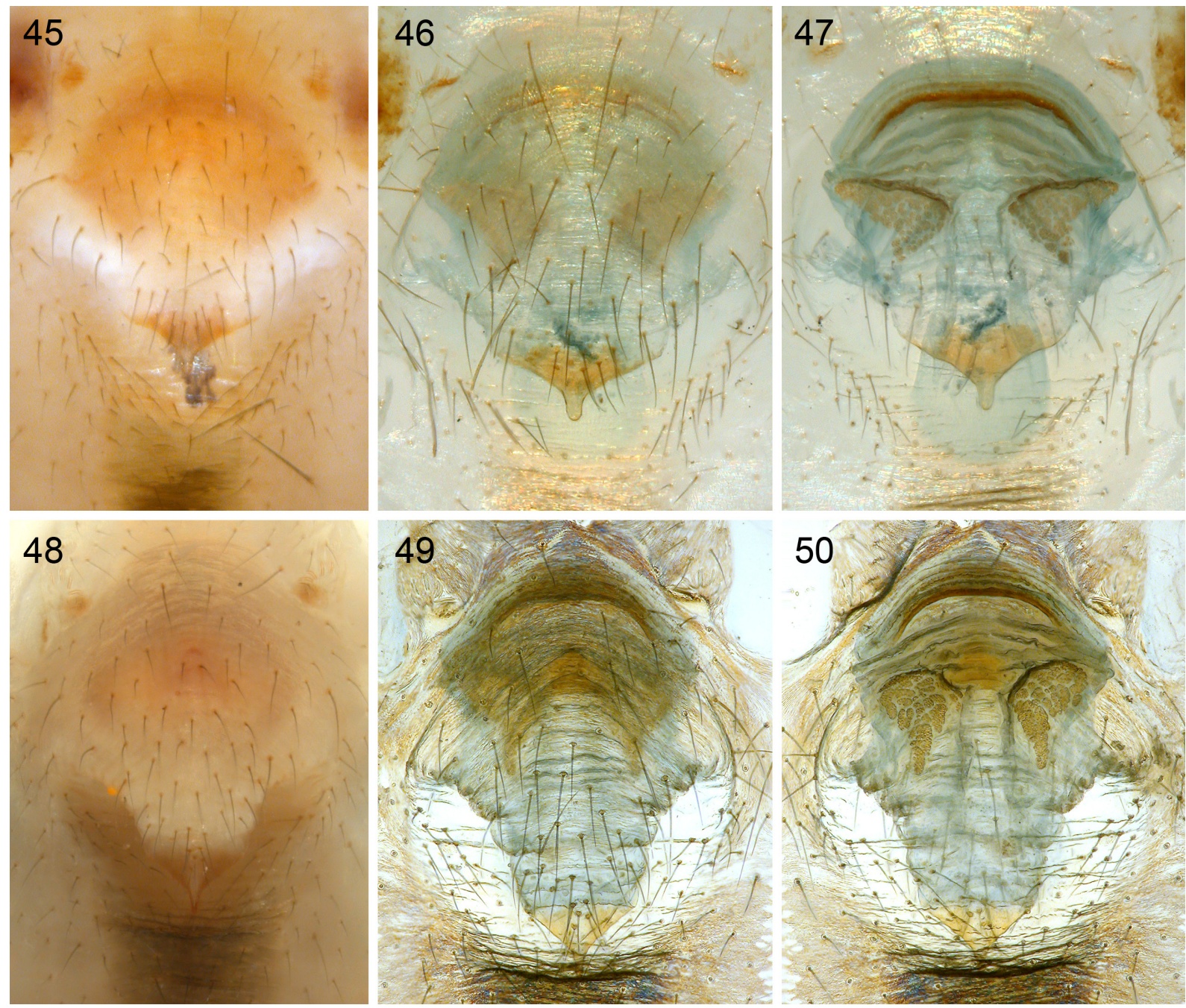

Figs 45-50. Aetana libjo Huber, sp. nov. (Figs 45-47) and Aetana baganihan Huber, sp. nov. (Figs 48-50), female genitalia; untreated in ventral view, cleared in ventral and dorsal views. 
HUBER B.A. et al., Revision of Aetana spiders

Male (variation)

Tibia 1 in 6 other males: 8.3-9.0 (mean 8.6); ratio of palpal tibia length/width: 2.1-2.4. Some specimens with white marks on abdomen in addition to black marks.

\section{Female}

In general similar to male (Fig. 9); eye triads closer together (distance PME-PME $215 \mu \mathrm{m}$ ); clypeus unmodified; tibiae with short vertical hairs in low density; entire median area of carapace darker; clypeus also slightly darker; abdomen with or without white marks; tibia 1 in 9 females: 6.2-7.2 (mean 6.7). Epigynum with large, weakly sclerotized area, posteriorly protruding with short, narrow scape (Figs 28, 45-46); internal genitalia with large median membranous structure of unknown function (Fig. 29).

\section{Natural history}

The spiders were found in strongly domed webs among the vegetation. When disturbed, they ran a short distance in the dome, vibrated vigorously for a short time, and then made slow circular movements with their abdomen. Males and females were often found close to each other, but always in separate webs. The locality is shared with the ground-dwelling A. paragua Huber, sp. nov.

\section{Distribution}

Known from type locality only (Fig. 3).

Aetana baganihan Huber, sp. nov. urn:1sid:zoobank.org:act:AA06D026-A4F7-4EA9-9661-77707B2CCFB9

Figs 10-12, 41-44, 48-50

\section{Diagnosis}

Distinguished from very similar $A$. libjo Huber, sp. nov. by shapes of bulbal processes (compare Figs 38-39 and 41-42), by longer male palpal tibia (2.9-3.2 × longer than wide vs. 2.1-2.4 in A. libjo Huber, sp. nov.), and by longer epigynum and narrower scape (compare Figs 28 and 43); from next closest known relative (A. ocampoi Huber, sp. nov.) by light coloration and several details of male palp and epigynum (especially shapes of bulb and scape). Distinguished from all other congeners by simple procursus and complex bulbal processes and by narrow epigynal scape.

\section{Etymology}

Named for the type locality; noun in apposition.

\section{Material examined}

Holotype

PHILIPPINES: ${ }^{\wedge}$, Mindanao, Davao del Sur Prov., Marilog Distr., Baganihan $\left(7.469^{\circ} \mathrm{N}, 125.250^{\circ} \mathrm{E}\right)$, $1210 \mathrm{~m}$ a.s.1., primary forest near road, among low vegetation, 15 Feb. 2014 (B.A. Huber), ZFMK (Ar 13932).

\section{Other material}

PHILIPPINES: Mindanao, $2 \precsim \hat{\jmath}, 3$ 우, same data as holotype, ZFMK (Ar 13933); 1 juvenile, in pure ethanol, same data as holotype, ZFMK (Phi 258). 


\section{Description}

Male (holotype)

MeAsurements. Total body length 3.2, carapace width 1.1. Leg 1: $39.3(9.0+0.5+9.1+17.4+3.3)$, tibia 2: 5.3, tibia 3: 3.6, tibia 4: 5.2; tibia $1 \mathrm{~L} / \mathrm{d}$ : 77. Distance PME-PME $325 \mu \mathrm{m}$, diameter PME $135 \times 110 \mu \mathrm{m}$, distance PME-ALE $20 \mu \mathrm{m}$; AME absent.

CoLor. Carapace ochre-yellow with black lateral margins, pair of small dark marks behind ocular area, and dark median mark at posterior rim; ocular area and clypeus pale ochre; sternum bright orange; leg coxae ochre-yellow, other leg segments greenish-ochre (especially femora) to light brown (distal segments); abdomen grey, with distinct dorsal and lateral pattern of black marks and rows of white marks, ventrally with brown band between gonopore and spinnerets (mid-section indistinct).

Body. Habitus as in Figs 10-12; ocular area slightly raised, each triad on low hump directed toward lateral; carapace only anteriorly with very shallow and narrow median furrow; clypeus with indistinct pair of processes near rim, provided with some slightly stronger hairs; sternum wider than long $(0.70 / 0.55)$, unmodified.

Chelicerae. As in A. libjo Huber, sp. nov. ( $c f$. Fig. 40), with pair of ridge-shaped apophyses distally near median line, without proximal lateral apophyses; without modified hairs; without stridulatory ridges.

Palps. Proximal segments very similar to A. libjo ( $c f$. Figs 26-27), trochanter apophysis and femur apophysis slightly larger, tibia longer (length/width: 0.70/0.24). Genital bulb longer than in A. libjo sp. nov., with all three processes different (Figs 41-42): dorsal process wider proximally; central hinged process with smaller prolateral flap and different tip; ventral hinged process relatively shorter.

LEGS. Without spines, with curved hairs on metatarsi $1-3$, with vertical hairs in higher than usual density in one retrolatero-dorsal row on each tibia; retrolateral trichobothrium on tibia 1 at $2 \%$; prolateral trichobothrium absent on tibia 1, present on other tibiae. Tarsus 1 with $\sim 30$ pseudosegments, distally distinct.

Male (variation)

Tibia 1 in 2 other males: 8.9, 9.3; ratio of palpal tibia length/width: 2.9, 3.2. Other males without or with indistinct white marks on abdomen.

\section{Female}

In general similar to male; eye triads closer together (distance PME-PME $230 \mu \mathrm{m}$ ); clypeus unmodified; tibiae with short vertical hairs in low density; entire median area on carapace darker; clypeus also slightly darker (one female with wide brown median band on carapace extending over ocular area and clypeus); abdomen with or without white marks; tibia 1 in 3 females: 6.7, 6.8, 7.0. Epigynum with large, weakly sclerotized area, posteriorly protruding with short, narrow scape (Figs 43, 48-49); internal genitalia with large median membranous structure of unknown function (Fig. 44).

\section{Natural history}

The spiders were found in strongly domed sheet-webs among high grasses in well-preserved forest. As in A. libjo Huber, sp. nov., males and females were sometimes found close to each other but in separate webs. The locality is shared with the ground-dwelling A. kiukoki Huber, sp. nov.

\section{Distribution}

Known from type locality only (Fig. 3). 
HUBER B.A. et al., Revision of Aetana spiders

\author{
Aetana kiukoki Huber, sp. nov. \\ urn:1sid:zoobank.org:act:23ED16FE-E6AA-40B4-B55E-A2C31CB86A22
}

Figs 51-52, 57-69, 87-89

\title{
Diagnosis
}

Distinguished from closest known relatives (A. paragua Huber, sp. nov., A. loboc Huber, sp. nov., A. pasambai Huber, sp. nov.) by distinctive modification of male clypeus (Figs 59, 62, 65; similar only in A. paragua Huber, sp. nov., see Fig. 72), and long tongue-shaped posterior projection of epigynum (Figs 60, 87; very similar in A. paragua Huber, sp. nov., see Fig. 73; much shorter in A. loboc Huber, sp. nov., see Fig. 78; female of $A$. pasambai Huber, sp. nov. unknown). Distinguished from $A$. paragua Huber, sp. nov. also by longer male eye stalks (Fig. 59), more strongly curved apophysis on male palpal femur (Fig. 58), different shape of distal procursus elements (Fig. 58), and pore plates closer together (Fig. 61). Distinguished from A. loboc Huber, sp. nov. and A. pasambai Huber, sp. nov. also by modification of male palpal femur (only one large retrolateral process; Fig. 58) and absence of median process on male ocular area.

\section{Etymology}

Named for Filipino painter Ang Kiukok (1931-2005).

\section{Material examined}

Holotype

PHILIPPINES: ${ }^{\lambda}$, Mindanao, Davao del Sur Prov., Marilog Distr., Baganihan $\left(7.469^{\circ} \mathrm{N}, 125.250^{\circ} \mathrm{E}\right)$, 1210 m a.s.l., primary forest near road, near ground, 15 Feb. 2014 (B.A. Huber), ZFMK (Ar 13934).

\section{Other material}

PHILIPPINES, Mindanao Isl.: $7 \lesssim \precsim, 7 q q, 9$ juvs, same data as holotype, ZFMK (Ar 13935-36); 1 , 6 juvs, in pure ethanol, same data, ZFMK (Phi 256). - 1 + , 11 juvs from Barangay Baganihan, 'site 1' $\left(7.438^{\circ} \mathrm{N}, 125.226^{\circ} \mathrm{E}\right), 1000 \mathrm{~m}$ a.s.l., 5 Dec. 2014 (M.A. Responte), MSU-IIT; 4 우, 17 juvs, from same locality, 'site $2^{\prime}\left(7.456^{\circ} \mathrm{N}, 125.239^{\circ} \mathrm{E}\right), 6$ Dec. 2014 (M.A. Responte), MSU-IIT; 9 juvs, from same locality, 'site 3' ( $\left.7.470^{\circ} \mathrm{N}, 125.245^{\circ} \mathrm{E}\right), 7$ Dec 2014 (M.A. Responte), MSU-IIT. - 4 q 9,1 juv., Marilog Distr., Epol Spring Resort $\left(7.456^{\circ} \mathrm{N}, 125.237^{\circ} \mathrm{E}\right), \sim 1100 \mathrm{~m}$ a.s.l., degraded forest, near ground, $15 \mathrm{Feb}$. 2014 (B.A. Huber), ZFMK (Ar 13937); 3 우, in pure ethanol, same data, ZFMK (Phi 253). -1 ${ }^{2}, 1$ 우,

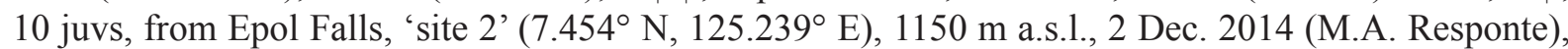
MSU-IIT; 1 \&, 4 juvs, from same locality, 'site 3' $\left(7.451^{\circ} \mathrm{N}, 125.240^{\circ} \mathrm{E}\right), 1200 \mathrm{~m}$ a.s.1., 3 Dec. 2014 (M.A. Responte), MSU-IIT; 1 juv., from same locality, 'site 1' $\left(7.455^{\circ} \mathrm{N}, 125.237^{\circ} \mathrm{E}\right), 1100 \mathrm{~m}$ a.s.1., 1 Dec. 2014 (M.A. Responte), MSU-IIT. $-60^{\lambda} 0^{\lambda}, 2$ 우, 2 juvs, Mt. Matutum, Kawit Forest, 'site 1' $\left(6.338^{\circ}\right.$ N, 125.104 ${ }^{\circ}$ E), 950 m a.s.l., along brook, near ground, 13 Feb. 2014 (B.A. Huber), ZFMK (Ar 13938); 4 juvs, in pure ethanol, same data, ZFMK (Phi 268). - 1 o, 2 우우, Bukidnon Prov., Barangay San Jose, Blue Water Cave $\left(7.706^{\circ} \mathrm{N}, 125.032^{\circ} \mathrm{E}\right), 200 \mathrm{~m}$ a.s.l., near ground at cave entrance, 16 Feb. 2014 (B.A.

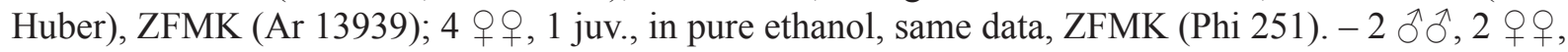
1 juv., Barangay San Jose, Kabyaw Cave $\left(\sim 7.704^{\circ} \mathrm{N}, 125.038^{\circ} \mathrm{E}\right), \sim 200 \mathrm{~m}$ a.s.1., near ground near cave entrance, 16 Feb. 2014 (B.A. Huber), ZFMK (Ar 13940). - 4 ô $\partial^{2}, 8$ 우 0 , Barangay San Jose, doline near Kabyaw Cave $\left(7.703^{\circ} \mathrm{N}, 125.038^{\circ} \mathrm{E}\right), 220 \mathrm{~m}$ a.s.1., near ground, 16 Feb. 2014 (B.A. Huber), ZFMK (Ar 13941). -3 우, Bukidnon Prov., CEDAR (Center for Ecological Development and Recreation) $\left(8.251^{\circ}\right.$ $\mathrm{N}, 125.034^{\circ} \mathrm{E}$ ), $760 \mathrm{~m}$ a.s.l., forest along river, near ground, $16 \mathrm{Feb} .2014$ (B.A. Huber), ZFMK (Ar 13942); 1 , in pure ethanol, same data, ZFMK (Phi 246). -10 , 4 q $q, 3$ juvs, from CEDAR $\left(8.251^{\circ} \mathrm{N}\right.$, $125.027^{\circ}$ E), 15 Nov. 2014 (E.P. Mondejar), MSU-IIT. $-3 \partial^{\lambda}, 7$ q $q$, Bukidnon Prov., Santo Domingo $\left(7.782^{\circ} \mathrm{N}, 125.397^{\circ} \mathrm{E}\right), 560 \mathrm{~m}$ a.s.l., forest remnant along brook, near ground, 8-9 Feb. 2014 (B.A. Huber), ZFMK (Ar 13943); 1, 6 juvs, in pure ethanol, same data, ZFMK (Phi 285). -2 $\widehat{\partial}$, Bukidnon 
Prov., near Santo Domingo, Penolohan $\left(7.769^{\circ} \mathrm{N}, 125.420^{\circ} \mathrm{E}\right), 640 \mathrm{~m}$ a.s.l., forest above Salug River, near ground, 8 Feb. 2014 (B.A. Huber) ZFMK (Ar 13944); 2 우 in pure ethanol, same data, ZFMK (Phi 277). $-5 \hat{\jmath}, 15$ 우, 3 juvs, Misamis Occidental Prov., Iligan, NPC Nature's Park near Cristina Falls $\left(8.186^{\circ} \mathrm{N}, 124.192^{\circ} \mathrm{E}\right), 90 \mathrm{~m}$ a.s.l., near ground, 17 Feb. 2014 (B.A. Huber), ZFMK (Ar 13945-46); 3 우, 2 juvs, in pure ethanol, same data, ZFMK (Phi 244).

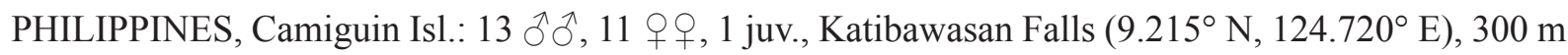
a.s.l., near ground, 19 Feb. 2014 (B.A. Huber, P.N. Banaag), ZFMK (Ar 13947-48); 1 ㅇ, in pure ethanol,

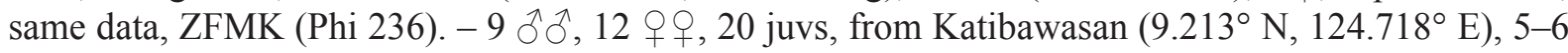
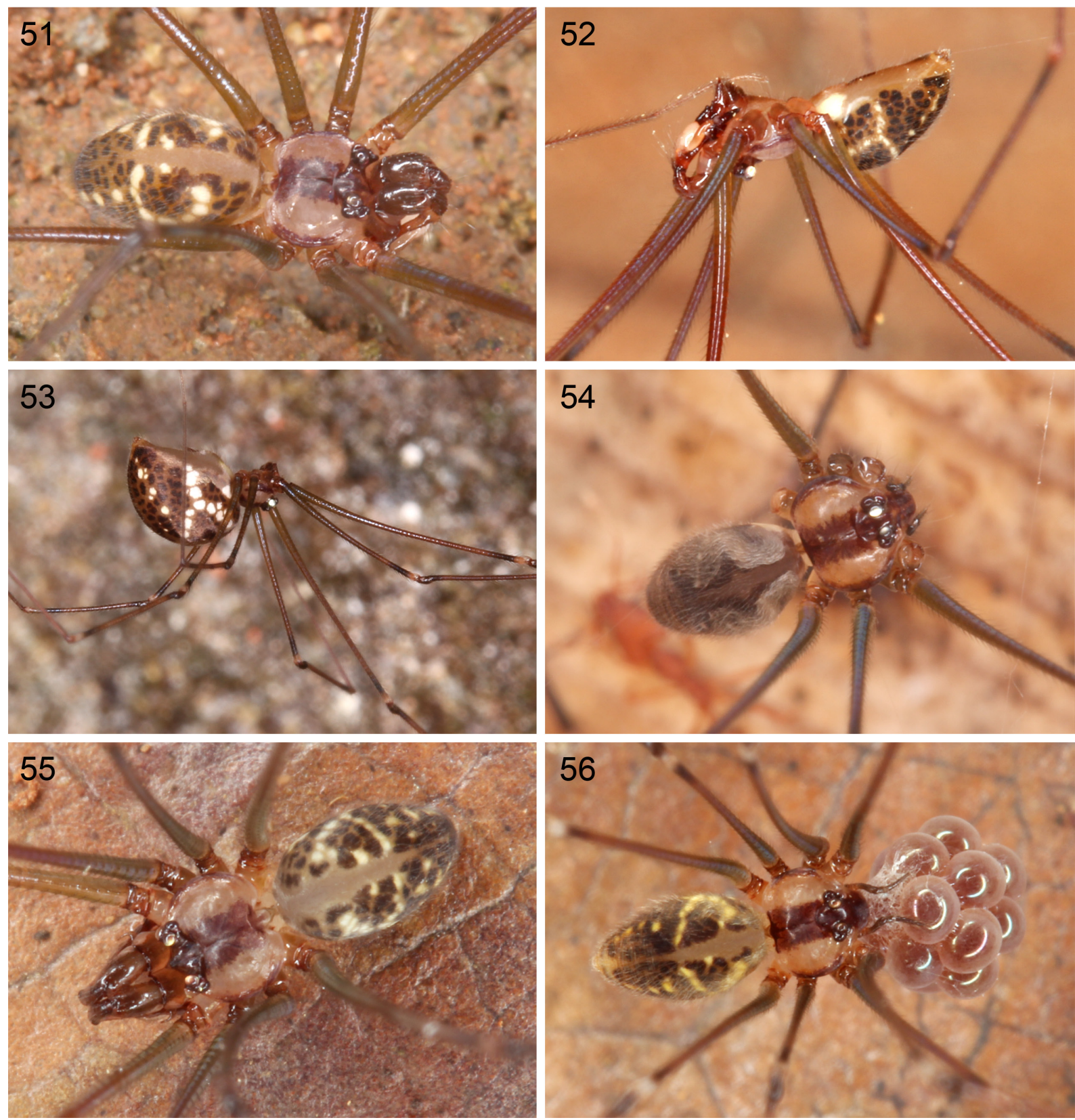

Figs 51-56. Live specimens. Aetana kiukoki group. 51-53. A. kiukoki Huber, sp. nov., ô from Baganihan (51), $\delta$ and $q$ from Santo Domingo (52-53), Mindanao. 54. A. paragua Huber, sp. nov., $q$ from Dinagat Island, Mindanao. 55-56. A. loboc Huber, sp. nov., $\overbrace{}^{\Uparrow}$ and + with eggsac from near Loboc, Bohol. 


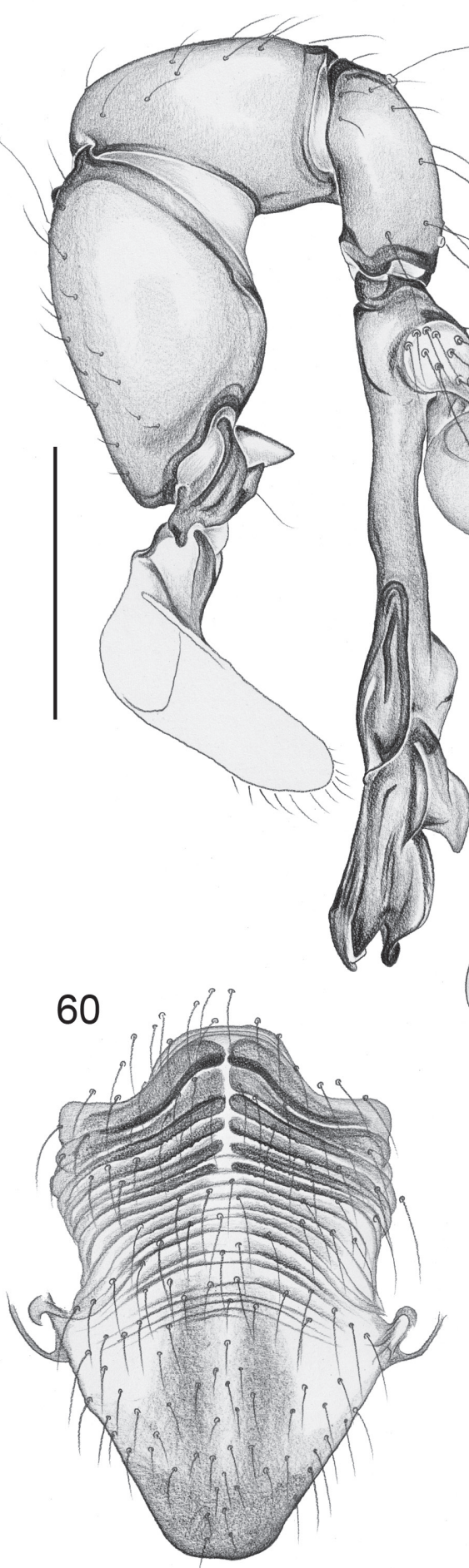

\section{7}
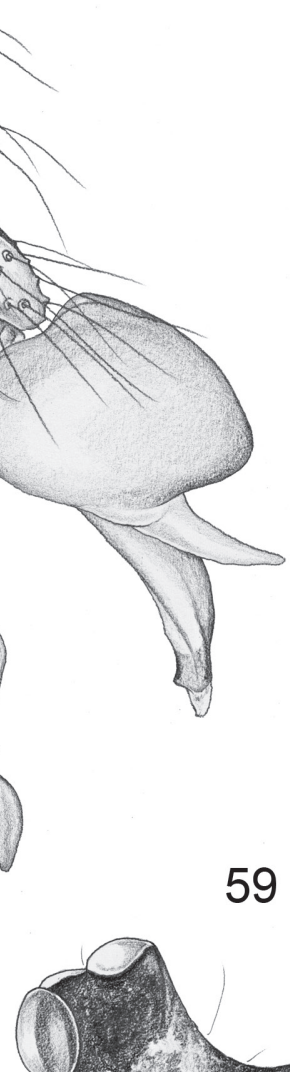

59
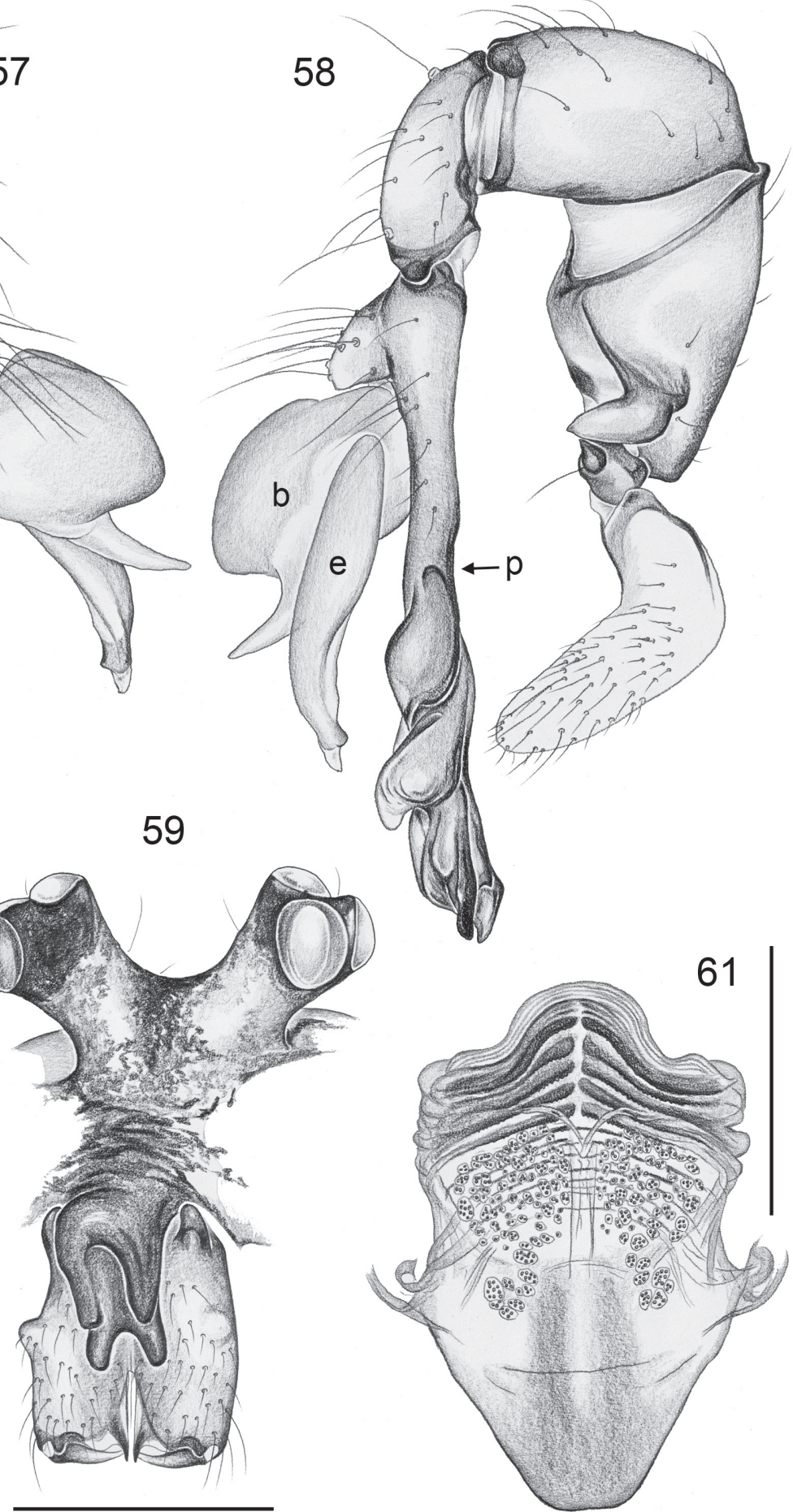

Figs 57-61. Aetana kiukoki Huber, sp. nov. 57-58. Left male palp, prolateral and retrolateral views. 59. Male prosoma, oblique frontal view. 60-61. Cleared female genitalia, ventral and dorsal views. $b=$ genital bulb; e = embolus; $\mathrm{p}=$ procursus. Scale lines: $0.5 \mathrm{~mm}$. 

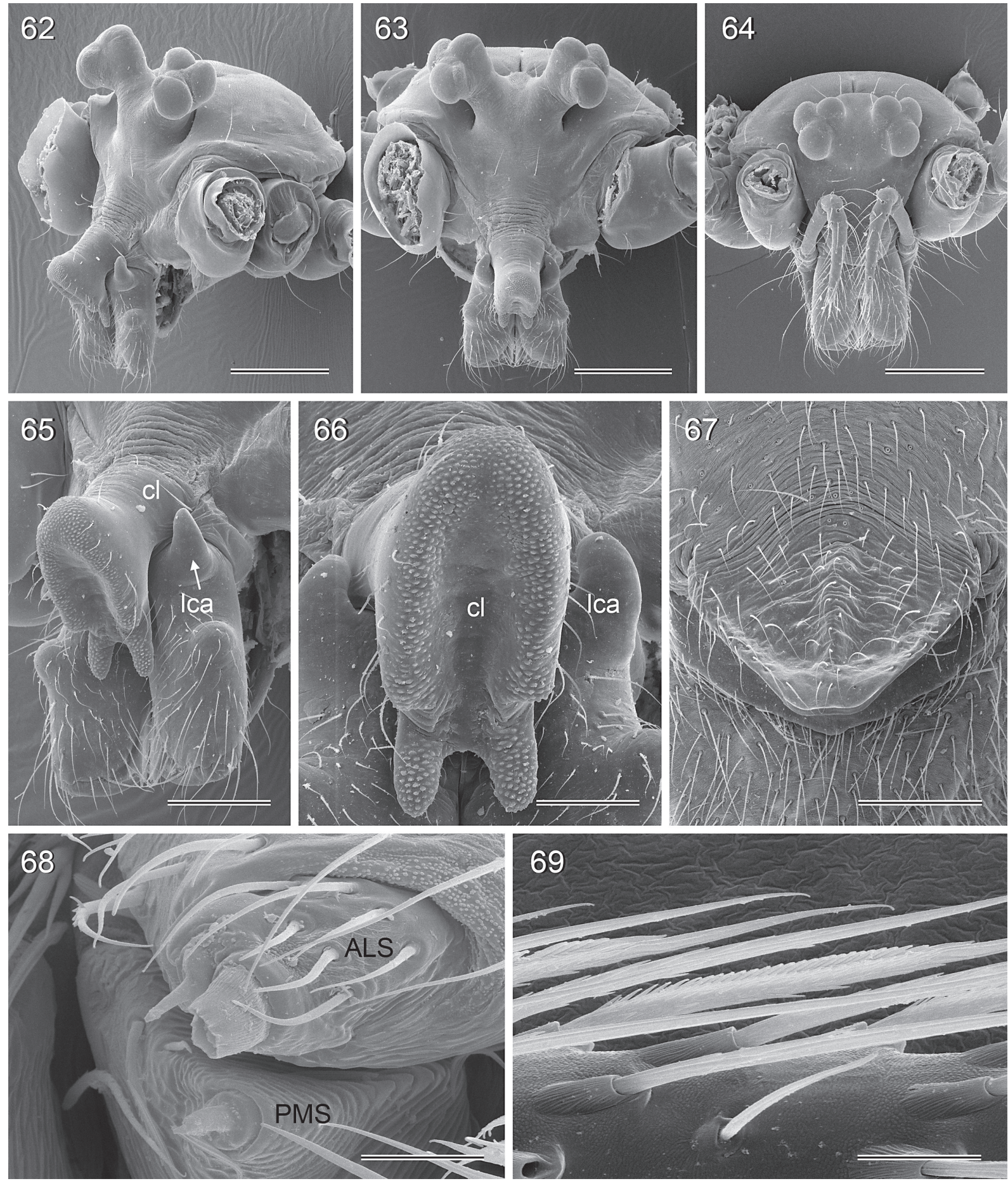

Figs 62-69. Aetana kiukoki Huber, sp. nov. 62-63. Male prosoma, oblique frontal and frontal views. 64. Female prosoma, frontal view. 65. Male clypeus and chelicerae, oblique frontal view. 66. Male clypeus modification, frontal view. 67. Epigynum, ventral view. 68. Male ALS and PMS. 69. Comb-hair on female tarsus $4 . \mathrm{cl}=$ clypeus; $1 \mathrm{ca}=$ lateral cheliceral apophysis. Scale lines: $62-64=400 \mu \mathrm{m} ; 65,67=$ $200 \mu \mathrm{m} ; 66=100 \mu \mathrm{m} ; 68-69=20 \mu \mathrm{m}$. 


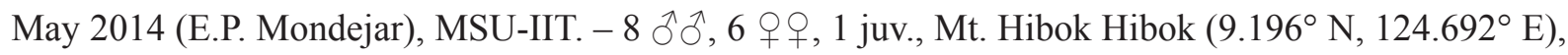
600 m a.s.1., near ground, 18 Feb. 2014 (B.A. Huber, P.N. Banaag), ZFMK (Ar 13949-50); 2 우, 1 juv., in pure ethanol, same data, ZFMK (Phi 240).

Assigned tentatively (no male available)

PHILIPPINES, Mindanao Isl., Davao Oriental: 1 , , from Mount Hamiguitan WS (access San Isidro), 'site 1' (6.720 ${ }^{\circ} \mathrm{N}, 126.172^{\circ}$ E), 490 m a.s.l., 9 Feb. 2015 (M.A. Responte), ZFMK (Ar 13951); 7 juvs, from same locality, 'site $3^{\prime}\left(6.732^{\circ} \mathrm{N}, 126.179^{\circ} \mathrm{E}\right), 1250 \mathrm{~m}$ a.s.1., 11 Feb. 2015 (M.A. Responte), MSUIIT.

\section{Description}

Male (holotype)

Measurements. Total body length 3.0, carapace width 1.2. Leg 1: $34.2(7.9+0.5+8.0+14.8+3.0)$, tibia 2: 5.0, tibia 3: 3.5, tibia 4: 5.1; tibia $1 \mathrm{~L} / \mathrm{d}$ : 72. Distance PME-PME $355 \mu \mathrm{m}$, diameter PME $150 \times 120 \mu \mathrm{m}$, distance PME-ALE $\sim 35 \mu \mathrm{m}$; AME absent.

COLOR. Carapace ochre-yellow with narrow lateral marginal bands and wide dark brown median band including ocular area and clypeus; sternum with pair of wide brown bands converging posteriorly; legs greenish ochre with slightly darker rings on femora (subdistally, with light tip), and tibiae (proximally and subdistally, the latter followed by light tip); abdomen ochre-gray, dorsally and laterally covered with many black and white marks, ventrally with dark band behind gonopore and very indistinct mark in front of spinnerets.

Body. Habitus as in Figs 51-52; ocular area raised, each triad on additional short stalk directed toward lateral (Figs 59, 62-63), without median process; carapace with very shallow median furrow in anterior part only (Fig. 63); clypeus with large distinctive process, strongly protruding in upper part, with two pairs of rounded apophyses in distal part, densely covered with small scales (Figs 65, 66); sternum wider than long $(0.75 / 0.60)$, unmodified. ALS and PMS as in Fig. 68.

Chelicerae. As in Fig. 59, with pair of dark lateral apophyses proximally and pair of weakly sclerotized humps laterally, without modified hairs; without stridulatory ridges.

PALPS. As in Figs 57-58; coxa unmodified; trochanter with short retrolatero-ventral apophysis; femur with strong retrolateral apophysis distally curved toward ventral; patella large; tibia small, dorsal trichobothrium in very proximal position, retrolateral trichobothrium in very distal position; tarsus with long procursus, distally complex, apparently with two hinged structures; bulb with large embolus and smaller, semitransparent, pointed process.

Legs. Without spines; with curved hairs on metatarsi 1-3 (few curved hairs also on tibiae 1-2); few vertical hairs; retrolateral trichobothrium on tibia 1 at $3 \%$; prolateral trichobothrium absent on tibia 1 , present on other tibiae; tarsus 1 with $\sim 30$ pseudosegments, only distally distinct.

Male (variation)

Tibia 1 in 48 other males: 7.0-9.8 (mean: 8.2). Ventral mark behind gonopore in most males slightly asymmetrical.

\section{Female}

In general similar to male (Fig. 53) but clypeus unmodified; eye triads much closer together (distance PME-PME $155 \mu \mathrm{m}$ ), not on stalks (Fig. 64); without stridulatory apparatus between carapace and abdomen. Tibia 1 in 56 females: 4.9-7.5 (mean: 6.1); dark and light rings on legs often more distinct than in males. Tarsus 4 comb-hairs with very dense tines (Fig. 69). Epigynum in anterior part weakly 
sclerotized, internal structures visible through cuticle, with flat, tongue-shaped scape (Figs 60, 87), without membranous pockets behind epigynum. Internal genitalia as in Figs 61 and 89; pore plates close together; without sclerotized internal pockets; with distinct transversal sclerotized ridges provided with many small teeth. The single female from Mt. Hamiguitan cannot be unambiguously assigned to this species rather than to A. paragua and is therefore assigned tentatively.

\section{Natural history}

The spiders were found in domed sheet webs close to the ground, usually in well protected dark spaces among and under large rocks and logs in forests. Males and females were sometimes found together in one web. At Baganihan, some specimens (especially juveniles) were found among mosses in deep furrows of trees up to $1.5 \mathrm{~m}$ above the ground. At both localities on Camiguin Island, the spiders were observed to be much more agile and quick when disturbed than at other localities.

\section{Distribution}

Known from numerous localities on Mindanao Island and from Camiguin Island (Fig. 4).

Aetana paragua Huber, sp. nov.

urn:1sid:zoobank.org:act:9E9FEDE8-BEB5-46D4-929C-6C2259AA7FDB

Figs $54,70-74,90-92$

\section{Diagnosis}

Distinguished from closest known relatives (A. kiukoki Huber, sp. nov., A. loboc Huber, sp. nov., A. pasambai Huber, sp. nov.) by distinctive modification of male clypeus (Fig. 72; similar only in A. kiukoki Huber, sp. nov.), and tongue-shaped posterior projection of epigynum (Fig. 73; very similar to A. kiukoki Huber, sp. nov.; much shorter in A. loboc Huber, sp. nov.; female of A. pasambai Huber, sp. nov. unknown). Distinguished from A. kiukoki Huber, sp. nov. also by shorter male eye stalks (Fig. 72), weakly curved apophysis on male palpal femur (Fig. 71), different shape of distal procursus elements (Fig. 71), and pore plates wider apart (Fig. 74). Distinguished from A. loboc Huber, sp. nov. and $A$. pasambai Huber, sp. nov. also by modification of male palpal femur (only one large retrolateral process) and absence of median process in male ocular area.

\section{Etymology}

Named for the type locality; noun in apposition.

\section{Material examined}

Holotype

PHILIPPINES: ${ }^{\lambda}$, Dinagat Isl., near Libjo, Paragua Forest, 'site 1' $\left(10.222^{\circ} \mathrm{N}, 125.553^{\circ} \mathrm{E}\right), 130 \mathrm{~m}$ a.s.l., forest at brook, near ground, 20 Feb. 2014 (B.A. Huber), ZFMK (Ar 13952).

\section{Other material}

PHILIPPINES: Dinagat Is1., $2 \hat{\delta} \hat{\partial}, 4$ q $q$, same data as holotype, ZFMK (Ar 13953); $1 \hat{\delta}$, in pure ethanol, same data, ZFMK (Phi 230). - 1 ㅇ, 1 juv., Paragua Forest, 'site 2' $\left(10.241^{\circ} \mathrm{N}, 125.545^{\circ} \mathrm{E}\right)$, $240 \mathrm{~m}$ a.s.l., forest along brook, near ground, 20 Feb. 2014 (B.A. Huber), ZFMK (Ar 13954).

\section{Description}

Male (holotype)

Measurements. Total body length 3.0, carapace width 1.2. Leg 1: $35.2(8.0+0.5+8.2+15.5+3.0)$, tibia 2: 4.9, tibia 3: 3.4, tibia 4: 4.9; tibia $1 \mathrm{~L} / \mathrm{d}$ : 67. Distance PME-PME $230 \mu \mathrm{m}$, diameter PME $135 \times 110 \mu \mathrm{m}$, distance PME-ALE $\sim 35 \mu \mathrm{m}$; AME absent. 
HUBER B.A. et al., Revision of Aetana spiders

CoLor. Carapace ochre-yellow with narrow lateral marginal bands and wide dark brown median band including ocular area and clypeus; sternum with pair of wide brown bands converging posteriorly, labium proximally dark brown; legs greenish ochre with barely visible darker rings on femora (subdistally, with light tip), and tibiae (proximally and subdistally, the latter followed by light tip); abdomen ochre-gray, dorsally and laterally covered with many black marks, with few indistinct white marks, ventrally with dark band behind gonopore and very indistinct mark in front of spinnerets.

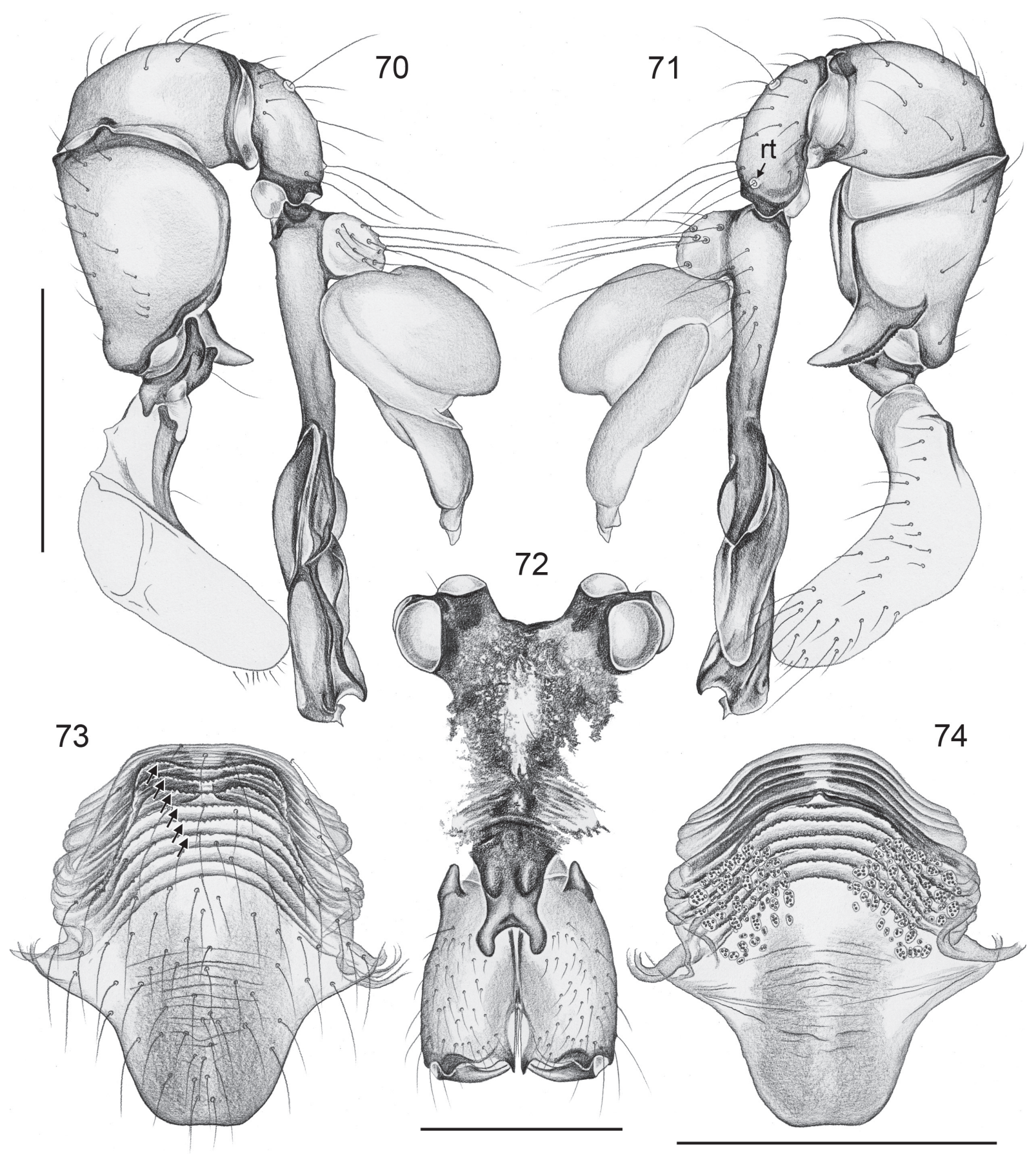

Figs 70-74. Aetana paragua Huber, sp. nov. 70-71. Left male palp, prolateral and retrolateral views. 72. Male prosoma, frontal view. 73-74. Cleared female genitalia, ventral and dorsal views (arrows point at serrated ridges). $\mathrm{rt}=$ retrolateral trichobothrium. Scale lines: $0.5 \mathrm{~mm}$. 
Body. Habitus as in A. kiukoki Huber, sp. nov. (cf. Figs 51-52); ocular area raised, each triad on additional hump directed toward lateral, without median process; carapace with very shallow median furrow in anterior part only; clypeus with large distinctive process (Fig. 72), strongly protruding in upper part, with two pairs of rounded apophyses set with small scales; sternum wider than long $(0.80 / 0.55)$, unmodified.

CheliCERAe. As in Fig. 72, with pair of dark lateral apophyses proximally, barely visible lateral humps more distally; without modified hairs; without stridulatory ridges.

Palps. As in Figs 70-71; very similar to A. kiukoki Huber, sp. nov., but retrolateral apophysis of femur less strongly curved, distal elements of procursus different, and semitransparent pointed process on bulb smaller.

LEGS. Without spines; with curved hairs on metatarsi 1-3 (few curved hairs also on tibiae 1-2); few vertical hairs; retrolateral trichobothrium on tibia 1 at $3 \%$; prolateral trichobothrium absent on tibia 1 , present on other tibiae; tarsus 1 with $\sim 30$ pseudosegments, only distally distinct.

Male (variation)

Tibia 1 in 2 other males: 8.2, 8.3.

Female

In general similar to male but clypeus unmodified; eye triads much closer together (distance PME-PME $125 \mu \mathrm{m}$ ); without stridulatory apparatus between carapace and abdomen. Tibia 1 in 4 females: 5.5, 5.6, 5.6, 5.8; dark and light rings on legs often more distinct than in males. Epigynum and internal genitalia very similar to those of $A$. kiukoki Huber, sp. nov., but tongue-shaped posterior projection slightly shorter and wider (Figs 73, 90), and pore plates wider apart (Fig. 74).

\section{Natural history}

The spiders were found in domed webs very close to the ground. At the same locality, A. libjo Huber, sp. nov. occurred higher among the vegetation.

\section{Distribution}

Known from two neighboring localities on Dinagat Island only (Fig. 4).

$$
\begin{aligned}
& \text { Aetana loboc } \text { Huber, sp. nov. } \\
& \text { urn:Isid:zoobank.org:act:CAD63F67-D442-43BF-ACBC-062F4B3DCA0A }
\end{aligned}
$$

Figs 55-56, 75-86, 93-95

\section{Diagnosis}

Distinguished from closest known relative (A. pasambai Huber, sp. nov.) by distinctive modification of male clypeus (Fig. 77; longer and narrower), by median process between eye stalks larger and in more dorsal position (Fig. 77), by longer male palpal tibia and procursus (Fig. 76), and by stronger ventral apophysis on male palpal femur (female of $A$. pasambai Huber, sp. nov. unknown); from other close relatives (A. paragua Huber, sp. nov.; A. kiukoki Huber, sp. nov.) by modifications of male palpal femur (two processes instead of one), presence of median process between eye stalks, and very short tongueshaped posterior projection of epigynum (Fig. 78).

\section{Etymology}

Named for the type locality; noun in apposition. 


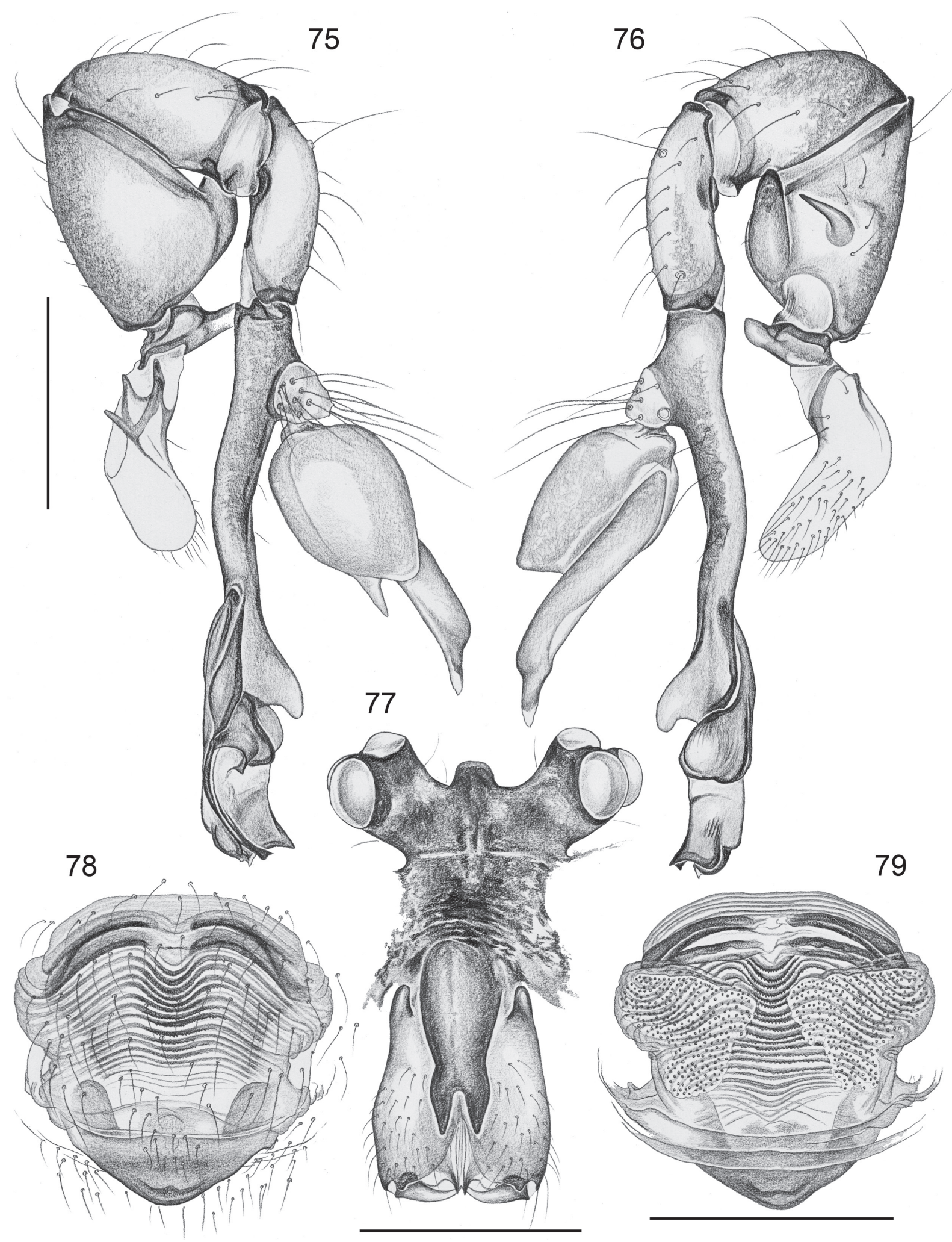

Figs 75-79. Aetana loboc Huber, sp. nov. 75-76. Left male palp, prolateral and retrolateral views. 77. Male prosoma, frontal view. 78-79. Cleared female genitalia, ventral and dorsal views. Scale lines: $0.5 \mathrm{~mm}$. 

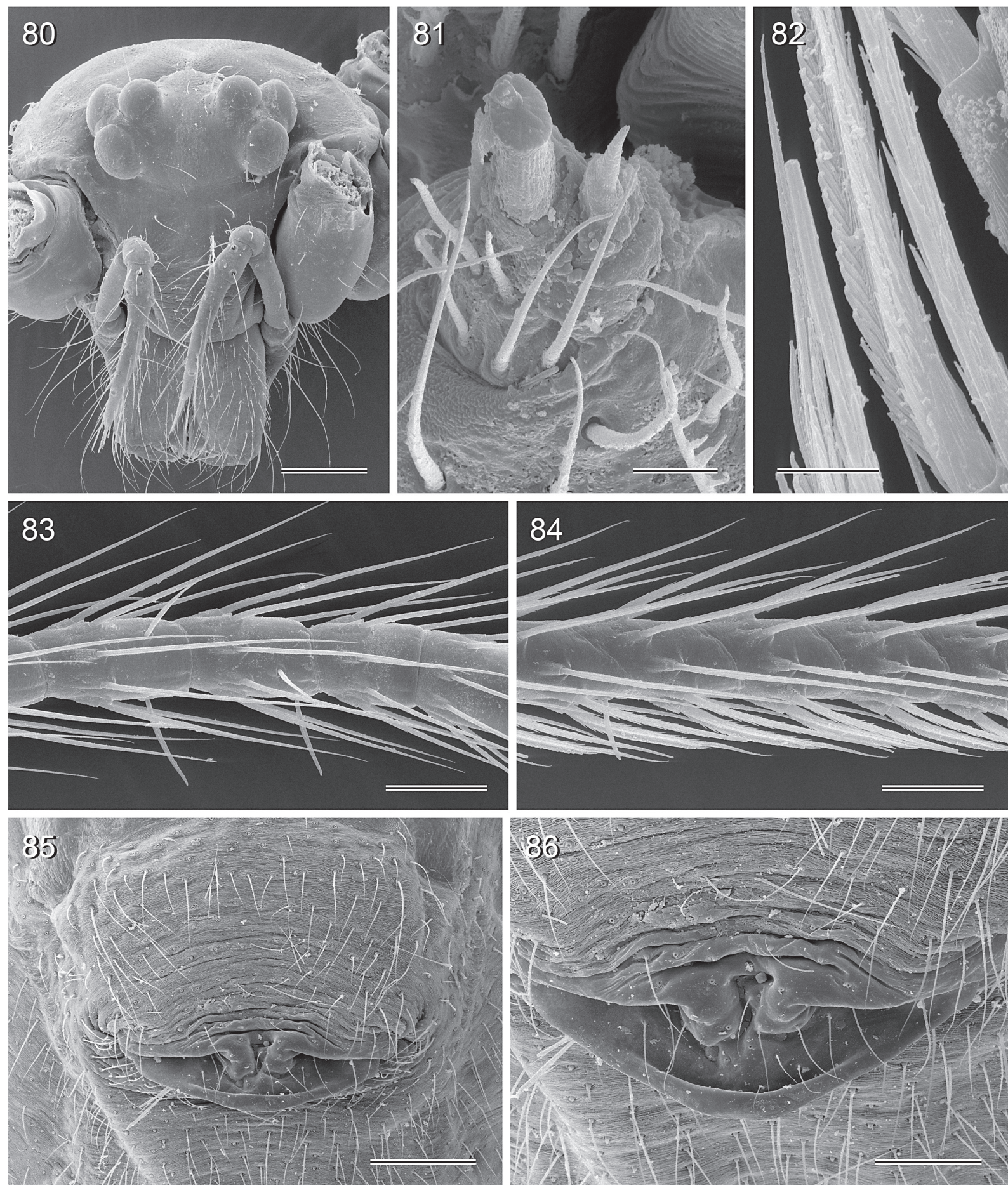

Figs 80-86. Aetana loboc Huber, sp. nov. 80. Female prosoma, frontal view. 81. Female ALS. 82. Comb-hair on female tarsus 4. 83. Detail of female tarsus 1. 84. Detail of female tarsus 4. 85. Epigynum. 86. Detail of preceding. Scale lines: $80,85=200 \mu \mathrm{m} ; 81=10 \mu \mathrm{m} ; 82=8 \mu \mathrm{m} ; 83-84=40 \mu \mathrm{m} ; 86=$ $100 \mu \mathrm{m}$. 
HUBER B.A. et al., Revision of Aetana spiders

\section{Material examined}

\section{Holotype}

PHILIPPINES: ${ }^{\wedge}$, Bohol Isl., near Loboc, above Loboc River $\left(9.651^{\circ} \mathrm{N}, 124.022^{\circ} \mathrm{E}\right), \sim 50 \mathrm{~m}$ a.s.l., ravine in degraded forest, 5 Mar. 2014 (B.A. Huber), ZFMK (Ar 13955).
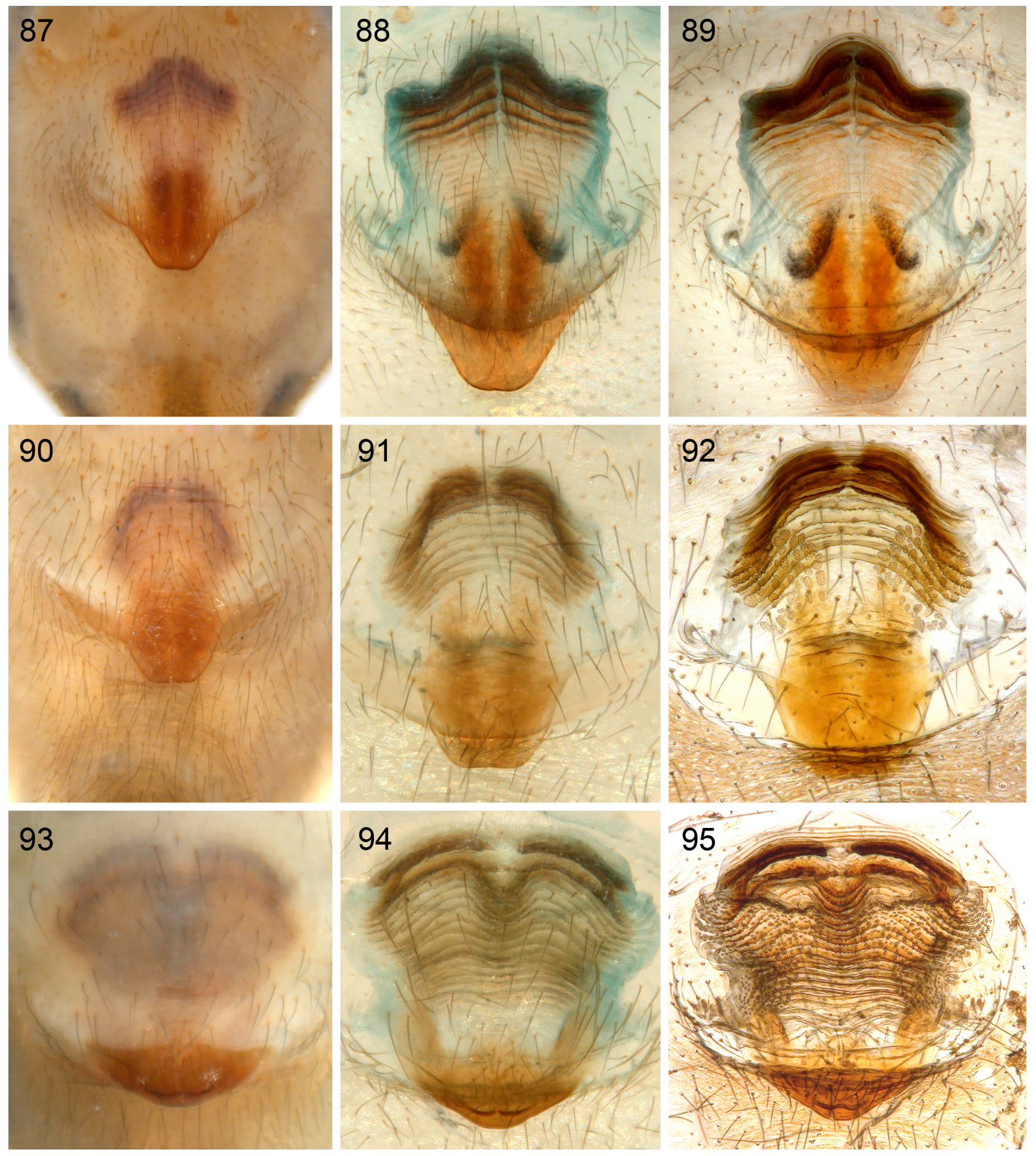

Figs 87-95. Aetana kiukoki group. Female genitalia; untreated in ventral view, cleared in ventral and dorsal views. - 87-89. A. kiukoki Huber, sp. nov. - 90-92. A. paragua Huber, sp. nov. - 93-95. A. loboc Huber, sp. nov. 


\section{Other material}

PHILIPPINES: Bohol Isl., $4 \hat{\jmath} \widehat{o}, 13$ 우, 1 juv., same data as holotype, ZFMK (Ar 13956-57); 3 우, 3 juvs, in pure ethanol, same data as holotype, ZFMK (Phi 201). $-3 \hat{\jmath} \sigma^{\lambda}, 3$ 우, at Loboc River $\left(9.651^{\circ} \mathrm{N}\right.$, 124.022 ${ }^{\circ}$ E), near ground, 20 m a.s.1., 4 Mar. 2014 (B.A. Huber), ZFMK (Ar 13958). - $1 \jmath^{\lambda}, 1$ q, Rajah Sikatuna (Magsaysay Park) $\left(9.705^{\circ} \mathrm{N}, 124.123^{\circ} \mathrm{E}\right), 430 \mathrm{~m}$ a.s.1., forest, 6 Mar. 2014 (B.A. Huber), ZFMK (Ar 13959).

\section{Description}

Male (holotype)

Measurements. Total body length 3.1, carapace width 1.2. Leg 1: $32.4(7.5+0.5+7.6+14.1+2.7)$, tibia 2: 4.5, tibia 3: 3.2, tibia 4: 4.9; tibia $1 \mathrm{~L} / \mathrm{d}$ : 73. Distance PME-PME $340 \mu \mathrm{m}$, diameter PME $135 \times 120 \mu \mathrm{m}$, distance PME-ALE $35 \mu \mathrm{m}$; AME absent.

CoLOR. Carapace ochre-yellow with narrow lateral marginal bands and wide dark brown median band including ocular area and clypeus; sternum with pair of wide brown bands converging posteriorly, labium proximally not dark brown; legs ochre to light brown, with indistinct darker rings on femora (subdistally, with light tip), and tibiae (proximally and subdistally, the latter followed by light tip); abdomen ochre-gray, dorsally and laterally covered with many black marks, with few indistinct white marks, ventrally with small spot behind gonopore and very indistinct mark in front of spinnerets.

Body. Habitus as in Fig. 55; ocular area raised, each triad on short stalk directed toward lateral, with distinctive median process (Fig. 77); carapace with very shallow median furrow in anterior part only; clypeus with large distinctive process (Fig. 77), strongly protruding in upper part, with distinctive pair of distal apophyses; sternum wider than long $(0.75 / 0.60)$, unmodified.

Chelicerae. As in Fig. 77, with pair of dark lateral apophyses proximally, without lateral humps more distally; without modified hairs; without stridulatory ridges.

PALPS. As in Figs 75-76; coxa unmodified; trochanter with wide ventral apophysis; femur large, with strong ventral and slender retrolateral apophyses; patella very large; tibia small but long, dorsal trichobothrium in very proximal position, retrolateral trichobothrium in very distal position; tarsus with very long procursus, distally complex, apparently with two hinged structures; bulb with large embolus and small semitransparent pointed process.

Legs. Without spines; with curved hairs on metatarsi 1-3 (few curved hairs also on tibiae 1-2); few vertical hairs; retrolateral trichobothrium on tibia 1 at $2 \%$; prolateral trichobothrium absent on tibia 1 , present on other tibiae; tarsus 1 with $\sim 25$ pseudosegments, only distally distinct.

Male (variation)

Tibia 1 in 7 other males: 6.5-7.7 (mean 7.1).

Female

In general similar to male but clypeus unmodified; eye triads much closer together (distance PMEPME $135 \mu \mathrm{m}$ ); without stridulatory apparatus between carapace and abdomen; without ventral dark band on abdomen. Tibia 1 in 17 females: 5.0-5.7 (mean: 5.3); dark and light rings on legs often more distinct than in males. Epigynum in anterior part weakly sclerotized, internal structures partly visible through cuticle, with short posterior projection with submarginal transversal groove (Figs 78, 85-86, 93), without membranous pockets behind epigynum; internal genitalia as in Figs 79 and 95; without sclerotized internal pockets; with distinct transversal sclerotized ridges provided with many small teeth. 


\section{Natural history}

The spiders were found in domed webs close to the ground, hidden under rocks or logs.

\section{Distribution}

Known from two neighboring localities on Bohol Island only (Fig. 4).

$$
\begin{aligned}
& \text { Aetana pasambai Huber, sp. nov. } \\
& \text { urn:1sid:zoobank.org:act:041DF955-4589-4503-AF5D-1EC15C107E8E }
\end{aligned}
$$

Figs 96-98

\section{Diagnosis}

Distinguished from closest known relative (A. loboc Huber, sp. nov.) by distinctive modification of male clypeus (Fig. 96; shorter and wider), by median process between eye stalks smaller and in more frontal position (Fig. 96), by shorter male palpal tibia and procursus (Fig. 98), and by smaller ventral apophysis on male palpal femur (female of $A$. pasambai Huber, sp. nov. unknown); from other close relatives ( $A$. paragua sp. nov., A. kiukoki Huber, sp. nov.) by modifications of male palpal femur (two processes instead of one), and by presence of median process between eye stalks.

\section{Etymology}

Named for Philippine-born cellist Wilfredo Pasamba.

\section{Material examined}

Holotype

PHILIPPINES: $\widehat{\jmath}$, Negros Isl., Negros Oriental Prov., Casaroro Falls $\left(9.281^{\circ} \mathrm{N}, 123.208^{\circ} \mathrm{E}\right), 550 \mathrm{~m}$ a.s.l., forest along river below waterfall, 10 Mar. 2014 (B.A. Huber), ZFMK (Ar 13960).

\section{Other material}

None.

\section{Description}

Male (holotype)

MeasuREMENTS. Total body length 3.3 , carapace width 1.1. Leg 1: $32.7(7.7+0.5+7.7+14.1+2.7)$, tibia 2: 4.7, tibia 3: 3.7, tibia 4: 5.0; tibia $1 \mathrm{~L} / \mathrm{d}$ : 69. Distance PME-PME $385 \mu \mathrm{m}$, diameter PME $135 \times 120 \mu \mathrm{m}$, distance PME-ALE $\sim 35 \mu \mathrm{m}$; AME absent.

CoLOR. Carapace ochre-yellow with narrow lateral marginal bands and wide dark brown median band including ocular area and clypeus; sternum with pair of wide brown bands converging posteriorly, with darker triangular mark posteriorly, labium proximally not dark brown; legs greenish ochre, with indistinct darker rings on femora (subdistally, with light tip), and tibiae (proximally and subdistally, the latter followed by light tip); abdomen ochre-gray, dorsally and laterally covered with many black marks, with some white marks, ventrally with dark band behind gonopore and very indistinct mark in front of spinnerets.

Body. Habitus as in A. loboc Huber, sp. nov. (cf. Fig. 55); ocular area raised, each triad on short stalk directed toward lateral, with small median process in frontal position (Fig. 96); carapace with very shallow median furrow in anterior part only; clypeus with large distinctive process (Fig. 96), protruding in upper part, with distinctive pair of distal apophyses; sternum wider than long $(0.80 / 0.55)$, unmodified. 
Chelicerae. As in Fig. 96, with pair of dark lateral apophyses proximally, without lateral humps more distally; without modified hairs; without stridulatory ridges.

PaLPS. As in Figs 97-98; very similar to A. loboc Huber, sp. nov., but femur apophyses of different sizes and positions, tibia and procursus shorter.

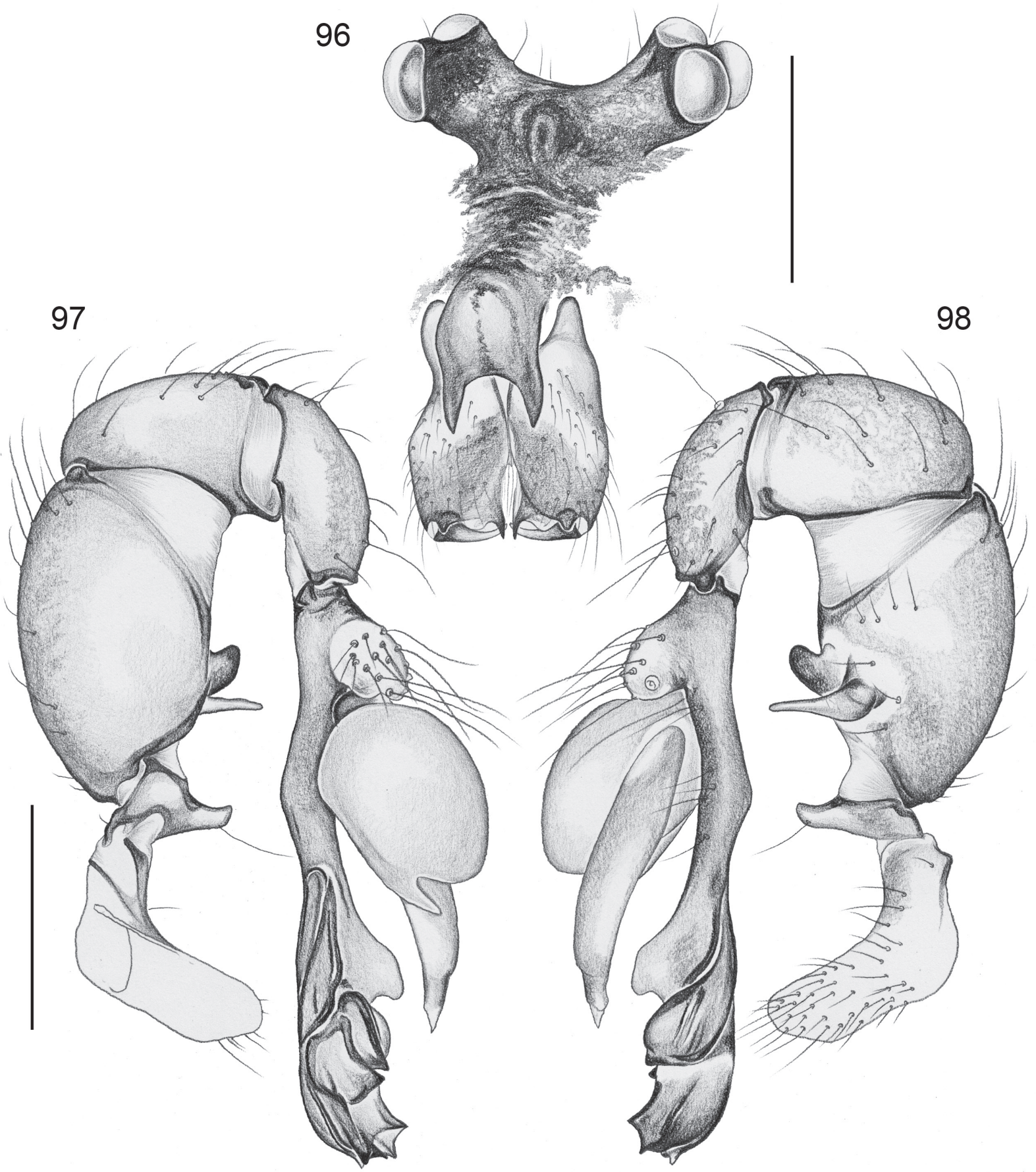

Figs 96-98. Aetana pasambai Huber, sp. nov. 96. Male prosoma, oblique frontal view. 97-98. Left male palp, prolateral and retrolateral views. Scale lines: $0.5 \mathrm{~mm}$. 
LEGS. Without spines; with curved hairs on tibiae and metatarsi 1-2; few vertical hairs; retrolateral trichobothrium on tibia 1 at $2 \%$; prolateral trichobothrium absent on tibia 1 , present on other tibiae; tarsus 1 with $\sim 25$ pseudosegments, only distally distinct.

\section{Female \\ Unknown}

\section{Natural history}

The specimen was found in a small hole in the ground.

\section{Distribution}

Known from type locality on Negros Island only (Fig. 4).

Aetana kinabalu Huber, 2005

Figs 99-103, 111-112, 163-165

Aetana kinabalu Huber, 2005a: 75-76, figs 108-109, 121-123 (ð).

\section{Note}

The original description was based on two males. Here we present data on new material from the type locality, a description of the female, and an emended diagnosis to account for the newly described congeners.

\section{Diagnosis}

Distinguished from closest known relative (A. lambir Huber, sp. nov.) by shape of prolatero-ventral apophysis of male palpal femur (pointed tip and subdistal branch of approximately same length; $c f$. Huber 2005a: fig. 121); also by presence of prolateral apophysis on femur, by details of procursus (shapes of sclerites on complex distal part; $c f$. Huber 2005a: figs 121-122), and by female genitalia (pair of internal pockets; position of pore plates; Figs 111-112).

\section{New material examined}

MALAYSIA-BORNEO, Sabah: 1 o , 1, 1 juv., Mt. Kinabalu, forest along Silau Silau Trail (6.010$\left.6.017^{\circ} \mathrm{N}, 116.537-116.543^{\circ} \mathrm{E}\right), 1550-1650 \mathrm{~m}$ a.s.l., domed webs among vegetation, 6 Aug. 2014 (B.A. Huber, S.B. Huber), ZFMK (Ar 13961); 2 q, 1 juv., in pure ethanol, same data, ZFMK (Bor 211). - 1 \%, Kinabalu N.P., 1550 m a.s.l., 2-8 Apr. 1998 (C.L. Deeleman-Reinhold, P. Zborowski), RMNH. $-2 \hat{\jmath} \partial^{\lambda}, 5$ q 9,3 juvs, Crocker Range between Kota Kinabalu and Tambuan, S-slope, forest along river $\left(5.783^{\circ} \mathrm{N}, 116.338-116.340^{\circ} \mathrm{E}\right), 1430-1480 \mathrm{~m}$ a.s.l., domed webs among vegetation, 3 Aug. 2014 (B.A. Huber, S.B. Huber), ZFMK (Ar 13962); 4 juvs, in pure ethanol, same data, ZFMK (Bor 171). -2 $\widehat{\jmath}$, 3 우, in very poor condition, Tawau $\left(4.406^{\circ} \mathrm{N}, 117.892^{\circ}\right.$ E), 6 Sep. 2009 (A. Floren), RMNH.

MALAYSIA-BORNEO, Sarawak: $2 \hat{\jmath}, 6$ 우, 3 juvs, Gunung Mulu N.P., forest near Deer Cave $\left(4.027^{\circ} \mathrm{N}, 114.818^{\circ}\right.$ E), $60 \mathrm{~m}$ a.s.1., 23-24 July 2014 (B.A. Huber, S.B. Huber), ZFMK (Ar 13963-64); same data, 3 우오, 5 juvs, in pure ethanol, ZFMK (Bor 182). -5 소, 2 우우, 4 juvs, Bario, forest along river $\mathrm{W}$ of town $\left(3.736^{\circ} \mathrm{N}, 115.437-115.443^{\circ} \mathrm{E}\right), 1150-1250 \mathrm{~m}$ a.s.l., domed webs among vegetation, 30 July 2014 (B.A. Huber, S.B. Huber), ZFMK (Ar 13965). - 1 क , 1 juv., Bario, forest along river N of town $\left(3.765-3.771^{\circ} \mathrm{N}, 115.444-115.448^{\circ} \mathrm{E}\right), 1170-1250 \mathrm{~m}$ a.s.l., domed webs among vegetation, 29 July 2014 (B.A. Huber, S.B. Huber), ZFMK (Ar 13966); 9 juvs, in pure ethanol, same data, ZFMK (Bor 233). 
Description (amendments to Huber 2005a)

\section{Male}

Thoracic furrow absent (contra Huber 2005a); clypeus slightly protruding (more than in female). Tibia 2 slightly longer than tibia 4 (e.g., 5.1/4.9; 4.9/4.8); curved hairs on metatarsi 2; tibia 1 in 7 males: 7.6-8.8 (mean: 8.3).

\section{Female}

Eye triads much closer together than in male (distance PME-PME $\sim 235 \mu \mathrm{m} v s .375 \mu \mathrm{m}$ ), not on stalks. Tibia 1 in 15 females: 5.9-7.3 (mean 6.4). Epigynum simple plate, darker laterally anteriorly; anterior
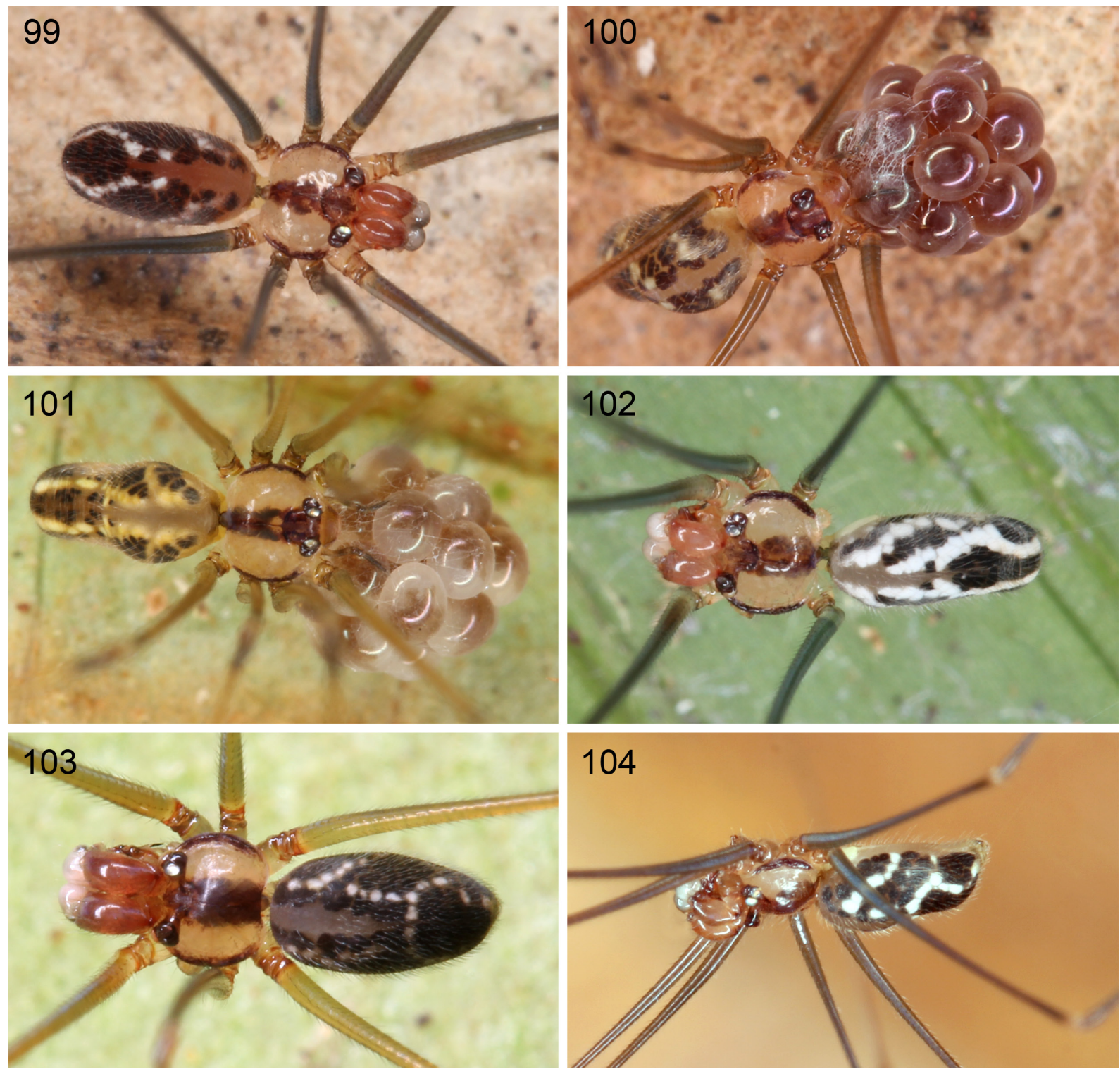

Figs 99-104. Live specimens. Aetana kinabalu group. - 99-103. A. kinabalu Huber, 2005. $\widehat{o}$ and $ᄋ$ with eggsac from Gunung Mulu, Sarawak $(99,100)$; $q$ with eggsac and $\widehat{\partial}$ from Crocker Range, Sabah $(101,102)$; and $\widehat{\partial}$ from Mt. Kinabalu, Sabah (103). - 104. A. gaya Huber, sp. nov., $\widehat{o}$ from Gaya Island, Sabah. 
HUBER B.A. et al., Revision of Aetana spiders

internal arc and internal sclerotized pockets visible through cuticle (Figs 111, 163-164). Internal genitalia as in Figs 112 and 165, with pair of sclerotized pockets and more lateral pair of membranous pockets.

\section{Variation}

In males from Gunung Mulu, the tiny cone-shaped process on the genital bulb ( $c f$. Huber 2005a: figs 121 and 122) is absent. Males from Bario with small additional process at basis of prolatero-ventral apophysis of femur.

\section{Natural history}

Webs were in most cases made of two sheets: an upper sheet in which the spider hung, and a lower sheet that had to be removed in order to catch the spider. At most localities, webs were found high among the
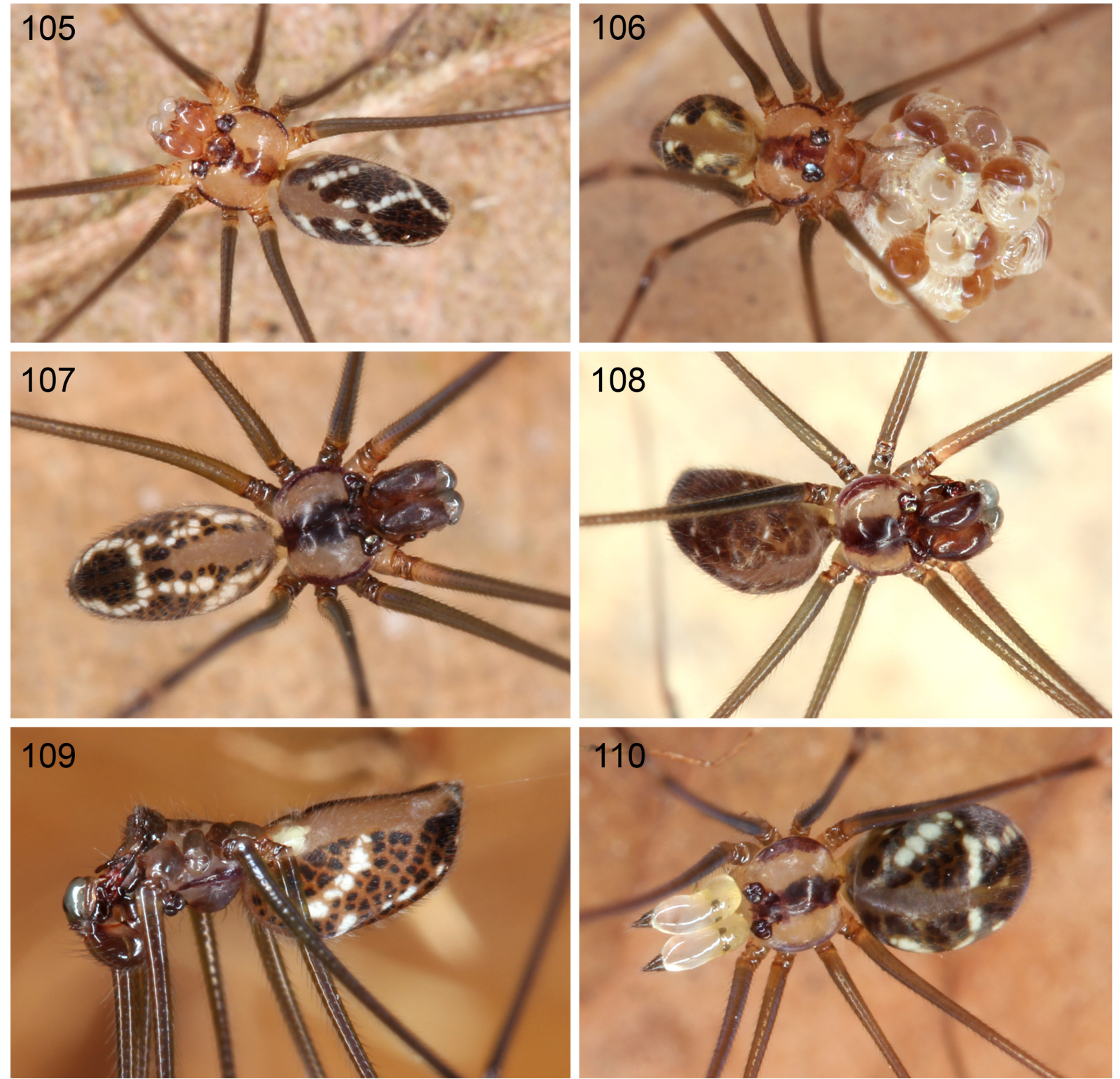

Figs 105-110. Live specimens. Aetana kinabalu group. - 105-106. A. lambir Huber, sp. nov., $\widehat{O}$ and $Q$ with eggsac from Lambir, Sarawak. - 107-108. A. poring Huber, sp. nov., ô 0 from Mt. Kinabalu, Sabah. - 109- 110. A. indah Huber, sp. nov., adult and penultimate instar, ôे $\hat{\jmath}$ from Crocker Range, Sabah. 
vegetation, even in the sunlight. At Gunung Mulu, webs were found among mosses and low vegetation on perpendicular rock surfaces about $2 \mathrm{~m}$ above the ground. At several localities, A. kinabalu was sympatric with a ground-dwelling congener: with $A$. poring Huber, sp. nov. at Mt. Kinabalu and Poring; with $A$. indah Huber, sp. nov. at Crocker Range.

\section{Distribution}

Widely distributed in Sabah and eastern Sarawak (Fig. 5).

Aetana lambir Huber, sp. nov. urn:1sid:zoobank.org:act:EFFAC871-4657-461F-9875-807E767DB6B8

Figs 105-106, 113-125, 166-168

\section{Diagnosis}

Distinguished from closest known relative (A. kinabalu) by shape of prolatero-ventral apophysis of male palpal femur (Fig. 113; pointed tip much longer than subdistal branch); also by details of procursus (shapes of sclerites on complex distal part), by absence of prolateral apophysis on femur, and by female genitalia (no internal sclerotized pockets; pore plates wider apart; Figs 116-117).

\section{Etymology}

Named for the type locality; noun in apposition.

\section{Material examined}

Holotype

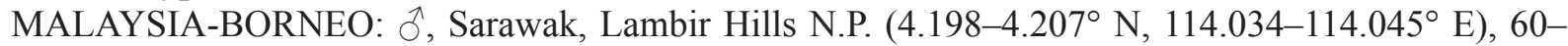
$150 \mathrm{~m}$ a.s.l., in domed webs among low vegetation, 22 July 2014 (B.A. Huber, S.B. Huber), ZFMK (Ar 13967).

\section{Other material}

MALAYSIA-BORNEO, Sarawak: $9 \hat{\partial} \widehat{\partial}, 11$ 우, same data as holotype, ZFMK (8 $\hat{\partial} \hat{\partial}, 10$ 우; Ar

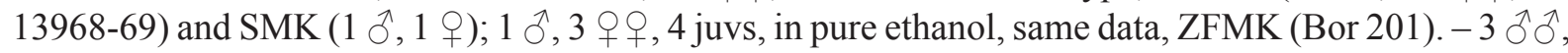
4 우, Niah Cave N.P., forest near headquarters $\left(3.820^{\circ} \mathrm{N}, 113.763^{\circ} \mathrm{E}\right), 40 \mathrm{~m}$ a.s.l., night collecting, domed webs among vegetation, 28 July 2014 (B.A. Huber, S.B. Huber), ZFMK (Ar 13970). $-6 \widehat{\partial} \widehat{\partial}, 3$ 우, Niah Cave N.P., forest near cave $\left(3.814^{\circ} \mathrm{N}, 113.771^{\circ} \mathrm{E}\right), 40 \mathrm{~m}$ a.s.l., among low vegetation, $28 \mathrm{July}$
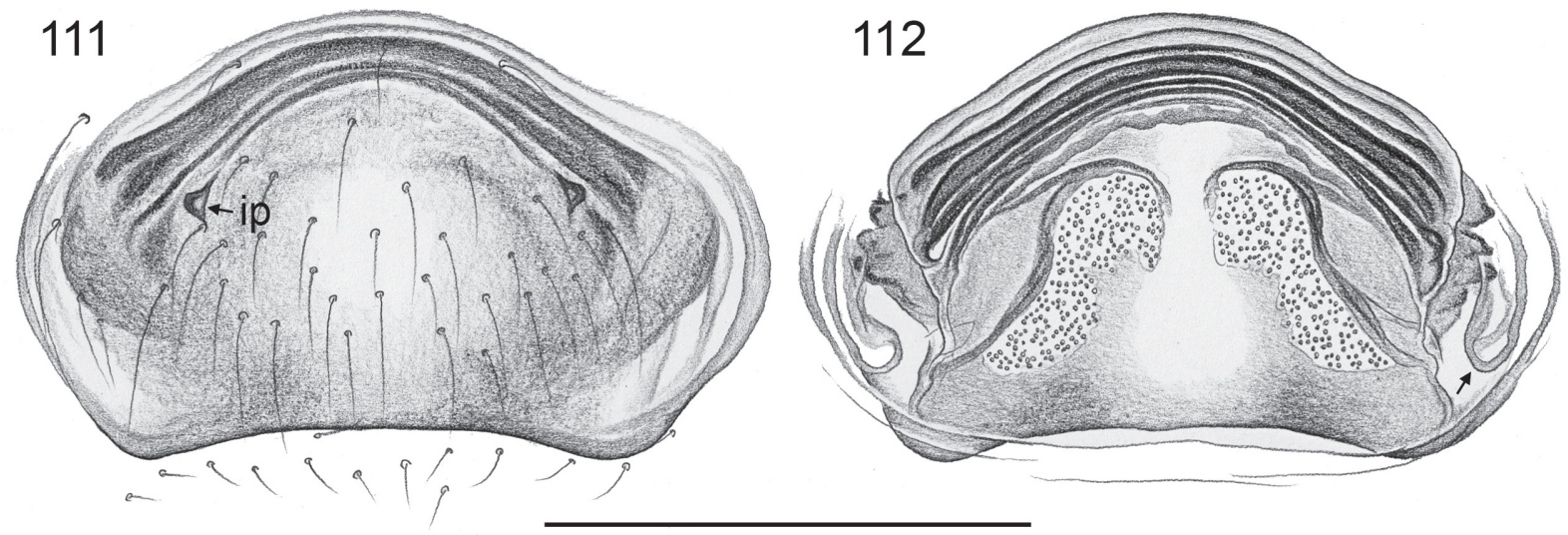

Figs 111-112. Aetana kinabalu Huber, 2005. Cleared female genitalia, ventral and dorsal views (arrow in Fig. 112 points at membranous pocket). ip = internal sclerotized pocket. Scale line: $0.5 \mathrm{~mm}$. 


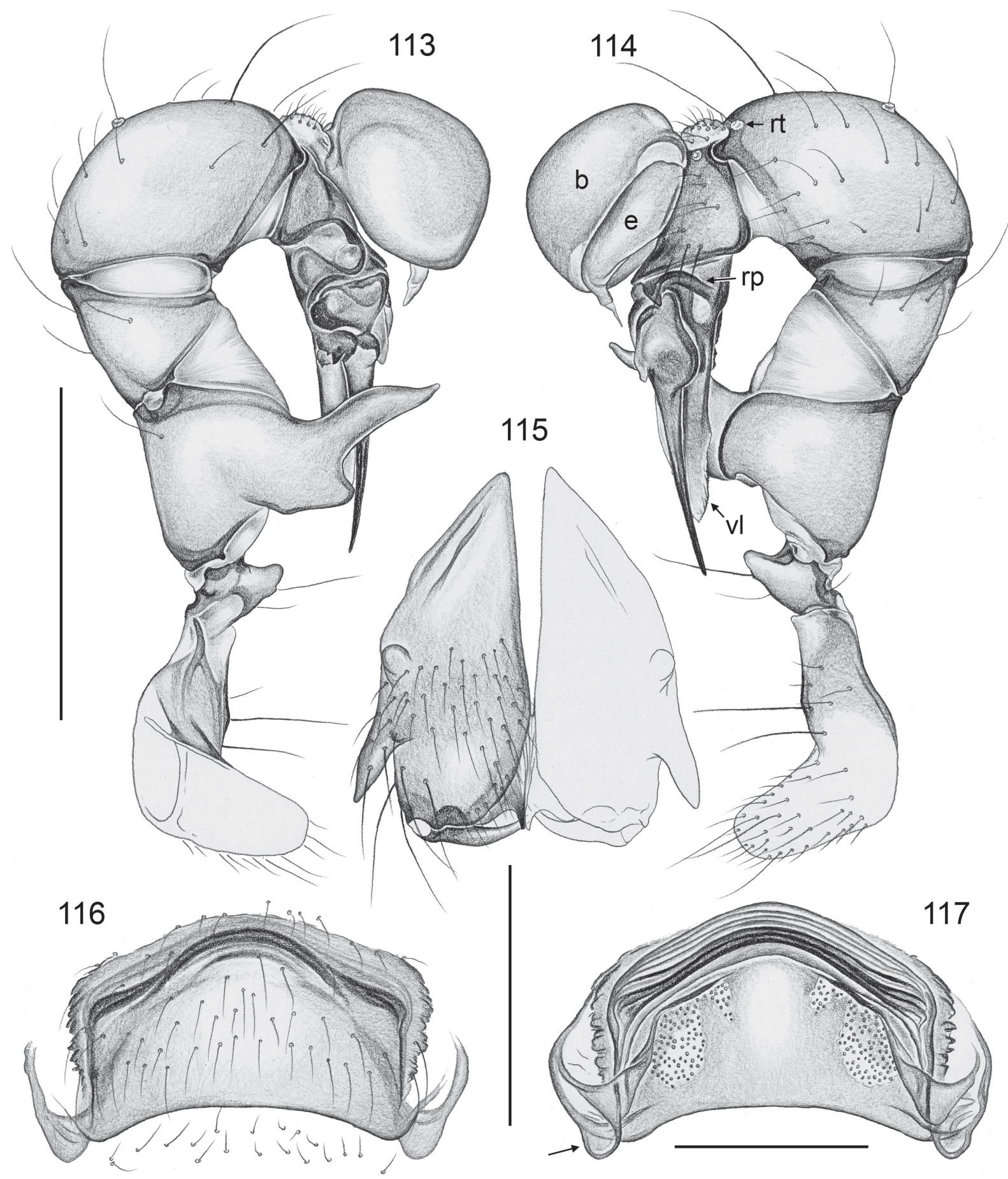

Figs 113-117. Aetana lambir Huber, sp. nov. 113-114. Left male palp, prolateral and retrolateral views. 115. Male chelicerae, frontal view. 116-117. Cleared female genitalia, ventral and dorsal views (arrow points at membranous pocket). $\mathrm{b}=$ genital bulb; $\mathrm{e}=$ embolus; $\mathrm{rp}=$ retrolatero-ventral process; $\mathrm{rt}=$ retrolateral trichobothrium; $\mathrm{vl}=$ ventral lamina. Scale lines: $113-114=0.5 \mathrm{~mm} ; 115-117=0.3 \mathrm{~mm}$. 

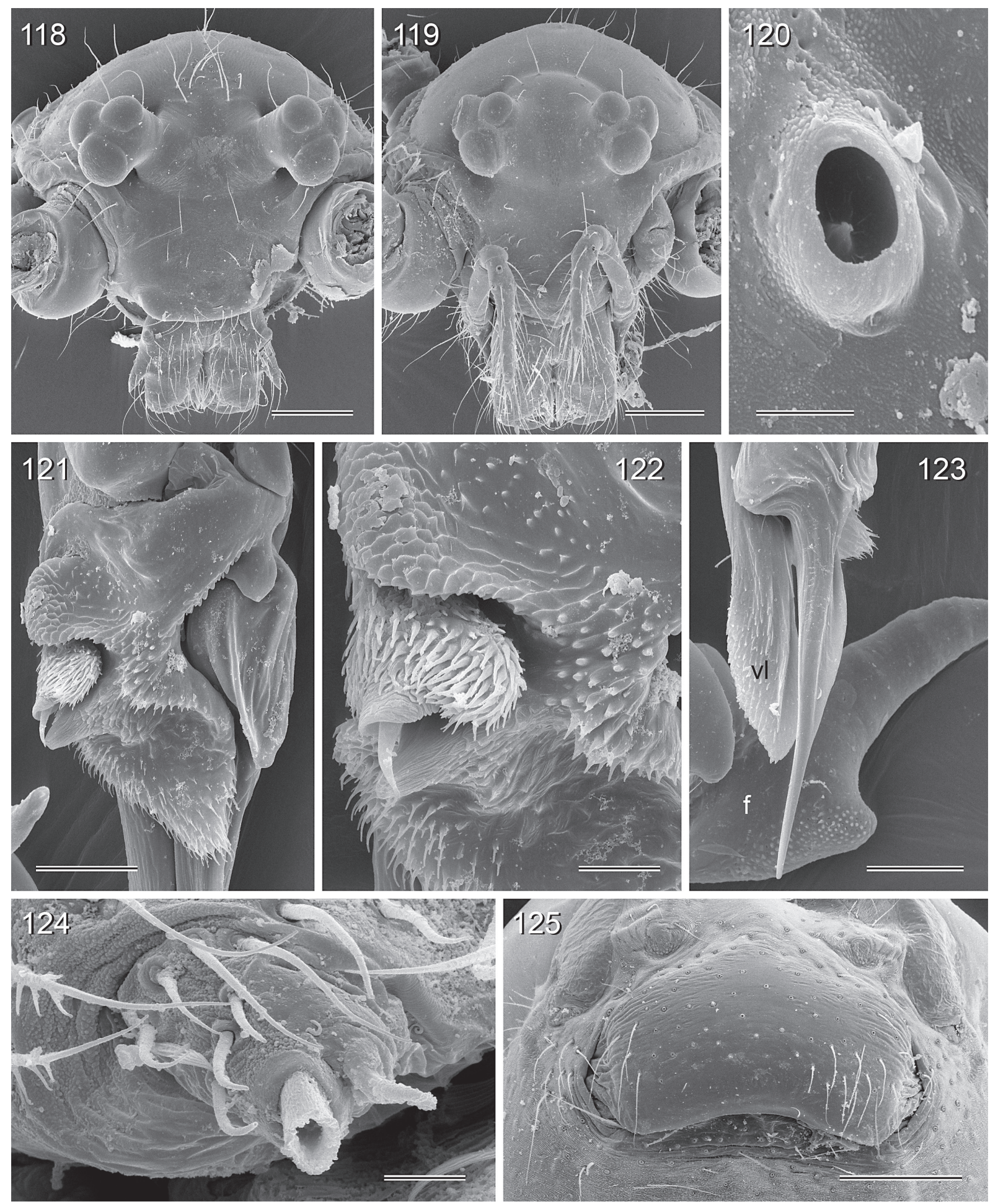

Figs 118-125. Aetana lambir Huber, sp. nov. 118-119. Male and female prosomata, frontal views. 120. Male palpal tarsal organ. 121. Left procursus, prolateral view. 122. Detail of preceding. 123. Right procursus (and femur apophysis), retrolateral view. 124. Female ALS. 125. Epigynum. $f=$ femur; $v l=$ ventral lamina. Scale lines: $118-119,125=200 \mu \mathrm{m} ; 120=8 \mu \mathrm{m} ; 121=50 \mu \mathrm{m} ; 122=20 \mu \mathrm{m} ; 123=$ $60 \mu \mathrm{m} ; 124=10 \mu \mathrm{m}$. 
2014 (B.A. Huber), ZFMK (Ar 13971). $-3 \hat{\partial} \widehat{\partial}, 11$ 우, 1 juv., Niah Cave N.P., forest along main trail (3.814-3.82 $\left.1^{\circ} \mathrm{N}, 113.763-113.771^{\circ} \mathrm{E}\right), 20-40 \mathrm{~m}$ a.s.l., domed webs among vegetation, 27 July 2014 (B.A. Huber, S.B. Huber), ZFMK (Ar 13972-73); $1 \hat{\jmath}, 1$ \&, 1 juv., same data, in pure ethanol, ZFMK (Bor 178).

\section{Description}

Male (holotype)

MEASUREMENTS. Total body length 2.5, carapace width 0.95 . Leg 1: $33.1(7.9+0.4+7.6+14.3+2.9)$, tibia 2: 4.4, tibia 3: 2.8, tibia 4: 4.2; tibia $1 \mathrm{~L} / \mathrm{d}$ : 87. Distance PME-PME $340 \mu \mathrm{m}$, diameter PME 105 $\mu \mathrm{m}$, distance PME-ALE $25 \mu \mathrm{m}$; AME absent.

COLOR. Carapace pale ochre with black lateral margins and brown median band including ocular area. Clypeus mostly pale ochre, at rim brown. Sternum pale ochre, laterally slightly darker. Legs ochre to light brown, slightly darker rings on femora (subdistally) and tibiae (proximally and subdistally); tips of femora and tibiae whitish. Abdomen with dorsal and lateral pattern of black and white marks; ventrally with brown mark near spinnerets.

BoDy. Habitus as in Fig. 105; ocular area slightly raised, each triad on short stalk directed toward lateral; carapace without thoracic furrow; clypeus slightly more protruding than usual; sternum wider than long (0.60/0.45), unmodified.

Chelicerae. As in Fig. 115, with pair of proximal lateral apophyses and pair of simple distal apophyses in very lateral position; without modified hairs; without stridulatory ridges.

PALPS. As in Figs 113-114, coxa unmodified; trochanter with short, rounded ventral apophysis; femur with distinct retrolatero-ventral apophysis, long prolatero-ventral apophysis with side branch, no prolateral process. Procursus complex, ventral transparent lamina proximally wide and slightly sclerotized; retrolatero-ventral process indistinct, apparently fused to procursus. Bulb simple, with short and wide embolus.

LEGS. Without spines, with curved hairs on metatarsi 2 only (single dorsal row; proximal half), with few vertical hairs; retrolateral trichobothrium on tibia 1 at $2.5 \%$; prolateral trichobothrium absent on tibia 1 , present on other tibiae. Tarsus 1 with $>20$ pseudosegments, only distally fairly distinct.

Male (variation)

Tibia 1 in 19 other males: 6.1-8.5 (mean 7.4); most males with small dark mark at gonopore.

\section{Female}

In general similar to male; eye triads closer together (distance PME-PME $220 \mu \mathrm{m}$ ), not on stalks; clypeus less protruding; no curved hairs on metatarsi. Tibia 1 in 26 females: 5.6-6.6 (mean 6.2). Epigynum very simple plate, wider than long (Fig. 125), anterior internal arc visible through cuticle (Figs 116, 166). Internal genitalia very simple, as in Figs 117 and 168, without internal sclerotized pockets, with pair of lateral membranous pockets. ALS as in Fig. 124.

\section{Natural history}

At the type locality (Lambir), the spiders were found among vegetation close to the ground, while at Niah they occurred higher among the vegetation, very similar to A. kinabalu, in the same type of twolayered web (see above). 


\section{Distribution}

Known from two localities in eastern Sarawak (Fig. 5).

Aetana gaya Huber, sp. nov.

urn:lsid:zoobank.org:act:3FF192B2-3F88-4BBF-A675-CA77FF9A72F1

Figs 104, 126-144, 169-171

\section{Diagnosis}

Distinguished from closest known relatives (A. kinabalu, A. lambir Huber, sp. nov., A. indah Huber, sp. nov., A. poring Huber, sp. nov.) by shape of prolatero-ventral apophysis of male palpal femur (Fig. 126; single pointed process without side branch); also by apophysis on male palpal trochanter (longer and more sclerotized than in A. kinabalu and A. lambir Huber, sp. nov.; shorter than in A. indah Huber, sp. nov. and $A$. poring Huber, sp. nov.), by shapes of sclerites on procursus (Figs 126-127), and by female genitalia (Figs 128-129, 169-171; short and wide epigynum with straight posterior margin; distinctive internal structures).

\section{Etymology}

Named for the type locality; noun in apposition.

\section{Material examined}

\section{Holotype}

MALAYSIA-BORNEO: $\delta^{\lambda}$, Sabah, Gaya Island, forest along small stream $\left(6.014-6.018^{\circ} \mathrm{N}\right.$, $\left.116.020^{\circ} \mathrm{E}\right), 30-80 \mathrm{~m}$ a.s.l., among rocks and tree buttresses, 4 Aug. 2014 (B.A. Huber, S.B. Huber), ZFMK (Ar 13974).

\section{Other material}

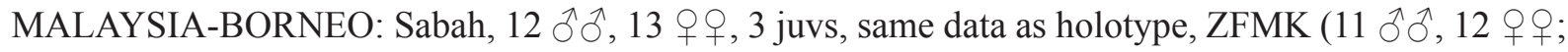
Ar 13975-76) and SMK (1 ㅅ, 1 q); same data, 7 우, 2 juvs, in pure ethanol, ZFMK (Bor 165).

\section{Description}

Male (holotype)

Measurements. Total body length 2.5, carapace width 0.9. Leg 1: $32.6(7.6+0.4+7.6+14.2+2.8)$, tibia 2: 4.4, tibia 3: 2.8, tibia 4: 4.2; tibia $1 \mathrm{~L} / \mathrm{d}$ : 96. Distance PME-PME $370 \mu \mathrm{m}$, diameter PME 105 $\mu \mathrm{m}$, distance PME-ALE $25 \mu \mathrm{m}$; AME absent.

COLOR. Carapace pale ochre with black lateral bands and wide brown median band including ocular area. Clypeus pale ochre with pair of brown marks at rim. Sternum medially ochre, laterally slightly darker. Legs ochre to light brown, indistinct darker rings on femora (subdistally) and tibiae (proximally and subdistally); tips of femora and tibiae whitish. Abdomen grey with dorsal and lateral pattern of black and white marks; ventrally with small brown marks near spinnerets and in genital area.

BoDy. Habitus as in Fig. 104; ocular area slightly raised, each triad on short stalk directed toward lateral (Figs 130-131); carapace without thoracic furrow (Fig. 135; only dark line in anterior part); clypeus slightly more protruding than usual; sternum wider than long $(0.75 / 0.55)$, unmodified. Gonopore with four epiandrous spigots (Fig. 143). Spinnerets as in Figs 141-142.

Chelicerae. As in A. lambir Huber, sp. nov. (cf. Fig. 115), with pair of proximal lateral apophyses and pair of simple distal apophyses in very lateral position; without modified hairs; without stridulatory ridges. 
HUBER B.A. et al., Revision of Aetana spiders

PALPS. As in Figs 126-127, coxa unmodified; trochanter with short ventral apophysis with small teeth prolaterally and small prolateral branch; femur with rounded retrolatero-ventral apophysis, long pointed prolatero-ventral apophysis without side branch, with small ventral process. Tarsal organ capsulate (Fig. 134). Procursus complex (Figs 137-140); retrolatero-ventral process with simple tip (Fig. 136). Bulb simple, with short and wide embolus.
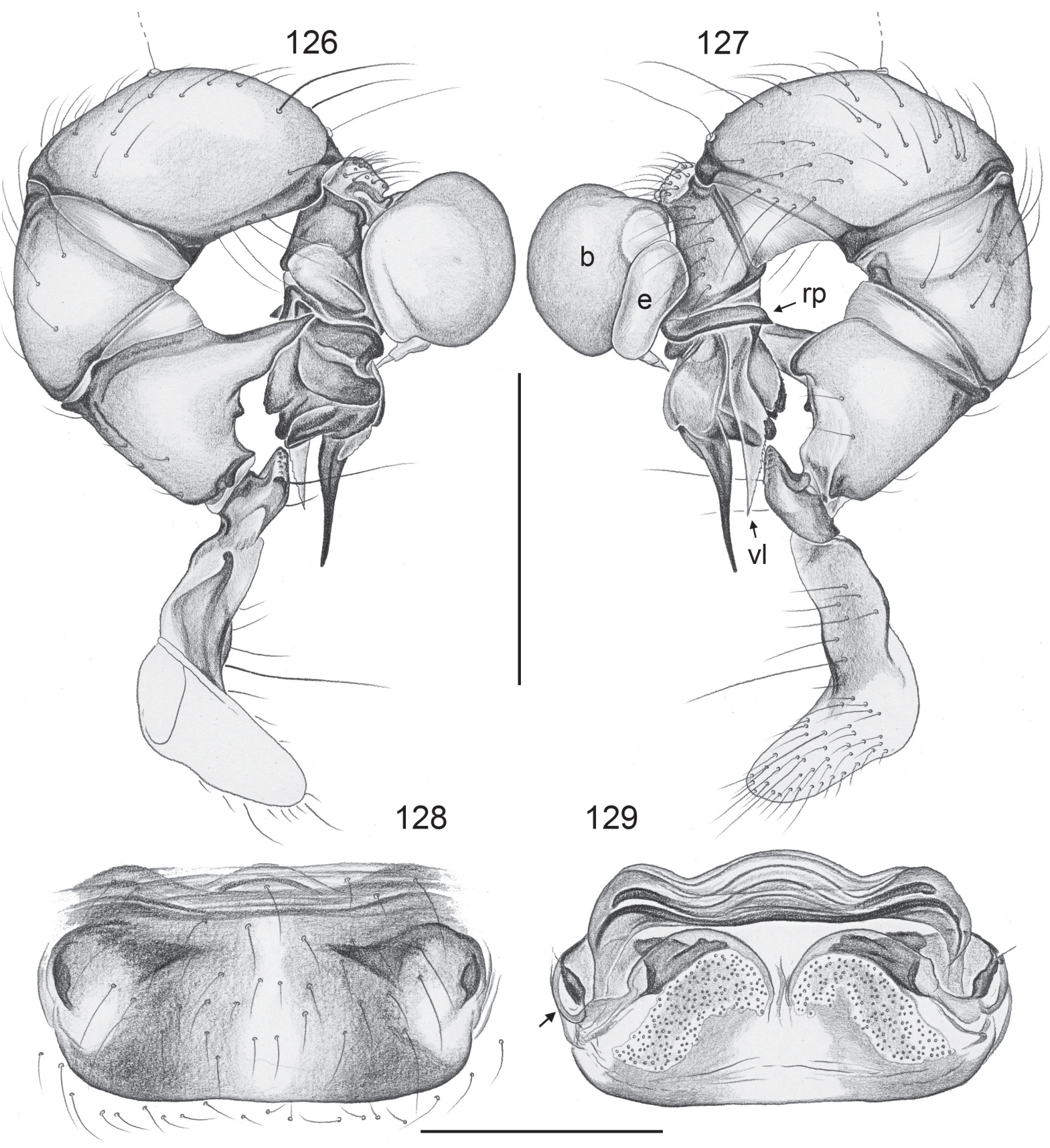

Figs 126-129. Aetana gaya Huber, sp. nov. 126-127. Left male palp, prolateral and retrolateral views. 128-129. Cleared female genitalia, ventral and dorsal views (arrow points at membranous pocket). $b=$ genital bulb; e = embolus; $r p=$ retrolatero-ventral process; $v l=$ ventral lamina. Scale lines: 126-127 = $0.5 \mathrm{~mm} ; 128-129=0.3 \mathrm{~mm}$. 


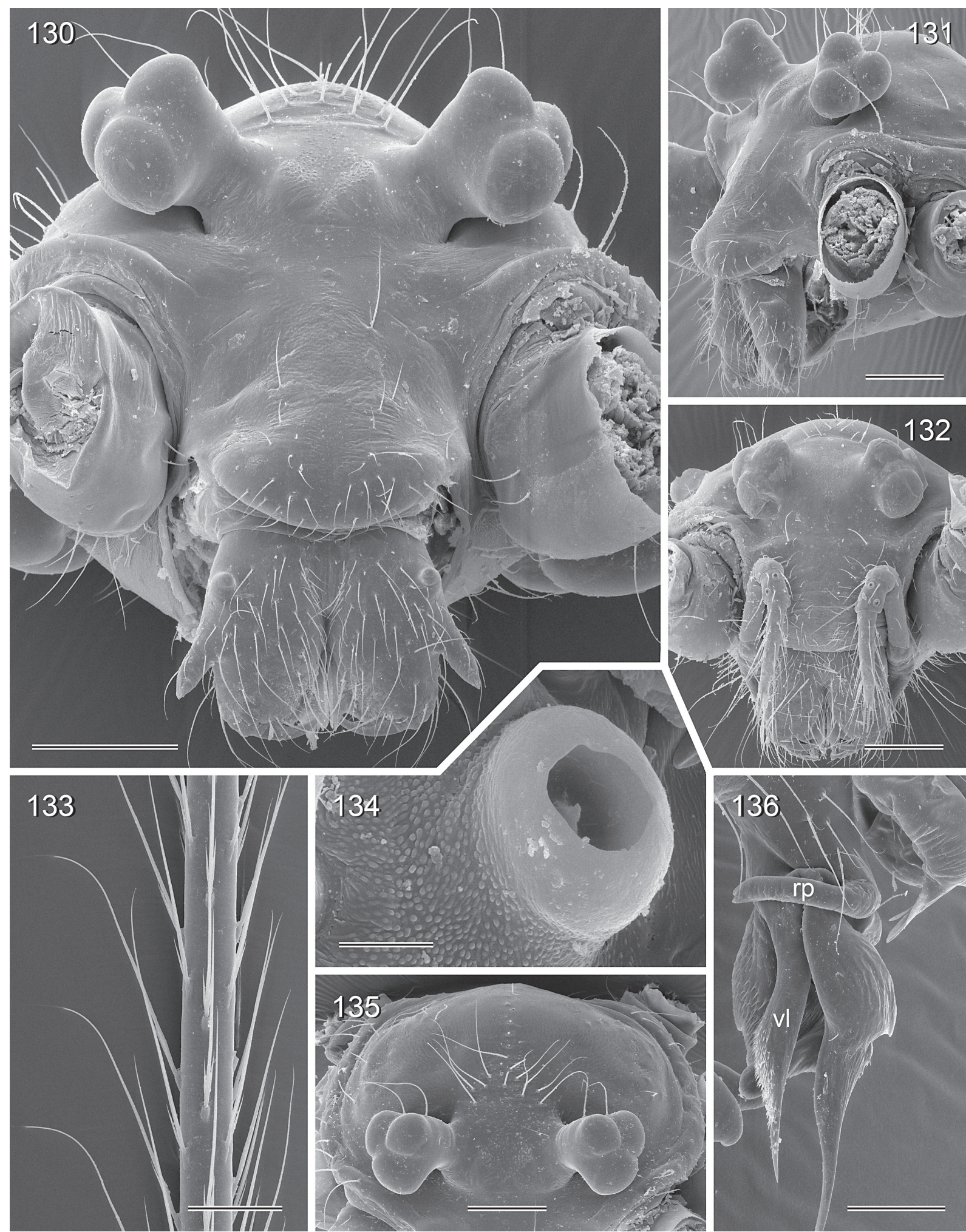

Figs 130-136. Aetana gaya Huber, sp. nov. 130-131. Male prosoma, frontal and oblique frontal views. 132. Female prosoma, frontal view. 133. Detail of male metatarsus 1. 134. Male palpal tarsal organ. 135. Male carapace and ocular area. 136. Right procursus, retrolateral view. $\mathrm{rp}=$ retrolatero-ventral process; $\mathrm{vl}=$ ventral lamina. Scale lines: $130-132,135=200 \mu \mathrm{m} ; 133=80 \mu \mathrm{m} ; 134=8 \mu \mathrm{m} ; 136=100 \mu \mathrm{m}$. 
HUBER B.A. et al., Revision of Aetana spiders
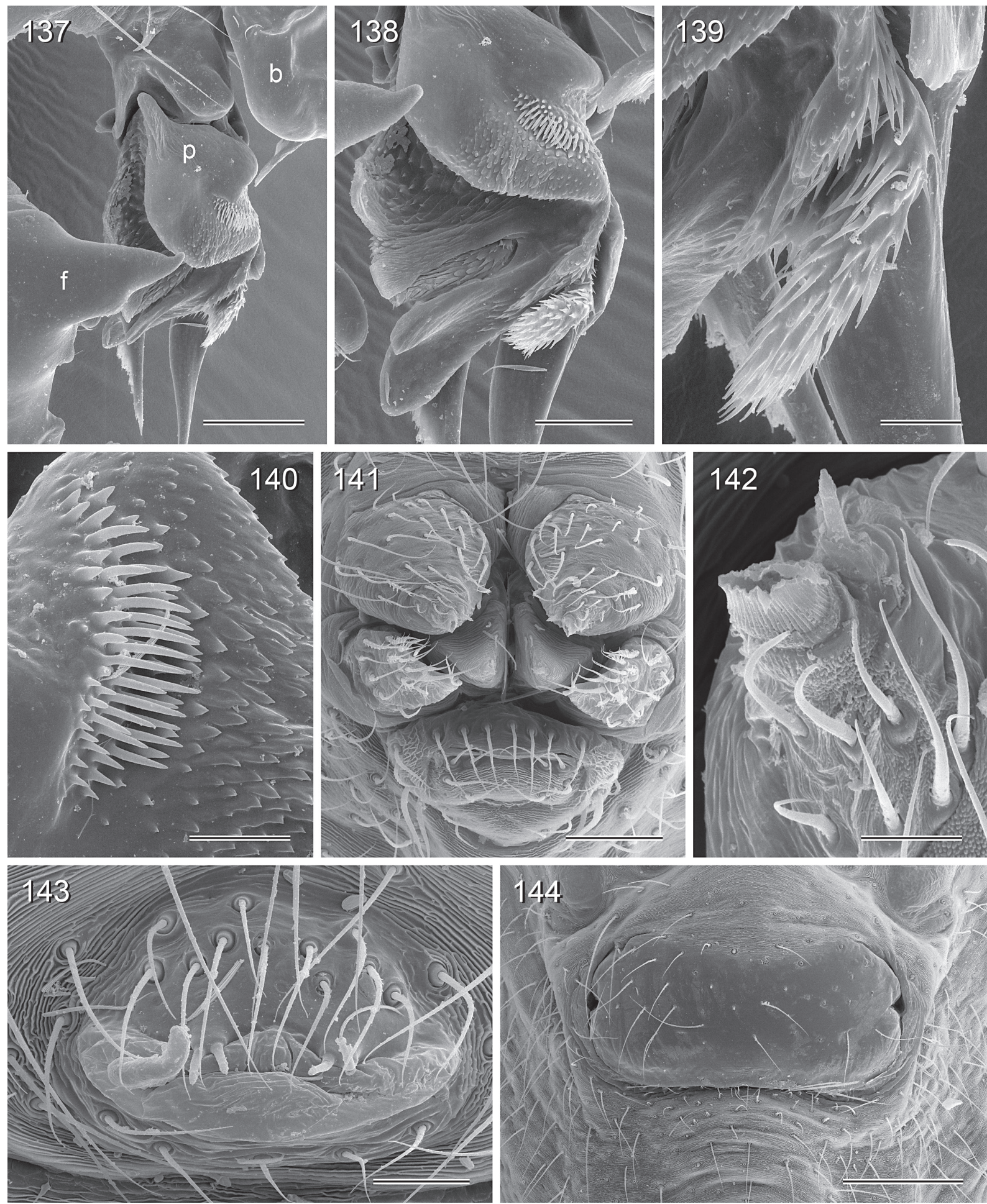

Figs 137-144. Aetana gaya Huber, sp. nov. 137. Left procursus, prolateral view. 138-140. Details of preceding. 141. Male spinnerets. 142. Male ALS. 143. Male gonopore. 144. Epigynum. $b=$ genital bulb; $\mathrm{f}=$ femur; $\mathrm{p}=$ procursus. Scale lines: $137=100 \mu \mathrm{m} ; 138,141=60 \mu \mathrm{m} ; 139-140=20 \mu \mathrm{m} ; 142=10 \mu \mathrm{m}$; $143=30 \mu \mathrm{m} ; 144=200 \mu \mathrm{m}$. 
LEgs. Without spines, with curved hairs dorsally on metatarsi 1 and 2 only (mostly on proximal half), with few vertical hairs; retrolateral trichobothrium on tibia 1 at $2.5 \%$; prolateral trichobothrium absent on tibia 1 , present on other tibiae. Tarsus 1 with $\sim 30$ pseudosegments, distally fairly distinct.

Male (variation)

Tibia 1 in 10 other males: 7.2-8.1 (mean 7.6).

Female

In general similar to male; eye triads closer together (distance PME-PME $185 \mu \mathrm{m}$ ), not on stalks (Fig. 132); clypeus less protruding; no curved hairs on metatarsi. Tibia 1 in 11 females: 4.9-5.8 (mean 5.3). Epigynum short and wide plate (Fig. 144), slightly protruding, with pair of distinctive curved darker marks (Figs 128, 169). Internal genitalia as in Figs 129 and 171, with sclerotized structures but apparently without sclerotized pockets, with pair of lateral membranous pockets.

\section{Natural history}

Most specimens were found close to the ground among logs, but some (mostly juveniles) built their webs in less protected places higher on trees.

\section{Distribution}

Known from Gaya Island only (Fig. 5).

Aetana poring Huber, sp. nov. urn:1sid:zoobank.org:act:2D2D173E-9AFC-4CDF-877F-40C44043E1C5

Figs 107-108, 145-149, 172-174

\section{Diagnosis}

Distinguished from closest known relative ( $A$. indah Huber, sp. nov.) by shape of prolatero-ventral apophysis of male palpal femur (Fig. 145; pointed tip much shorter), by distal cheliceral apophyses (Fig. 147; more pointed and gradually narrowing), and by female genitalia (Figs 148, 172; pair of dark lines; posterior rim curved toward posterior); from all other relatives also by strong apophysis prolateroproximally on male palpal femur (Fig. 145; present but smaller in $A$. indah Huber, sp. nov.).

\section{Etymology}

Named for the type locality; noun in apposition.

\section{Material examined}

Holotype

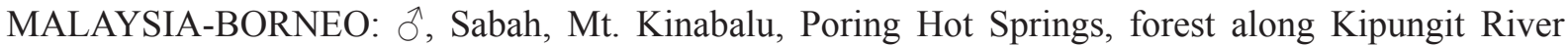
$\left(6.049^{\circ} \mathrm{N}, 116.712^{\circ} \mathrm{E}\right), 450 \mathrm{~m}$ a.s.l., near ground, 7 Aug. 2014 (B.A. Huber), ZFMK (Ar 13977).

\section{Other material}

MALAYSIA-BORNEO, Sabah: $2 \widehat{\partial} \widehat{\jmath}, 4$ + $q$, same data as holotype, ZFMK (Ar 13978-79); 1 , 2 juvs, in pure ethanol, same data, ZFMK (Bor 206). -4 + 9 , Mt. Kinabalu, forest along Silau Silau Trail $\left(6.010-6.017^{\circ} \mathrm{N}, 116.537-116.543^{\circ} \mathrm{E}\right), 1550-1650 \mathrm{~m}$ a.s.l., near ground, 6 Aug. 2014 (B.A. Huber, S.B. Huber), ZFMK (Ar 13980); 2 juvs, in pure ethanol, in ZFMK (Bor 210), same data. -2 ô $\widehat{o}^{2} 1$ +, Mt. Kinabalu, forest above Kinabalu Mountain Lodge (6.012-6.014 $\left.{ }^{\circ} \mathrm{N}, 116.534^{\circ} \mathrm{E}\right), 1570-1650$ m a.s.l., near ground, 5 Aug. 2014 (B.A. Huber, S.B. Huber), ZFMK (Ar 13981); 1 +, 1 juv., in pure ethanol, same data, ZFMK (Bor 215). - 5 우, 2 juvs, Kinabalu N.P., 1550 m a.s.l., 3 June 1979 and 26 July 1980 (C.L. \& P.R Deeleman), RMNH (2 vials). 
HUBER B.A. et al., Revision of Aetana spiders

\section{Description}

Male (holotype)

Measurements. Total body length 2.6, carapace width 1.1. Leg 1: $26.9(6.4+0.4+6.4+11.2+2.5)$, tibia 2: 3.8, tibia 3: 2.7, tibia 4: 4.0; tibia $1 \mathrm{~L} / \mathrm{d}$ : 63. Distance PME-PME $455 \mu \mathrm{m}$, diameter PME 105 $\mu \mathrm{m}$, distance PME-ALE $35 \mu \mathrm{m}$; AME absent.

COLOR. Carapace pale ochre with black lateral bands and wide brown median band including ocular area. Clypeus pale ochre with pair of brown marks at rim. Sternum medially ochre, laterally slightly darker. Legs ochre to light brown, indistinct darker rings on femora (subdistally) and tibiae (proximally and

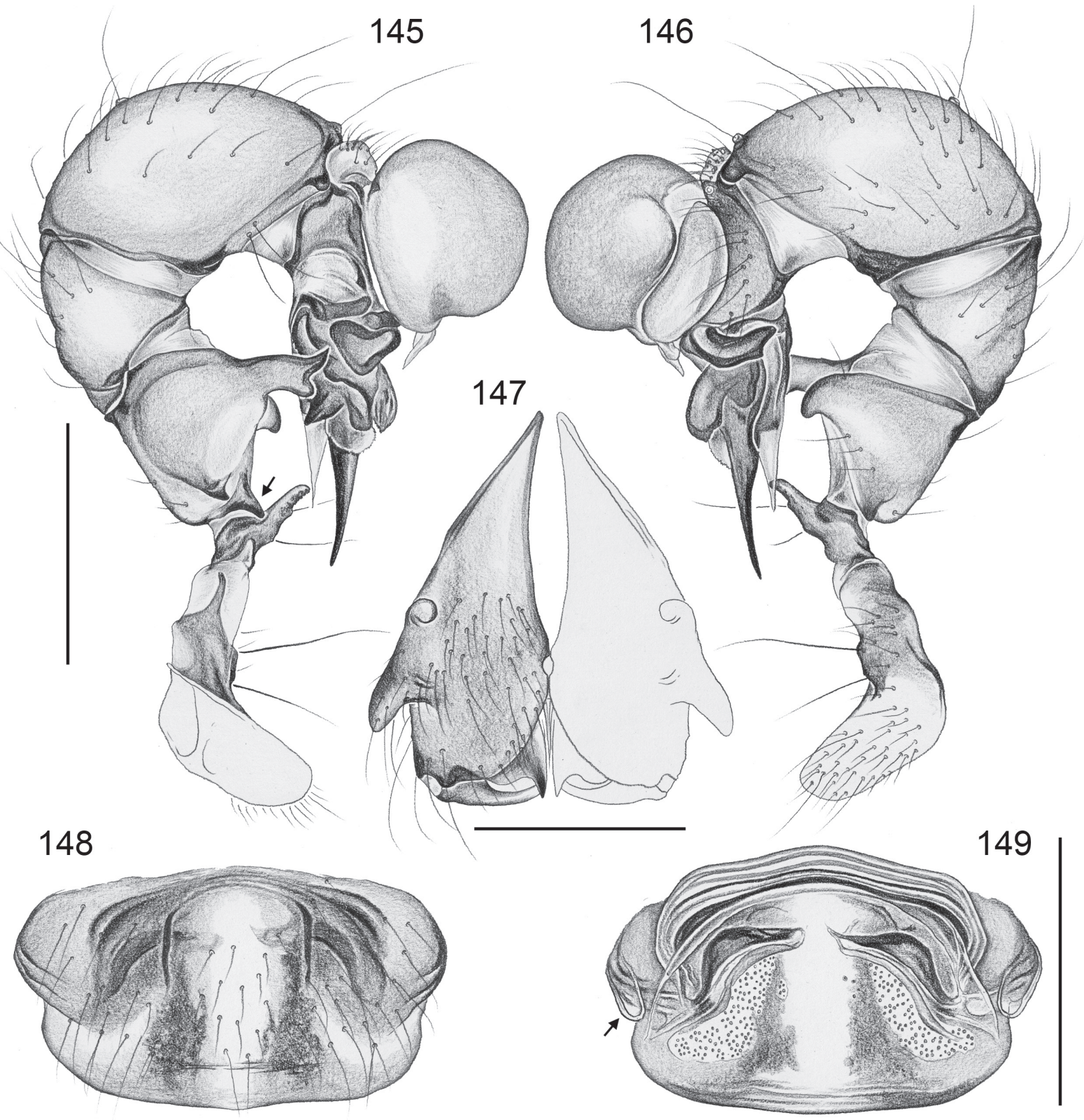

Figs 145-149. Aetana poring Huber, sp. nov. 145-146. Left male palp, prolateral and retrolateral views (arrow points at prolateral apophysis near hinge). 147. Male chelicerae, frontal view. 148-149. Cleared female genitalia, ventral and dorsal views (arrow points at membranous pocket). Scale lines: 145-146, $148-149=0.5 \mathrm{~mm} ; 147=0.3 \mathrm{~mm}$. 
subdistally); tips of femora and tibiae whitish. Abdomen grey with dorsal and lateral pattern of black and indistinct white marks; ventrally with small brown mark near spinnerets and in genital area.

BoDy. Habitus as in Figs 107-108; ocular area slightly raised, each triad on short stalk directed toward lateral; carapace without thoracic furrow (only dark line in anterior part); clypeus slightly more protruding than usual; sternum wider than long $(0.75 / 0.55)$, unmodified.

Chelicerae. As in Fig. 147, with pair of proximal lateral apophyses and pair of simple distal apophyses in very lateral position; without modified hairs; without stridulatory ridges.

PALPS. As in Figs 145-146; coxa unmodified; trochanter with slender ventral apophysis with very small teeth prolaterally; femur with rounded retrolatero-ventral apophysis, long prolatero-ventral apophysis with side branch, with two prolateral processes, one of them very close to trochanter. Procursus complex; retrolatero-ventral process with bifid tip. Bulb simple, with short and wide embolus.

LEGS. Without spines, with curved hairs dorsally on metatarsi 1 and 2 only (mostly on proximal half), with few vertical hairs; retrolateral trichobothrium on tibia 1 at $3.5 \%$; prolateral trichobothrium absent on tibia 1, present on other tibiae. Tarsus 1 with $\sim 30$ pseudosegments, distally fairly distinct.

Male (variation)

Tibia 1 in 4 other males: 6.1, 6.9, 7.1, 7.5; most males with distinct white marks on abdomen.

Female

In general similar to male; triads closer together (distance PME-PME $200 \mu \mathrm{m}$ ), not on stalks; clypeus less protruding; no curved hairs on metatarsi; abdomen with continuous ventral dark band between epigynum and spinnerets. Tibia 1 in 12 females: 4.2-5.8 (mean 5.1). Epigynum large brown plate (Figs 148,172 ), slightly protruding, with distinctive lighter median area bordered by dark lines (parallel or converging anteriorly), with internal sclerites visible through cuticle. Internal genitalia as in Figs 149 and 174, apparently without sclerotized pockets, with pair of lateral membranous pockets.

\section{Natural history}

The spiders were found close to the ground in small holes and cavities. They barely reacted to disturbance and were very easy to take from their webs. They share the locality with A. kinabalu, which lives higher among the vegetation.

\section{Distribution}

Known from two localities in Mt. Kinabalu area only (Fig. 5).

Aetana indah Huber, sp. nov. urn:1sid:zoobank.org:act:12E0B867-3A77-4B63-92FF-97DB7302137C

Figs 109-110, 150-162, 175-177

\section{Diagnosis}

Distinguished from closest known relative (A. poring Huber, sp. nov.) by shape of prolatero-ventral apophysis of male palpal femur (Fig. 150; pointed tip much longer), by distal cheliceral apophyses (Fig. 152; wide and distally rounded), and by female genitalia (Figs 153, 175; without pair of dark lines; posterior rim curved toward anterior); from all other congeners also by long apophysis on male palpal trochanter (in A. poring Huber, sp. nov. present but more slender and shorter). 


\section{Etymology}

The species name is the Malay word for 'beautiful'; used here as noun in apposition.

\section{Material examined}

\section{Holotype}

MALAYSIA-BORNEO: $\widehat{\delta}$, Sabah, Crocker Range between Kota Kinabalu and Tambuan, S-slope, forest along river $\left(5.783^{\circ} \mathrm{N}, 116.338-116.340^{\circ} \mathrm{E}\right), 1430-1480 \mathrm{~m}$ a.s.1., near ground, 3 Aug. 2014 (B.A. Huber, S.B. Huber), ZFMK (Ar 13982).

\section{Other material}

MALAYSIA-BORNEO, Sabah: 3 $\widehat{\partial}, 5$ + +, 3 juvs, same data as holotype, ZFMK (Ar 13983-84); 1 , 2 juvs, in pure ethanol, same data, ZFMK (Bor 170). - 1 ㄱ, 3 우 $ᄋ$, Crocker Range between Kota Kinabalu and Tambuan, N-slope, forest along river $\left(5.834^{\circ} \mathrm{N}, 116.336^{\circ} \mathrm{E}\right), 1600 \mathrm{~m}$ a.s.l., near ground, 3 Aug. 2014 (B.A. Huber, S.B. Huber), ZFMK (Ar 13985); 2 우, in pure ethanol, same data, ZFMK (Bor 168).

\section{Description}

Male (holotype)

Measurements. Total body length 2.8 , carapace width 1.2. Leg 1: $36.8(8.8+0.4+8.8+15.3+3.5)$, tibia 2: 5.2, tibia 3: 3.5, tibia 4: 5.3; tibia $1 \mathrm{~L} / \mathrm{d}$ : 84. Distance PME-PME $500 \mu \mathrm{m}$, diameter PME 115 $\mu \mathrm{m}$, distance PME-ALE $35 \mu \mathrm{m}$; AME absent.

COLOR. Carapace pale ochre with black lateral bands and wide brown median band including ocular area. Clypeus pale ochre with indistinct pair of brown marks at rim. Sternum medially ochre, laterally slightly darker. Legs ochre to light brown, indistinct darker rings on femora (subdistally) and tibiae (proximally and subdistally); tips of femora and tibiae whitish. Abdomen grey with dorsal and lateral pattern of black and indistinct white marks; ventrally with small brown mark near spinnerets and in genital area.

BoDy. Habitus as in Fig. 109; ocular area slightly raised, each triad on short stalk directed toward lateral; carapace without thoracic furrow (only dark line in anterior part); clypeus slightly more protruding than usual; sternum wider than long $(0.65 / 0.50)$, unmodified.

Chelicerae. As in Figs 152 and 161, with pair of proximal lateral apophyses and distinctive pair of wide distal apophyses in very lateral position, with additional pair of small processes on frontal side of distal apophyses (Fig. 160); without modified hairs; without stridulatory ridges.

Palps. As in Figs 150-151, coxa unmodified; trochanter with long ventral apophysis with small teeth prolaterally (Fig. 158); femur with rounded retrolatero-ventral apophysis, very long prolatero-ventral apophysis with two side branches, with small prolateral apophysis proximally close to trochanter. Procursus complex (Figs 155-158); retrolatero-ventral process with bifid tip. Bulb simple, with short and wide embolus (Fig. 159), weakly sclerotized.

Legs. Without spines, with curved hairs dorsally on metatarsi 1 and 2 only (mostly on proximal half), with few vertical hairs; retrolateral trichobothrium on tibia 1 at $2.5 \%$; prolateral trichobothrium absent on tibia 1 , present on other tibiae. Tarsus 1 with $\sim 35$ pseudosegments, fairly distinct.

Male (variation)

Tibia 1 in 4 other males: 8.7, 8.8, 8.9, 9.0. 


\section{Female}

In general similar to male; triads closer together (distance PME-PME $210 \mu \mathrm{m}$ ), not on stalks; clypeus less protruding; no curved hairs on metatarsi; abdomen with continuous ventral dark band between epigynum and spinnerets. Tibia 1 in 8 females: 6.3-7.2 (mean 6.7). Epigynum large brown plate, slightly protruding, with internal pockets and other sclerites visible through cuticle (Figs 153, 175). Internal genitalia as in Figs 154 and 177, with pair of membranous pockets near posterior margin.

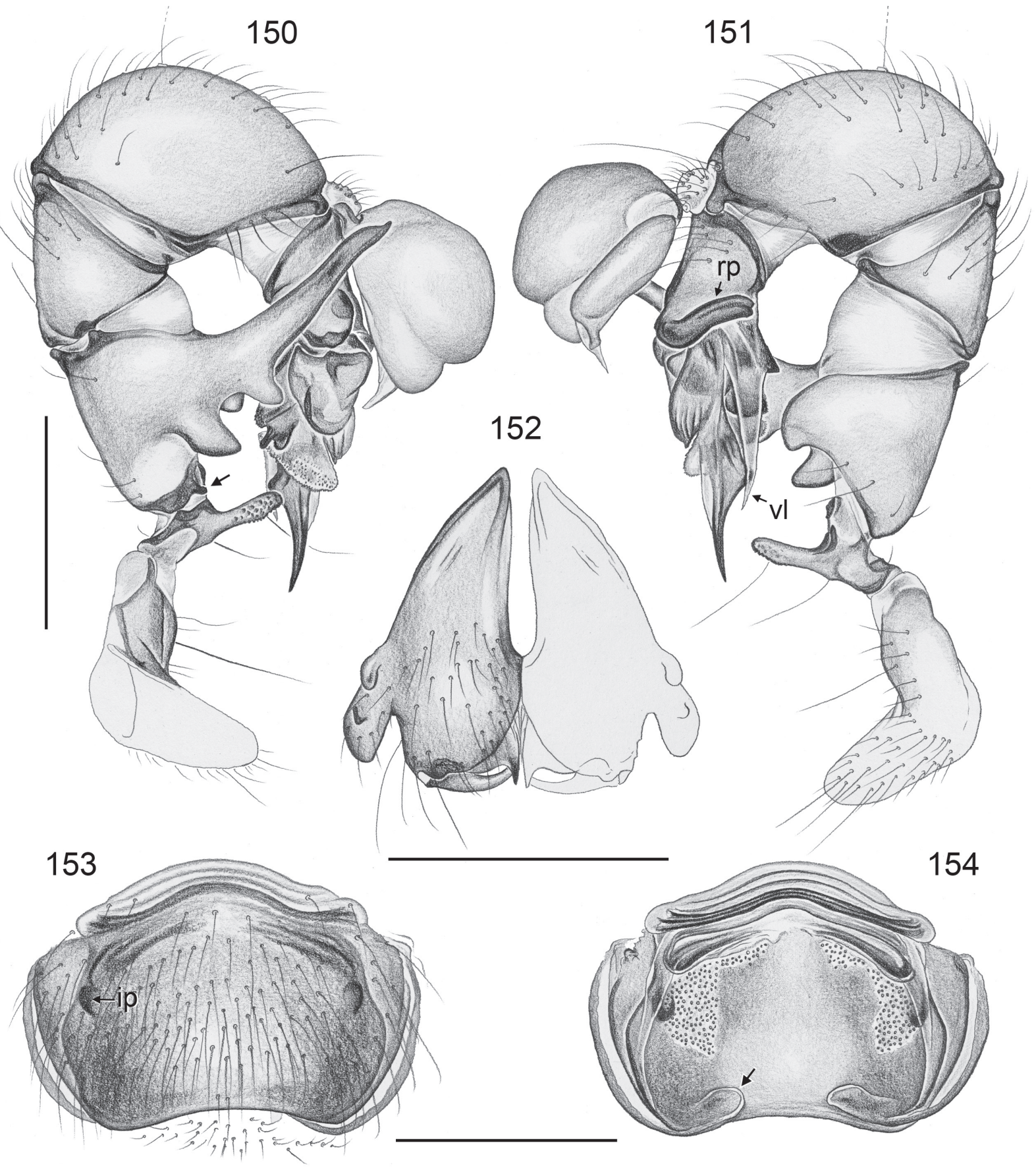

Figs 150-154. Aetana indah Huber, sp. nov. 150-151. Left male palp, prolateral and retrolateral views (arrow points at prolateral apophysis near hinge). 152. Male chelicerae, frontal view. 153-154. Cleared female genitalia, ventral and dorsal views (arrow points at membranous pocket). ip = internal sclerotized pocket; $\mathrm{rp}=$ retrolatero-ventral process; $\mathrm{vl}=$ ventral lamina. Scale lines: $0.5 \mathrm{~mm}$. 
HUBER B.A. et al., Revision of Aetana spiders
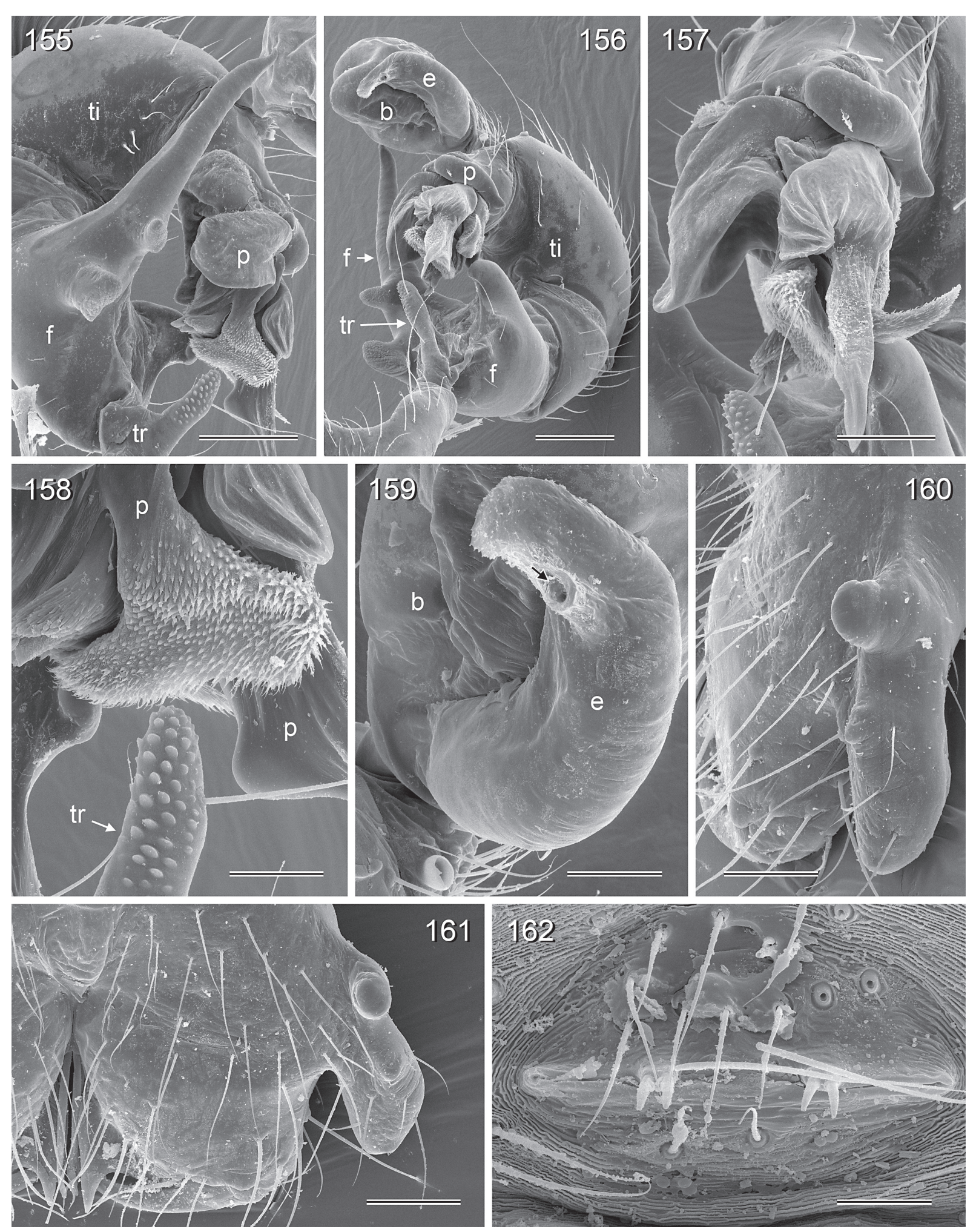

Figs 155-162. Aetana indah Huber, sp. nov. 155-156. Left palp, prolatero-distal and retrolaterodistal views. 157. Left procursus, retrolatero-distal view. 158. Detail of left procursus (and trochanter apophysis), prolateral view. 159. Left embolus (arrow points at sperm duct opening). 160-161. Left male cheliceral apophyses, oblique frontal and frontal views. 162. Male gonopore. $\mathrm{b}=$ genital bulb; e $=$ embolus; $\mathrm{f}=$ femur; $\mathrm{p}=$ procursus; $\mathrm{t} i=$ tibia; $\mathrm{tr}=$ trochanter. Scale lines: $155-156=200 \mu \mathrm{m} ; 157=$ $100 \mu \mathrm{m} ; 158-160=60 \mu \mathrm{m} ; 161=80 \mu \mathrm{m} ; 162=30 \mu \mathrm{m}$. 

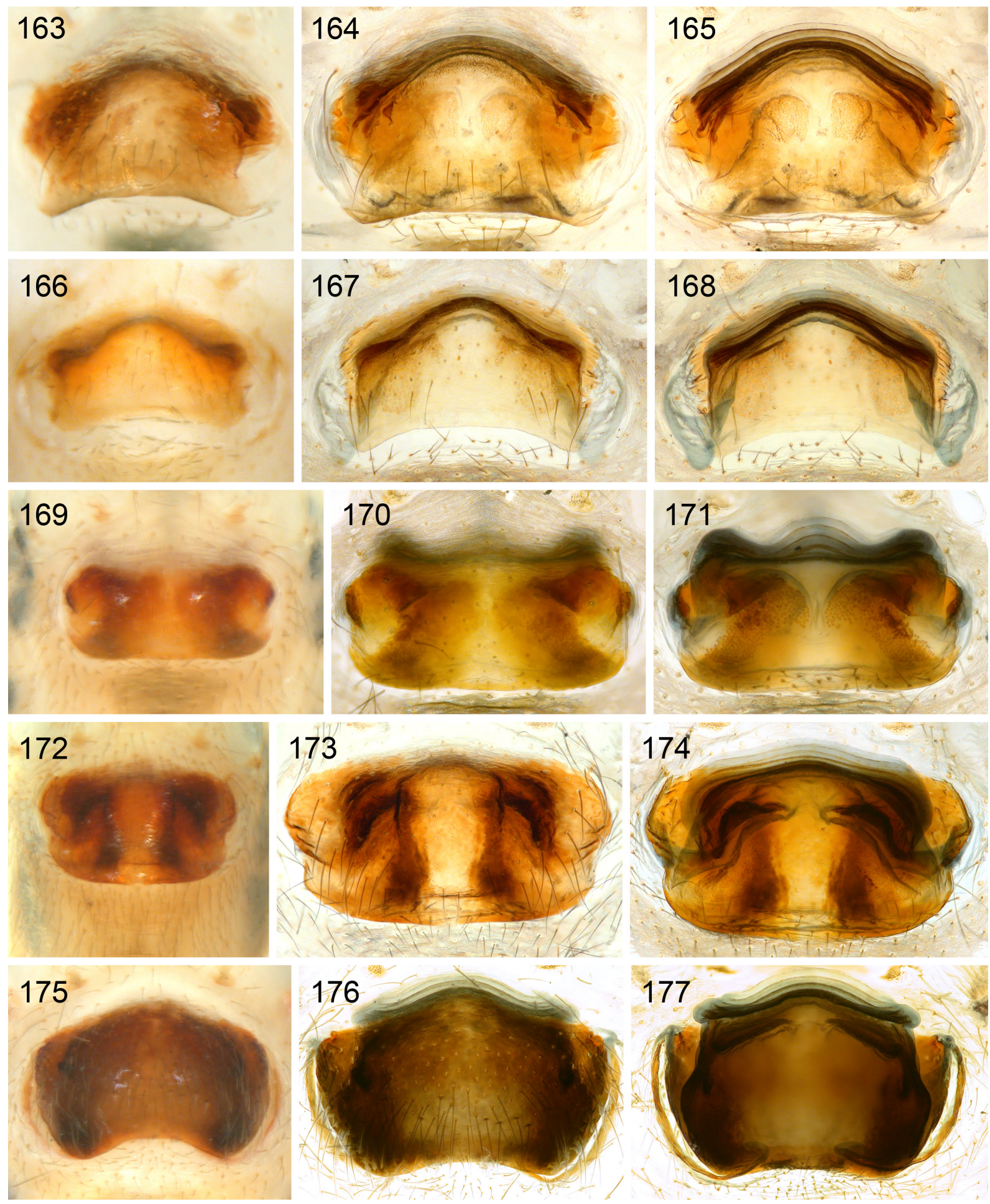

Figs 163-177. Aetana kinabalu group. Female genitalia; untreated in ventral view, cleared in ventral and dorsal views. - 163-165. A. kinabalu Huber, 2005. - 166-168. A. lambir Huber, sp. nov. - 169171. A. gaya Huber, sp. nov. - 172-174. A. poring Huber, sp. nov. - 175-177. A. indah Huber, sp. nov. 
HUBER B.A. et al., Revision of Aetana spiders

\section{Natural history}

The spiders were found very close to the ground in small holes and cavities and barely reacted to disturbance (similar only to $A$. poring Huber, sp. nov.; see above). They share the locality with $A$. kinabalu which lives higher among the vegetation.

\section{Distribution}

Known from Crocker Range only (Fig. 5).

$$
\begin{aligned}
& \text { Aetana abadae Huber, sp. nov. } \\
& \text { urn:Isid:zoobank.org:act:C0C92230-1 A67-45FC-BCC4-3B66E2E82EC0 }
\end{aligned}
$$

Figs 178-179, 186, 189-193, 195-197, 213-215

\section{Diagnosis}

Distinguished from closest known relative (A. omayan) by male clypeus modification (Fig. 191; apophyses closer together), distinct ventro-distal apophysis on male palpal femur (Fig. 190; only indistinct hump in A. omayan), and shape of epigynum (Fig. 213; whitish areas smaller and wider apart). Distinguished from other congeners by bipartite retrolatero-ventral process on procursus (Fig. 190), male palpal trochanter with prolateral apophysis (Fig. 189; other species with only ventral apophysis), and pair of internal sclerotized pockets in female genitalia (Figs 192-193).

\section{Etymology}

Named for Philippine-born cosmopolitan artist Pacita Abad (1946-2004), famous for her vibrant, colorful abstract work, but also for her paintings of tropical flowers and animal wildlife.

\section{Material examined}

\section{Holotype}

PHILIPPINES: ${ }^{\Uparrow}$, Negros Isl., Negros Oriental Prov., Twin Lakes N.P. $\left(9.365-9.368^{\circ} \mathrm{N}, 123.181^{\circ}\right.$ $123.182^{\circ}$ E), 850-950 m a.s.1., forest above Baliansasayao Crater Lake, 9 Mar. 2014 (B.A. Huber), ZFMK (Ar 13986).

\section{Other material}

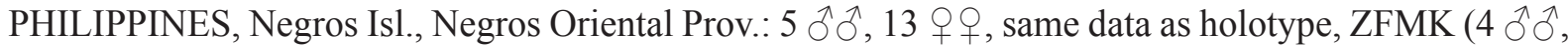
12 우; $\operatorname{Ar} 13987-88)$ and MSU-IIT (1 Ô, 1 ㅇ); 1 ㅇ, 4 juvs, in pure ethanol, same data, ZFMK (Phi 193). - $1 \mathrm{O}^{\wedge}$, Casaroro Falls $\left(9.281^{\circ} \mathrm{N}, 123.208^{\circ} \mathrm{E}\right), 550 \mathrm{~m}$ a.s.l., forest along river below waterfall, 10 Mar. 2014 (B.A. Huber), ZFMK (Ar 13989); 1 + , in pure ethanol, same data, ZFMK (Phi 189).

\section{Description}

Male (holotype)

Measurements. Total body length 3.4, carapace width 1.4. Leg 1: $44.3(10.6+0.6+10.6+19.2+$ 3.3), tibia 2: 6.6, tibia 3: 4.5, tibia 4: 6.5; tibia $1 \mathrm{~L} / \mathrm{d}$ : 80. Distance PME-PME $430 \mu \mathrm{m}$, diameter PME $140 \times 155 \mu \mathrm{m}$, distance PME-ALE $\sim 40 \mu \mathrm{m}$; AME absent.

COLOR. Carapace ochre-yellow with narrow lateral marginal bands and wide dark brown median band including ocular area and clypeus; sternum ochre-yellow, with darker triangular mark posteriorly and dark labium; legs ochre-yellow with slightly darker rings on femora (subdistally, with light tip), and tibiae (proximally and subdistally, the latter followed by light tip); abdomen ochre-gray, dorsally and laterally covered with many black marks, ventrally with dark mark behind gonopore. 

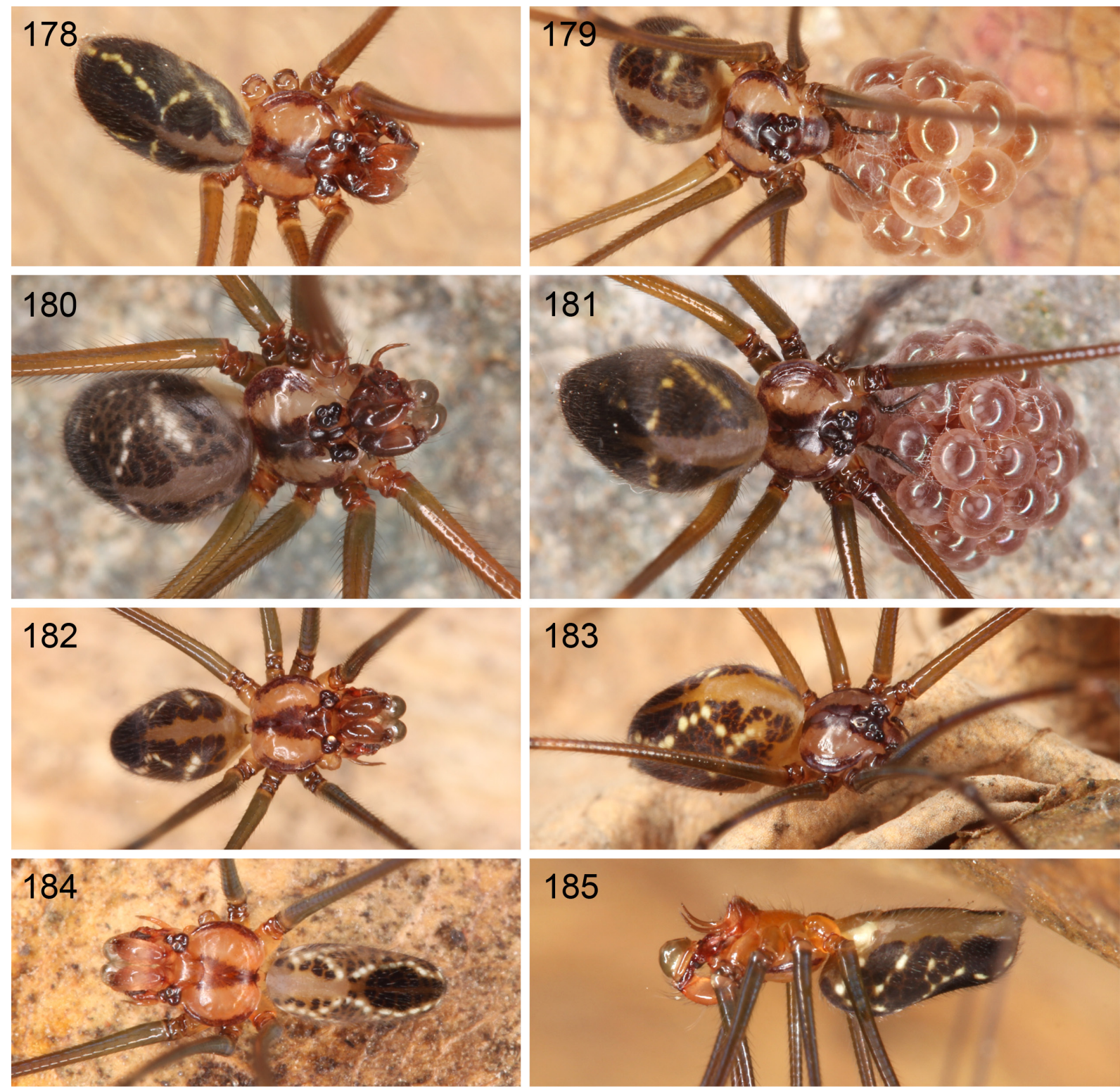

185
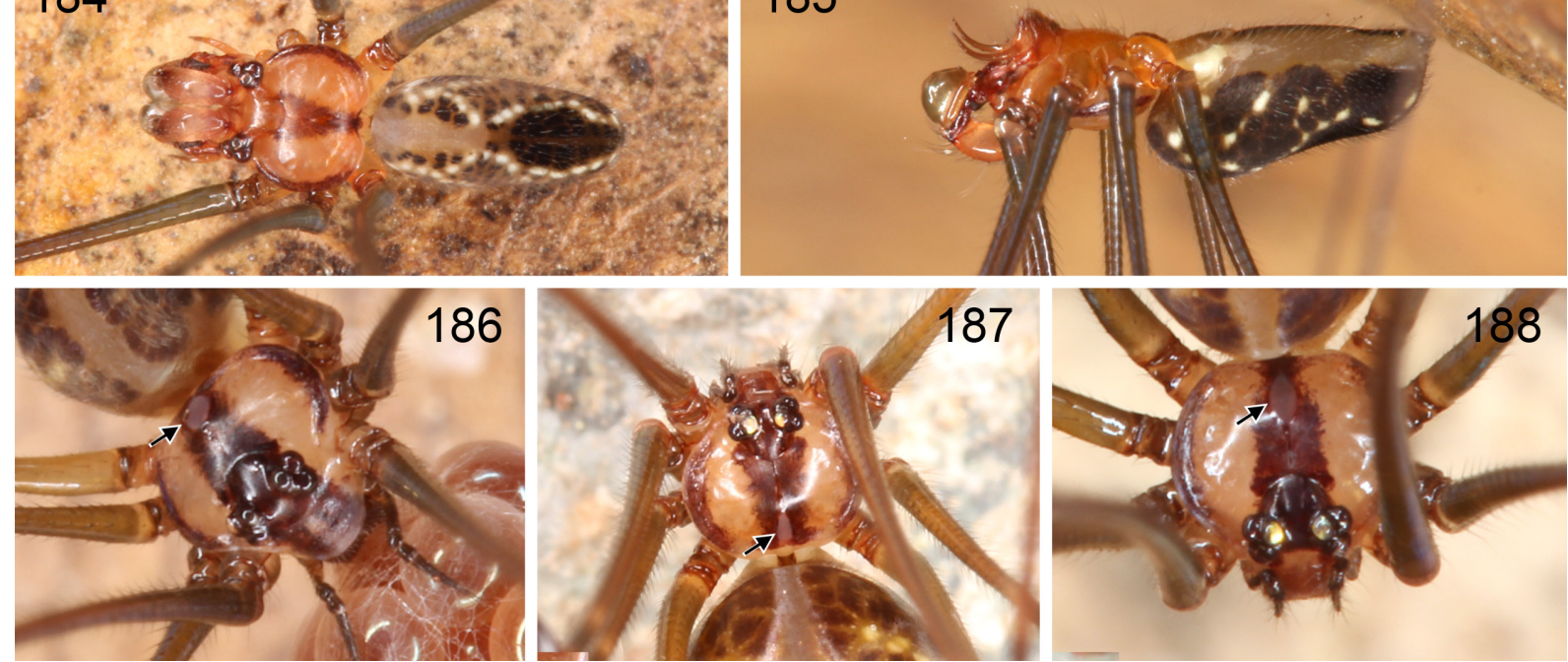

Figs 178-188. Live specimens. Aetana omayan group. - 178-179. A. abadae Huber, sp. nov., $\widehat{O}$ and $q$ with eggsac from Twin Lakes, Negros. - 180-181. A. omayan Huber, 2005, ô and $q$ with eggsac from Baguio, Luzon. - 182-183. A. manansalai Huber, sp. nov., $\widehat{O}$ and $\bigcirc$ from Mt. Banahaw, Luzon. - 184-185. A. lozadae Huber, sp. nov., ô $\widehat{o}$ from Mt. Isarog, Luzon. - 186-188. Female prosomata, showing stridulatory plates (arrows), in A. abadae Huber, sp. nov. (186), A. omayan Huber, 2005 (187) and $A$. manansalai Huber, sp. nov. (188). 
BoDy. Habitus as in Fig. 178; ocular area raised, each triad on additional short hump directed toward lateral, without process below ALE (Fig. 191); carapace with very shallow median furrow in anterior part only; clypeus with distinctive pair of apophyses (Fig. 191); sternum wider than long (0.95/0.65), unmodified.

Chelicerae. As in Fig. 191, with pair of lateral processes proximally and pair of long lateral apophyses distally; without modified hairs; without stridulatory ridges.

PALPS. As in Figs 189-190; coxa unmodified; trochanter with ventral and prolateral apophyses; femur with retrolateral hump, large prolateral apophysis, and ventro-distal apophysis; patella triangular in lateral view; tibia with retrolateral trichobothrium in very distal position; proximal part of procursus with bipartite retrolatero-ventral process, with complex and apparently partly hinged distal elements; bulb with only one process (weakly sclerotized embolus), distally with indistinct hump, without small knobs.

LEGS. Without spines; with curved hairs on metatarsi 1-3; few vertical hairs; retrolateral trichobothrium on tibia 1 at $2 \%$; prolateral trichobothrium absent on tibia 1, present on other tibiae; tarsus 1 with $\sim 25$ pseudosegments, only distally distinct.

Male (variation)

Tibia 1 in six other males: 9.8-10.6 (mean: 10.2). Dark spot behind gonopore absent in two males. Abdomen with or without additional white spots in dorso-lateral rows. Male from Casaroro Falls with large light brown mark on sternum posteriorly.

\section{Female}

In general similar to male but clypeus unmodified and more homogeneously dark brown; eye triads much closer together (distance PME-PME $165 \mu \mathrm{m}$ ); with indistinct stridulatory apparatus between carapace and abdomen: small modified area medially on carapace (Fig. 186) versus barely distinguishable hairless area on abdomen. Tibia 1 in 13 females: 7.8-8.8 (mean: 8.1). Epigynum large sclerotized plate with pair of light lateral humps (Figs 192, 195, 213), with pair of very indistinct membranous pockets behind epigynum in weakly modified cuticle (weak transversal ridges) (Figs 192, 195-196). Internal genitalia as in Figs 193 and 215, with distinct pair of sclerotized pockets.

\section{Natural history}

At both localities the spiders were found in domed sheet webs close to the ground, usually in well protected dark spaces under large rocks.

\section{Distribution}

Known from two localities on Negros Island only (type locality and nearby locality; Fig. 5).

Aetana omayan Huber, 2005

Figs 180-181, 187, 194, 198-212, 216-218

Aetana omayan Huber, 2005a: 73-74, figs 104-105, 110-114 (ぷ゚).

\section{Note}

The original description was based on a single male and two females. Here we present data on new material from the type locality and a nearby locality, as well as an amended diagnosis to account for the newly described congeners. 


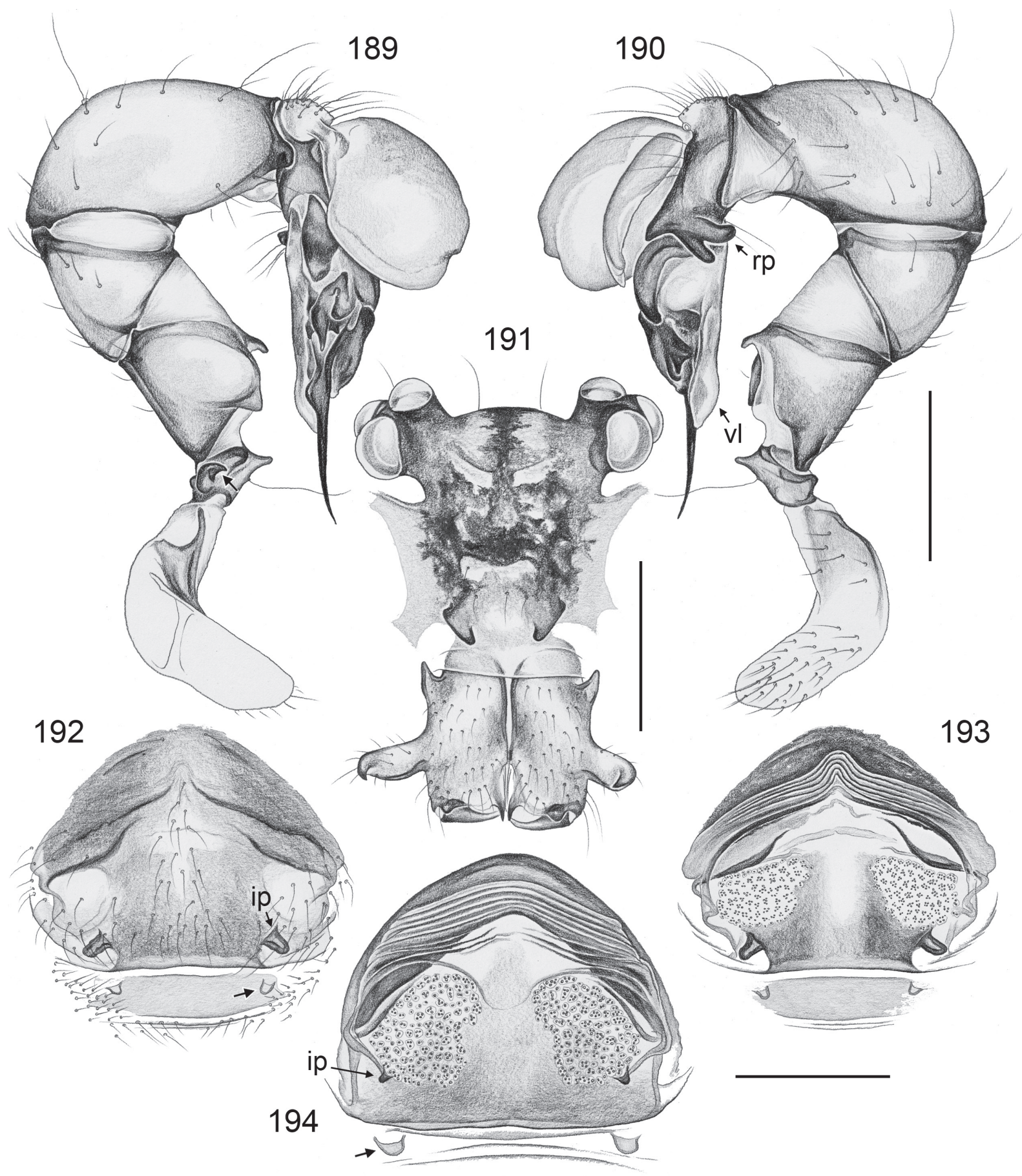

Figs 189-194. - 189-193. Aetana abadae Huber, sp. nov. 189-190. Left male palp, prolateral and retrolateral views. 191. Male prosoma, oblique frontal view. 192-193. Cleared female genitalia, ventral and dorsal views. - 194. A. omayan Huber, 2005, cleared female genitalia, dorsal view. Arrows point at membranous pockets. ip $=$ internal sclerotized pocket; $\mathrm{rp}=$ retrolatero-ventral process; $\mathrm{vl}=$ ventral lamina. Scale lines: $0.5 \mathrm{~mm}$ (female genitalia at same scale). 
HUBER B.A. et al., Revision of Aetana spiders
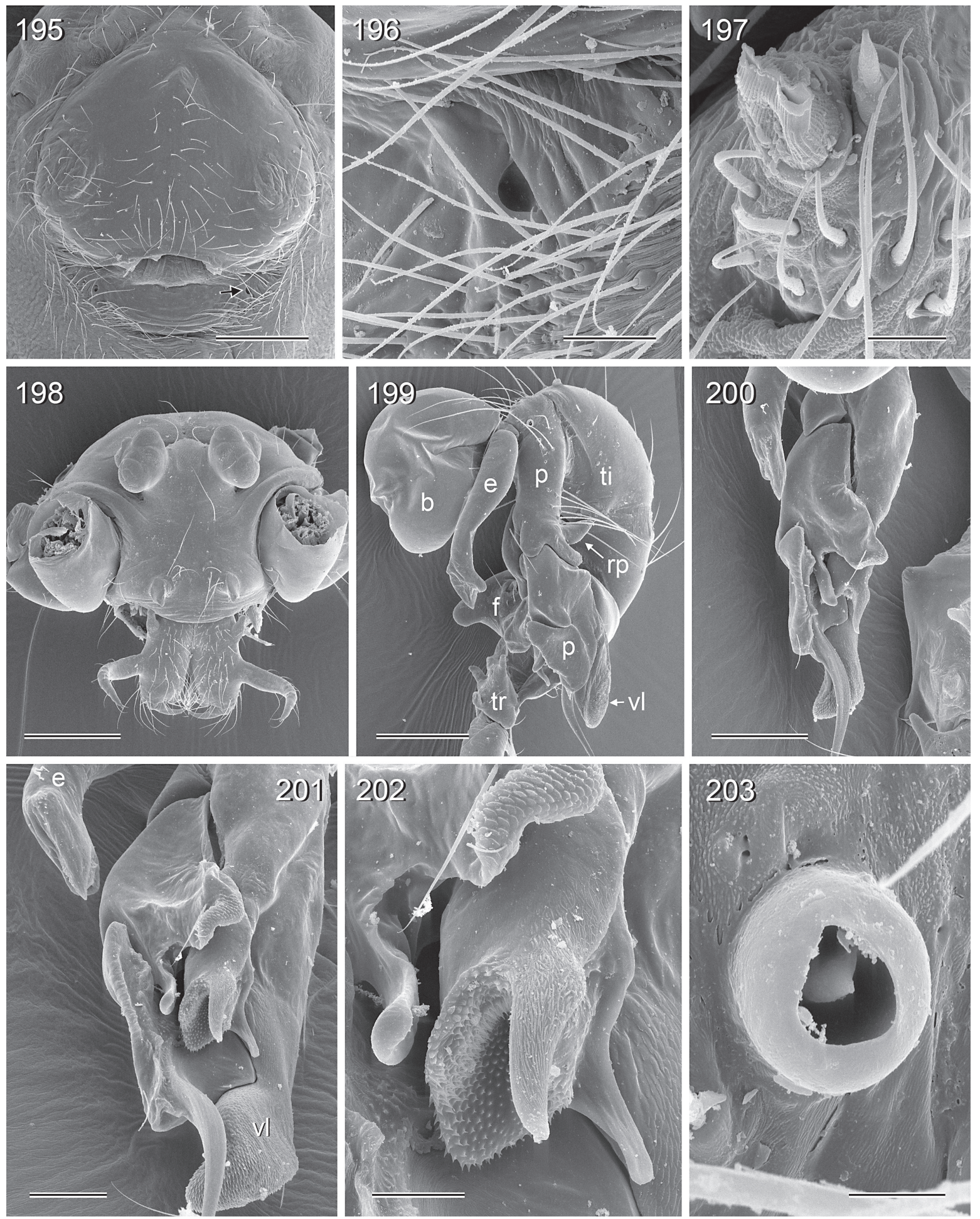

Figs 195-203. - 195-197. Aetana abadae Huber, sp. nov. 195. Epigynum, ventral view. 196. Detail of preceding, showing opening of membranous pocket (arrow on Fig. 195). 197. Female ALS. - 198-203. A. omayan Huber, 2005. 198. Male prosoma, frontal view. 199. Left palp, retrolateral view. 200-201. Right procursus, prolatero-dorsal and prolateral views. 202. Detail of preceding. 203. Male palpal tarsal organ. $\mathrm{b}=$ genital bulb; $\mathrm{e}=$ embolus; $\mathrm{f}=$ femur; $\mathrm{p}=$ procursus; $\mathrm{rp}=$ retrolatero-ventral process; $\mathrm{t} i=$ tibia; $\operatorname{tr}=$ trochanter; $\mathrm{vl}=$ ventral lamina. Scale lines: 195, $199=300 \mu \mathrm{m} ; 196,202=40 \mu \mathrm{m} ; 197,203$ $=10 \mu \mathrm{m} ; 198=500 \mu \mathrm{m} ; 200=200 \mu \mathrm{m} ; 201=100 \mu \mathrm{m}$. 


\section{Diagnosis}

Distinguished from closest known relative (A. abadae Huber, sp. nov.) by male clypeus modification (apophyses wider apart; $c f$. Huber 2005a: fig. 112), very indistinct ventro-distal apophysis on male palpal femur (distinct in $A$. abadae Huber, sp. nov., $c f$. Fig. 190), and shape of epigynum (whitish areas
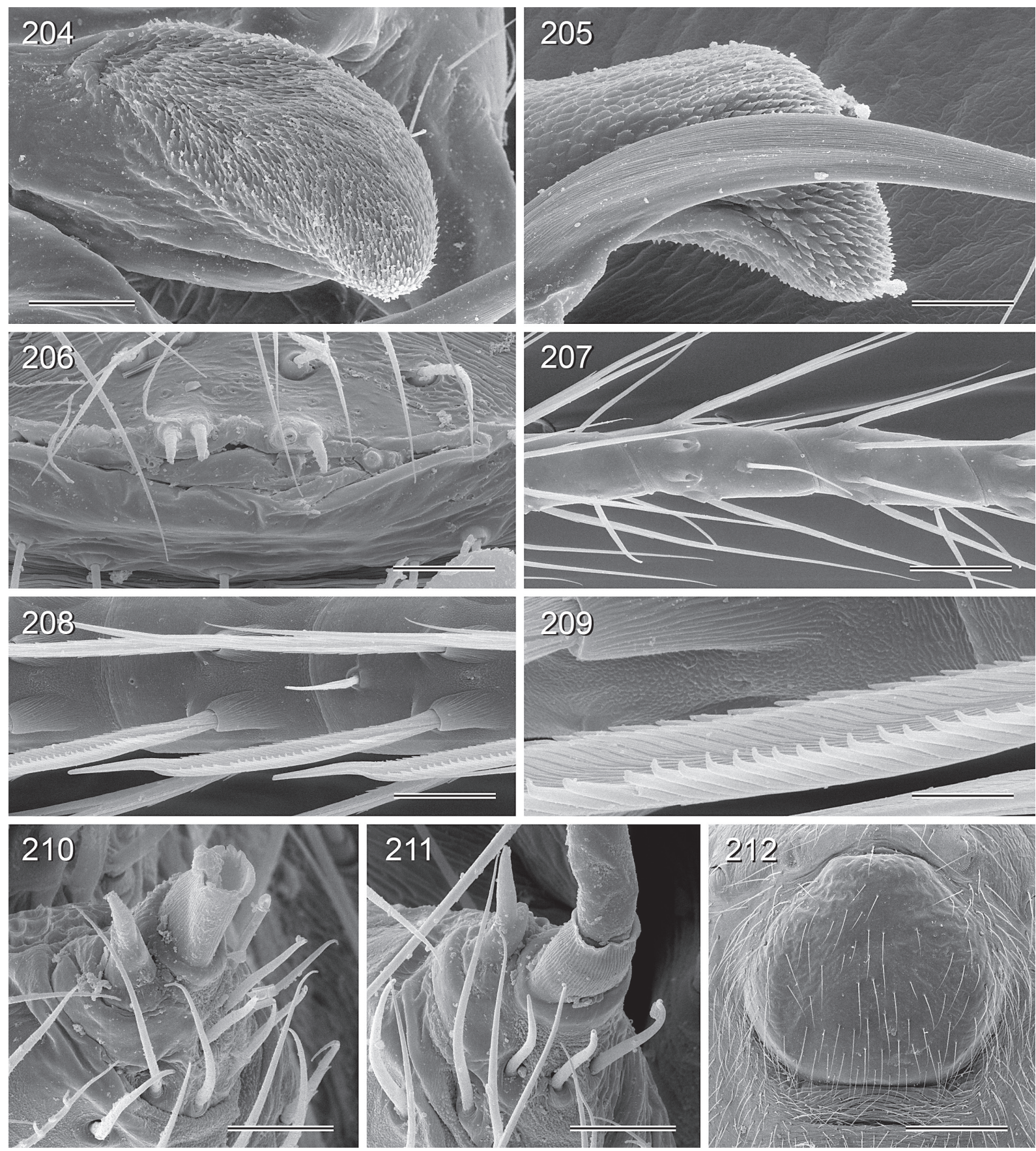

Figs 204-212. A. omayan Huber, 2005. 204. Left procursus tip (ventral lamina), retrolateral view. 205. Right procursus tip (pointed sclerite and ventral lamina), prolateral view. 206. Male gonopore. 207. Detail of male tarsus 1. 208-209. Comb-hairs on male tarsus 4. 210-211. Male and female ALS. 212. Epigynum. Scale lines: $204=50 \mu \mathrm{m} ; 205=40 \mu \mathrm{m} ; 206,208=30 \mu \mathrm{m} ; 207=60 \mu \mathrm{m} ; 209=8 \mu \mathrm{m}$; $210-211=20 \mu \mathrm{m} ; 212=400 \mu \mathrm{m}$. 
larger and closer together; Fig. 216). Distinguished from other congeners by bipartite retrolatero-ventral process on procursus (Huber 2005a: fig. 111), male palpal trochanter with prolateral apophysis (other species only with ventral apophysis), and pair of internal sclerotized pockets in female genitalia (Fig. 194).

\section{New material examined}

PHILIPPINES, Luzon Isl., Benguet Prov.: 9 えð, 16 우, 2 juvs, Baguio, Crystal Cave $\left(16.396^{\circ} \mathrm{N}\right.$,

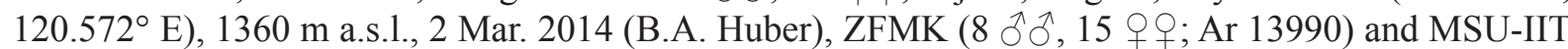

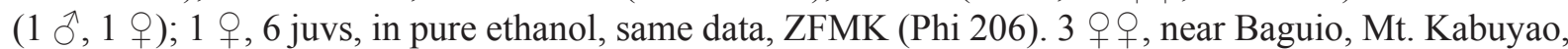
$\mathrm{N}$ slope $\left(16.374^{\circ} \mathrm{N}, 120.557^{\circ} \mathrm{E}\right), 1200-1400 \mathrm{~m}$ a.s.l., among rocks, 2 Mar. 2014 (B.A. Huber), ZFMK (Ar 13991); 1 + , 5 juvs, in pure ethanol, same data, ZFMK (Phi 205).

Description (amendments to Huber 2005a)

MALE. Tibia 2 slightly shorter than tibia 4 (e.g., 7.1/7.3); curved hairs on all tibiae and metatarsi; tibia 1 in 8 males: 9.7-10.9 (mean: 10.4).

FEMALE. Eye triads much closer together than in male (distance PME-PME 180-200 $\mu \mathrm{m} v s .300-400$ $\mu \mathrm{m})$; indistinct stridulatory apparatus between carapace and abdomen: small modified area medially on carapace (Fig. 187) versus light brown hairless area on abdomen; with pair of very indistinct membranous pockets behind epigynum in unmodified cuticle (Figs 194, 218). Tibia 1 in 16 females: 7.6-8.5 (mean: 8.2).
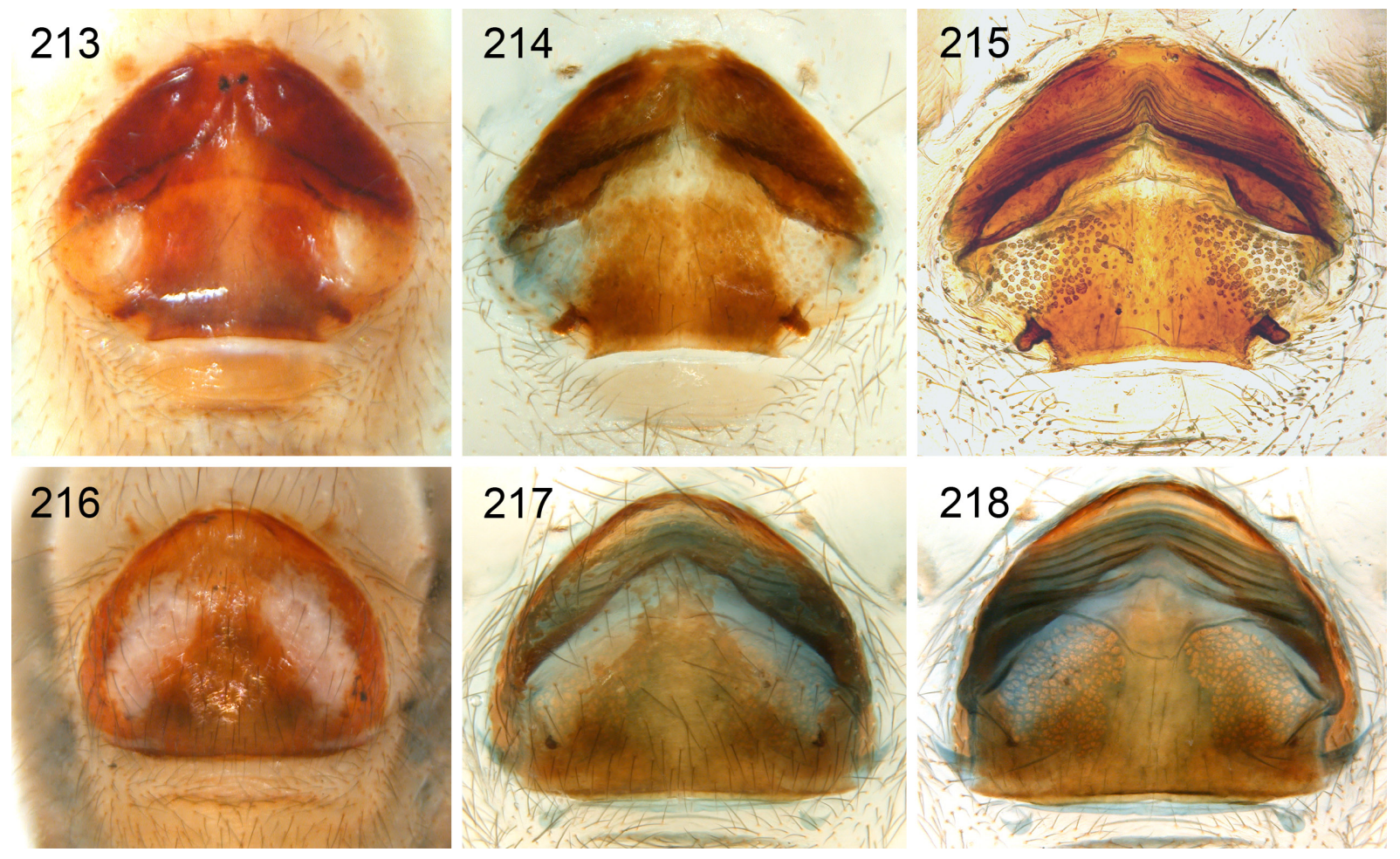

Figs 213-218. Aetana omayan group, female genitalia, part 1 ( $c f$. Figs 234-242); untreated in ventral view, cleared in ventral and dorsal views. 213-215. A. abadae Huber, sp. nov. 216-218. A. omayan Huber, 2005. 


\section{Natural history}

The type locality is a highly degraded and polluted cave in the midst of a suburb of Baguio City. The cave is actually a natural tunnel of about $50 \mathrm{~m}$ length, open on both sides. Within the cave, the spiders were found in high numbers, building their typical domed sheet webs mainly along lower parts of the cave walls near the ground, in crevices and small holes. The finding of the same species among rocks on nearby Mt. Kabuyao suggests that the species is actually widespread in the area and not in danger of extinction by further degradation of the cave.

\section{Distribution}

Known from two localities on Luzon Island only (type locality and nearby locality; Fig. 5).

$$
\begin{aligned}
& \text { Aetana manansalai Huber, sp. nov. } \\
& \text { urn:Isid:zoobank.org:act:087C21AC-F569-43EE-A817-3B0407A1C1EA }
\end{aligned}
$$

Figs 182-183, 188, 219-223, 229, 234-236

\section{Diagnosis}

Distinguished from closest known relatives (A. banahaw Huber, sp. nov., A. lozadae Huber, sp. nov.) by combination of smaller retrolatero-ventral process and smaller dorso-distal sclerite on procursus (compare Figs 229-231) and by narrower epigynum with anterior half wider and more heavily sclerotized than posterior half (Figs 222, 234). Distinguished from A. lozadae Huber, sp. nov. also by smaller projections at ALE (Fig. 221). Distinguished from other congeners by presence of projections at ALE, by long epigynum, and by posterior membranous pockets close together (Fig. 222).

\section{Etymology}

Named for the Filipino painter and illustrator Vicente Silva Manansala (1910-1981), most famous for his 'Madonna of the Slums'.

\section{Material examined}

Holotype

PHILIPPINES: ${ }^{\curvearrowright}$, Luzon Isl., Quezon Prov., between Lucban and Tayabas $\left(14.063^{\circ} \mathrm{N}, 121.567^{\circ} \mathrm{E}\right)$, 330 m a.s.l., degraded forest along river, near ground, 26 Feb. 2014 (B.A. Huber), ZFMK (Ar 13992).

\section{Other material}

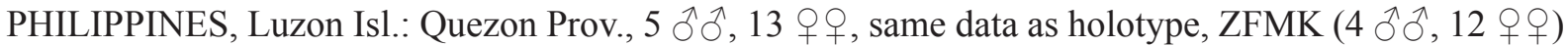
(Ar 13993-94) and MSU-IIT (1 $\mathcal{N}, 1$ ㅇ) ; 3 우, 1 juv., in pure ethanol, same data, ZFMK (Phi 213). Laguna Prov., $2 \widehat{\partial}^{\lambda}{ }^{\lambda}, 2$ 우, Mt. Banahaw, forest near Taytay Falls $\left(14.110^{\circ} \mathrm{N}, 121.507^{\circ} \mathrm{E}\right), 560 \mathrm{~m}$ a.s.1., near ground, 26 Feb. 2014 (B.A. Huber), ZFMK (Ar 13995).

\section{Description}

Male (holotype)

Measurements. Total body length 3.2, carapace width 1.3. Leg 1: $36.5(8.5+0.5+8.5+15.5+3.5)$, tibia 2: 5.2, tibia 3: 3.5, tibia 4: 5.3; tibia $1 \mathrm{~L} / \mathrm{d}$ : 67. Distance PME-PME $350 \mu \mathrm{m}$, diameter PME $125 \times 150 \mu \mathrm{m}$, distance PME-ALE $\sim 45 \mu \mathrm{m}$; AME absent.

CoLor. Carapace ochre-yellow with narrow lateral marginal bands and wide dark brown median band including posterior part of ocular area; clypeus ochre yellow with indistinct light brown pattern; sternum light brown to orange, laterally paler, labium darker; legs greenish ochre with slightly darker rings on femora (subdistally, with light tip), and tibiae (proximally and subdistally, the latter followed by light 


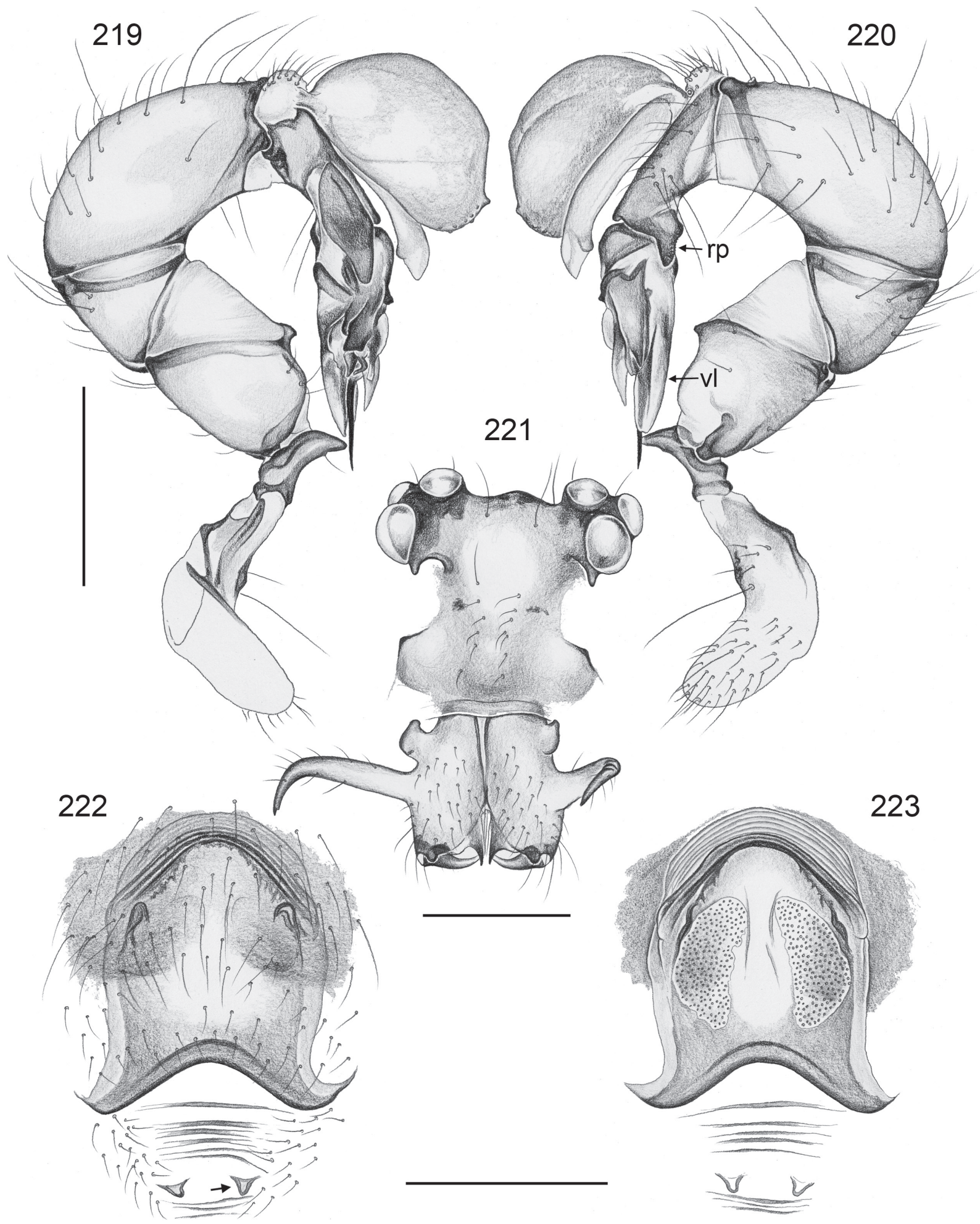

Figs 219-223. Aetana manansalai Huber, sp. nov. 219-220. Left male palp, prolateral and retrolateral views. 221. Male prosoma, oblique frontal view. 222-223. Cleared female genitalia, ventral and dorsal views. Arrow points at membranous pocket. $\mathrm{rp}=$ retrolatero-ventral process; $\mathrm{vl}=$ ventral lamina. Scale lines: $0.5 \mathrm{~mm}$. 
tip); abdomen ochre-gray, dorsally and laterally covered with many black marks, ventrally with dark mark behind gonopore and larger less distinct mark in front of spinnerets.

Body. Habitus as in Fig. 182; ocular area raised, each triad on additional short hump directed toward lateral, with small process below ALE (Fig. 221); carapace with very shallow median furrow in anterior part only; clypeus medially slightly projecting, with distinctive lateral plates bordered by sclerotized ridges (Fig. 221); sternum wider than long $(0.85 / 0.60)$, unmodified.

Chelicerae. As in Fig. 221, with pair of lateral processes proximally and pair of very long lateral apophyses; without modified hairs; without stridulatory ridges.

PaLPS. As in Figs 219-220; coxa unmodified; trochanter with ventral apophysis; femur with small ventro-distal apophysis and retrolateral ridge ending in small hump; patella triangular in lateral view; tibia with retrolateral trichobothrium in very distal position; proximal part of procursus with simple retrolatero-ventral process, with complex and apparently partly hinged distal elements (Fig. 229); bulb with only one process (weakly sclerotized embolus), distally with several small knobs.

LEGS. Without spines; with curved hairs on metatarsi 1-3; few vertical hairs; retrolateral trichobothrium on tibia 1 at $3 \%$; prolateral trichobothrium absent on tibia 1, present on other tibiae; tarsus 1 with $\sim 25$ pseudosegments, only distally distinct.

Male (variation)

Tibia 1 in 5 other males: 8.0-8.8 (mean: 8.3). Abdomen with or without additional white spots in dorsolateral rows.

Female

In general similar to male but clypeus unmodified and with pair of dark brown bands below ALE; eye triads much closer together (distance PME-PME $150 \mu \mathrm{m}$ ), without processes at ALE; with indistinct stridulatory apparatus between carapace and abdomen: modified area medially on carapace (Fig. 188) versus barely distinguishable hairless area on abdomen. Tibia 1 in 13 females: 5.8-6.5 (mean: 6.3); dark and light rings on legs often more distinct than in males. Epigynum long, anterior half of plate wider and more heavily sclerotized than posterior half, anterior half with pair of low humps (Figs 222, 234); area behind epigynum with pair of very indistinct membranous pockets in weakly modified cuticle (weak transversal ridges). Internal genitalia as in Figs 223 and 236, without sclerotized pockets.

\section{Natural history}

At both localities the spiders were found in domed sheet webs close to the ground, usually in well protected dark spaces under large rocks. The type locality suggests that the species does not depend on well preserved forests and is probably widespread in the area.

\section{Distribution}

Known from two localities on Luzon Island only (type locality and nearby locality; Fig. 5).

Aetana lozadae Huber, sp. nov. urn:1sid:zoobank.org:act:3526A886-2551-4FBE-900A-603D92A43E23

Figs 184-185, 224-228, 230, 237-239

\section{Diagnosis}

Distinguished from closest known relatives (A. manansalai Huber, sp. nov., A. banahaw Huber, sp. nov.) by combination of long projections at ALE (Fig. 226), large retrolatero-ventral process on procursus (Fig. 
230; similar to A. banahaw Huber, sp. nov.), and oval shape of epigynum (Figs 227, 237). Distinguished from other congeners by presence of projections at ALE, by epigynum longer than wide, and by posterior membranous pockets close together (Figs 227-228).

\section{Etymology}

Named for Filipino violinist Carmencita Lozada (1940-2006), prize winner of the Paganini International Violin Competition in Italy.

\section{Material examined}

Holotype

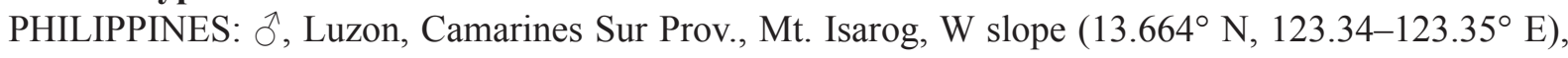
600-900 m a.s.1., forest, near ground, 23 Feb. 2014 (B.A. Huber), ZFMK (Ar 13996).

\section{Other material}

PHILIPPINES, Luzon Isl., Camarines Sur Prov.: $3 \hat{\jmath} \hat{\jmath}, 13$ 오, same data as holotype, ZFMK (Ar 13997-98); 1 ㅇ, in pure ethanol, same data, ZFMK (Phi 221). - 1 o, 1 \% , in pure ethanol, Mt. Isarog $\left(13.665^{\circ} \mathrm{N}, 123.354^{\circ} \mathrm{E}\right), 9.3 \mathrm{~km}$ E of Naga City, $920 \mathrm{~m}$ a.s.l., 31 May-2 June 2011 (M. Yngente et al.), CAS (9042055).

\section{Description}

Male (holotype)

Measurements. Total body length 3.9, carapace width 1.3. Leg 1: $40.1(9.2+0.5+9.2+17.7+3.5)$, tibia 2: 5.8, tibia 3: 4.0, tibia 4: 5.8; tibia $1 \mathrm{~L} / \mathrm{d}$ : 71. Distance PME-PME $390 \mu \mathrm{m}$, diameter PME $135 \times 155 \mu \mathrm{m}$, distance PME-ALE $\sim 45 \mu \mathrm{m}$; AME absent.

COLOR. Carapace ochre-yellow with narrow dark lateral marginal bands and wide dark brown median band including posterior part of ocular area; clypeus ochre yellow with indistinct light brown pattern; sternum light brown to orange, labium darker; legs greenish ochre with slightly darker rings on femora (subdistally, with light tip), and tibiae (proximally and subdistally, the latter followed by light tip); abdomen ochre-gray, dorsally and laterally covered with many black marks, ventrally with dark mark behind gonopore and larger less distinct mark in front of spinnerets.

Body. Habitus as in Figs 184-185; ocular area raised, each triad on additional hump directed toward lateral, with long process at ALE (Fig. 226); carapace with very shallow median furrow in anterior part only; clypeus medially not projecting, with distinctive lateral plates bordered by sclerotized ridges (Fig. $226)$; sternum wider than long $(0.85 / 0.65)$, unmodified.

Chelicerae. As in Fig. 226, with pair of lateral processes proximally and pair of very long lateral apophyses, without modified hairs; without stridulatory ridges.

PaLPS. As in Figs 224-225; very similar to A. manansalai Huber, sp. nov. and A. banahaw Huber, sp. nov.; procursus as in Fig. 230.

LEGS. Without spines; with curved hairs on metatarsi 1-2; few vertical hairs; retrolateral trichobothrium on tibia 1 at $2 \%$; prolateral trichobothrium absent on tibia 1, present on other tibiae; tarsus 1 with $\sim 25$ pseudosegments, only distally distinct.

Male (variation)

Tibia 1 in 2 other males: 8.8, 9.2. Abdomen with or without additional white spots in dorso-lateral rows (white spots seem to get partly lost or indistinct in alcohol). 


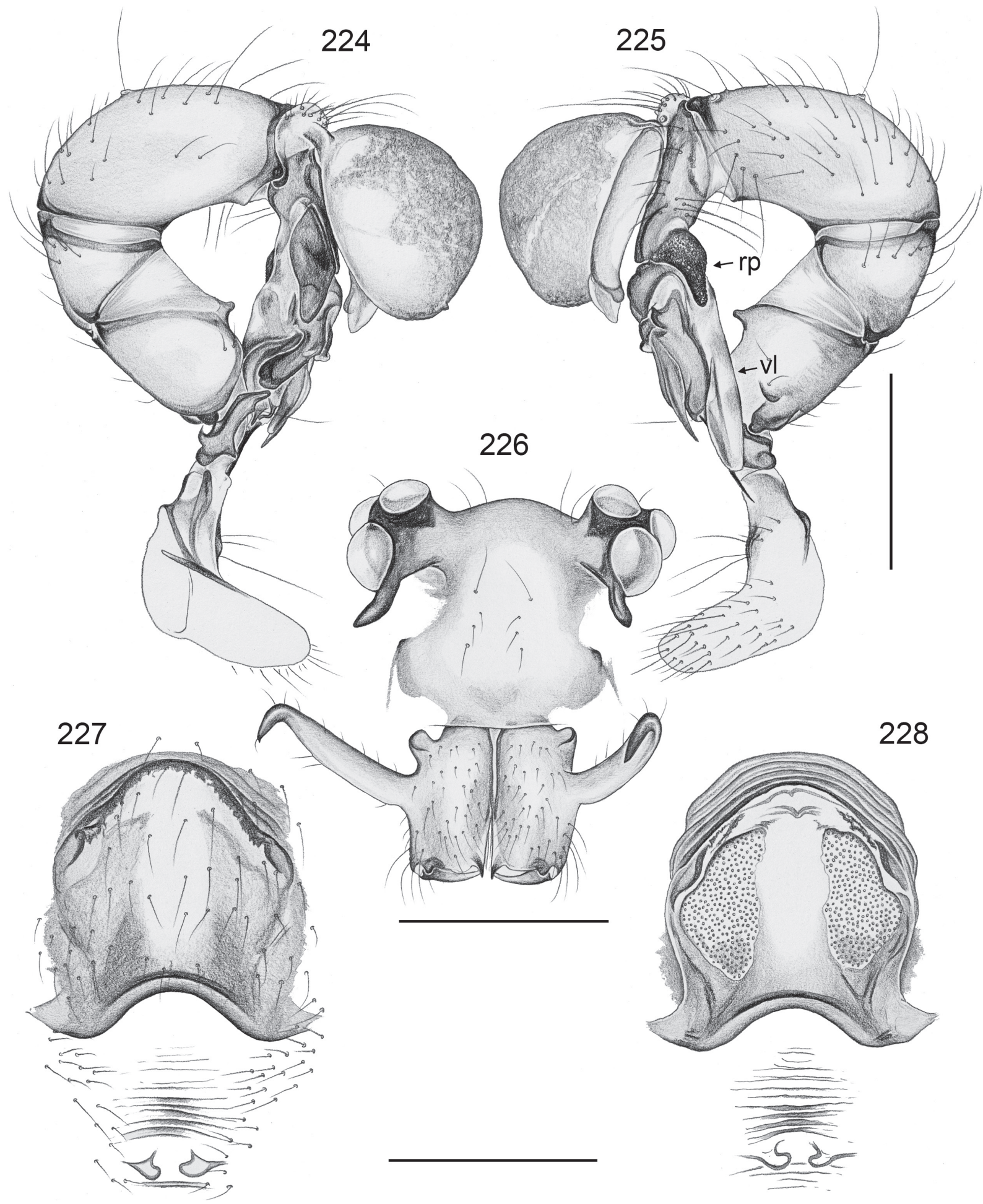

Figs 224-228. Aetana lozadae Huber, sp. nov. 224-225. Left male palp, prolateral and retrolateral views. 226. Male prosoma, oblique frontal view. 227-228. Cleared female genitalia, ventral and dorsal views. $\mathrm{rp}=$ retrolatero-ventral process; $\mathrm{vl}=$ ventral lamina. Scale lines: $0.5 \mathrm{~mm}$. 

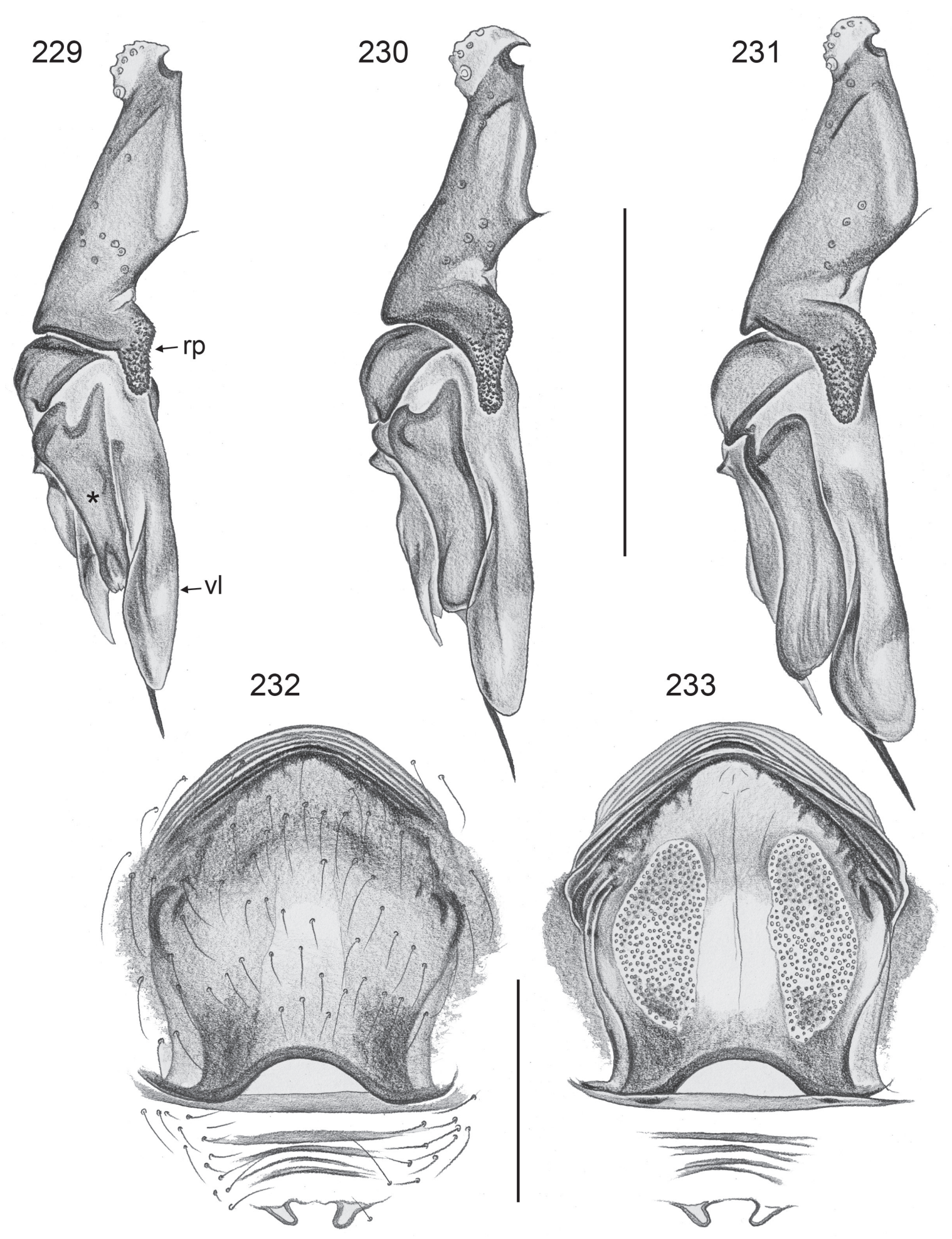

Figs 229-233. Left procursi, retrolateral views (asterisk: retrolatero-distal sclerite). - 229. Aetana manansalai Huber, sp. nov. - 230. A. lozadae Huber, sp. nov. - 231. A. banahaw Huber, sp. nov. Figs 229-231 at same scale. - 232-233. A. banahaw Huber, sp. nov., cleared female genitalia, ventral and dorsal views. $\mathrm{rp}=$ retrolatero-ventral process; $\mathrm{vl}=$ ventral lamina. Scale lines: $0.5 \mathrm{~mm}$. 


\section{Female}

In general similar to male but clypeus unmodified and most females with pair of dark brown bands below ALE; eye triads much closer together (distance PME-PME $155 \mu \mathrm{m}$ ), without processes near ALE; with indistinct stridulatory apparatus between carapace and abdomen: modified area medially on carapace (smaller than in $A$. manansalai Huber, sp. nov.) versus barely distinguishable hairless area on abdomen. Tibia 1 in 9 females: 6.7-7.7 (mean: 7.2); dark and light rings on legs often more distinct than in males. Epigynum oval, longer than wide (Figs 227, 237), anterior half with pair of low humps; area behind epigynum with pair of very indistinct membranous pockets in weakly modified cuticle (weak transversal ridges). Internal genitalia as in Figs 228 and 239, without sclerotized pockets.

\section{Natural history}

The spiders were found in domed sheet webs close to the ground, usually in well protected dark spaces under large rocks and logs, but apparently not as deeply hidden in these cavities as the sympatric A. ocampoi Huber, sp. nov.

\section{Distribution}

Known from type locality on Luzon Island only (Fig. 5).

Aetana banahaw Huber, sp. nov. urn:1sid:zoobank.org:act:6D270C60-BBF0-4DFE-88BC-1F90D87C5D8F

Figs 231-233, 240-242

\section{Diagnosis}

Distinguished from closest known relatives (A. manansalai Huber, sp. nov., A. lozadae Huber, sp. nov.) by shape of procursus (large retrolatero-distal sclerite; compare Figs 229-231) and by pentagonal epigynum (Figs 232, 240); from $A$. manansalai Huber, sp. nov. also by larger retrolatero-ventral process on procursus (Fig. 231) and narrower apophysis of male palpal trochanter; from A. lozadae Huber, sp. nov. also by smaller projections at ALE (similar to A. manansalai Huber, sp. nov.; cf. Fig. 221). Distinguished from other congeners by presence of projections at ALE, by longer than wide epigynum, and by posterior membranous pockets close together (Fig. 232).

\section{Etymology}

Named for the type locality; noun in apposition.

\section{Material examined}

Holotype

PHILIPPINES: §̋, Luzon Isl., Laguna Prov., Mt. Banahaw, forest near Taytay Falls $\left(14.110^{\circ} \mathrm{N}\right.$, $121.507^{\circ}$ E), 560 m a.s.l., near ground, 26 Feb. 2014 (B.A. Huber), ZFMK (Ar 13999).

\section{Other material}

PHILIPPINES, Luzon Isl., Laguna Prov.: 7 ふึત, 4 우, same data as holotype, ZFMK (Ar 14000-01); 1 , 4 juvs, in pure ethanol, same data, ZFMK (Phi 217). - 1 q, 1 juv., in pure ethanol, Mt. Banahaw (14.103 ${ }^{\circ}$ $\left.\mathrm{N}, 121.518^{\circ} \mathrm{E}\right), 4.38 \mathrm{~km}$ W of Lucban, $790 \mathrm{~m}$ a.s.1., 16 May 2011 (H. Wood et al.), CAS (9045550).

\section{Description}

Male (holotype)

Measurements. Total body length 3.7, carapace width 1.35. Leg 1: $36.7(8.6+0.5+8.6+15.4+$ 3.6), tibia 2: 5.5, tibia 3: 3.8, tibia 4: 5.6; tibia $1 \mathrm{~L} / \mathrm{d}$ : 63. Distance PME-PME $395 \mu \mathrm{m}$, diameter PME $140 \mu \mathrm{m}$, distance PME-ALE 70 $\mu \mathrm{m}$; AME absent. 

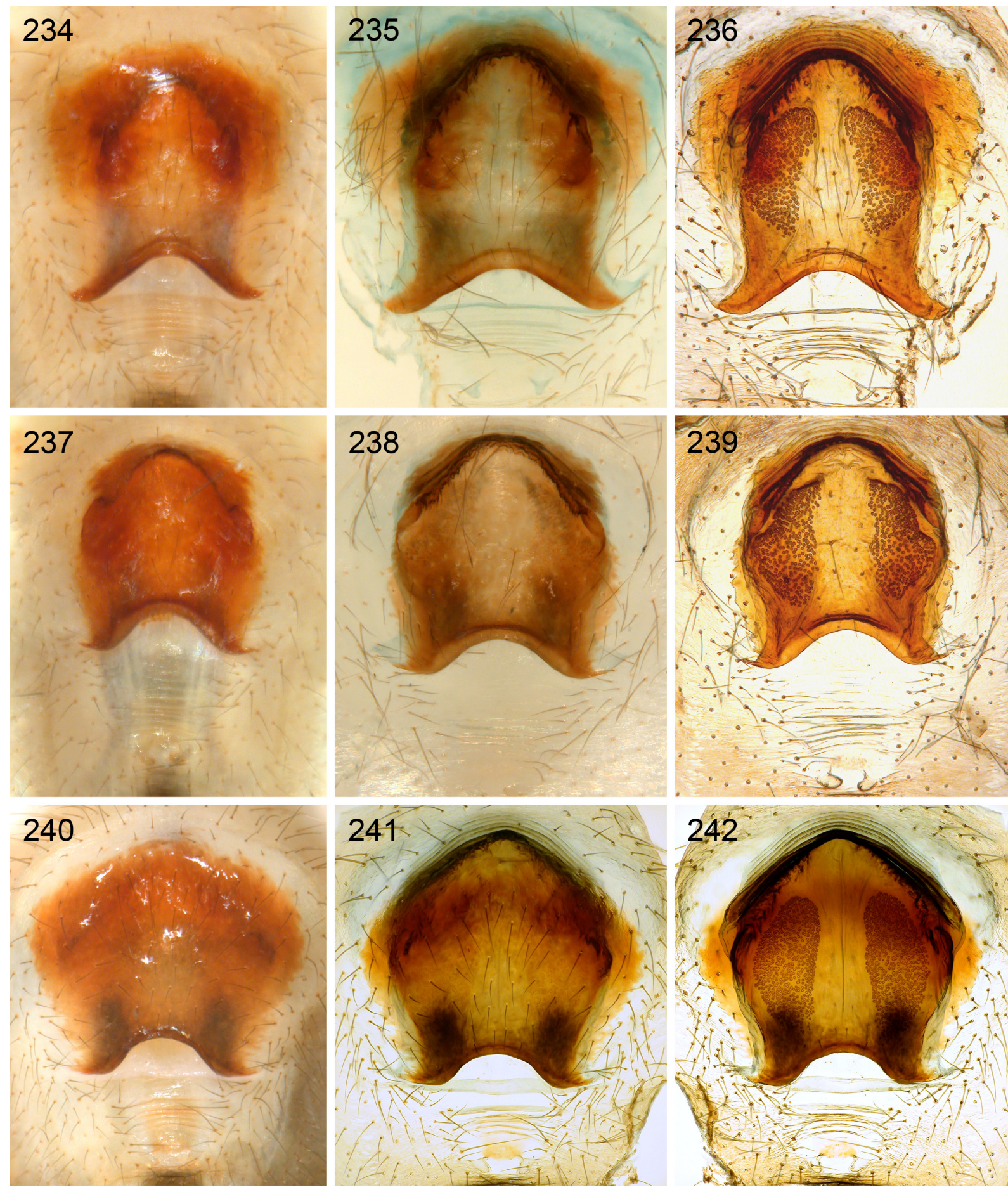

Figs 234-242. Aetana omayan group, female genitalia, part 2 (cf. Figs 213-218); untreated in ventral view, cleared in ventral and dorsal views. - 234-236. A. manansalai Huber, sp. nov. — 237-239. A. lozadae Huber, sp. nov. - 240-242. A. banahaw Huber, sp. nov. 
CoLor. Carapace ochre-yellow with narrow dark lateral marginal bands and wide dark brown median band including posterior part of ocular area; clypeus ochre yellow, small marks below each eye triad; sternum monochromous light brown, labium darker; legs greenish ochre with very indistinct darker rings on femora (subdistally, with light tip), and tibiae (proximally and subdistally, the latter followed by light tip); abdomen ochre-gray, dorsally and laterally covered with many black marks, ventrally with dark mark behind gonopore and larger, less distinct mark in front of spinnerets.

Body. Habitus very similar to A. lozadae Huber, sp. nov. (cf. Figs 184-185); ocular area raised, each triad on additional short hump directed toward lateral, with small process below ALE (only slightly longer than in A. manansalai Huber, sp. nov.; cf. Fig. 221); carapace with very shallow median furrow in
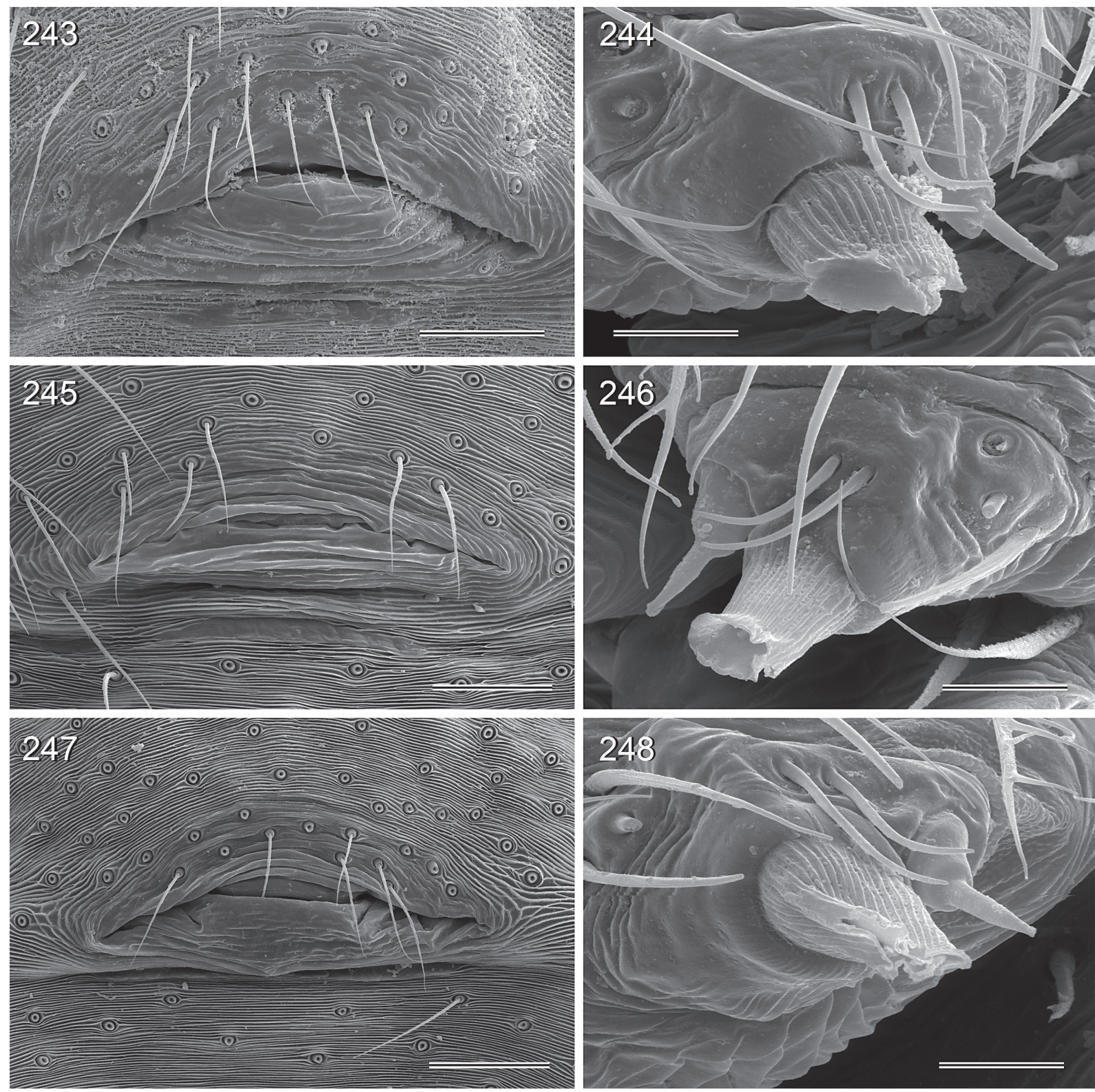

Figs 243-248. Male gonopores and ALS. - 243-244. Khorata khammouan Huber, 2005. - 245246. K. dupla Yao \& Li, 2013. - 247-248. K. circularis Yao \& Li, 2013. Scale lines: $243=50 \mu \mathrm{m} ; 244$, $246,248=10 \mu \mathrm{m} ; 245=40 \mu \mathrm{m} ; 247=60 \mu \mathrm{m}$. 
anterior part only; clypeus with distinctive lateral plates bordered by sclerotized ridges; sternum wider than long $(0.9 / 0.7)$, unmodified.

Chelicerae. As in close relatives ( $c f$. Figs 221, 226), with pair of lateral processes proximally and pair of very long lateral apophyses; without modified hairs; without stridulatory ridges.

PALPS. In general as in A. manansalai Huber, sp. nov. and A. lozadae Huber, sp. nov. (cf. Figs 219-220, 224-225); coxa unmodified; trochanter with ventral apophysis slightly narrower than in A. manansalai Huber, sp. nov.; femur with ventro-distal apophysis and retrolateral ridge ending in small hump; patella triangular in lateral view; tibia with retrolateral trichobothrium in very distal position; proximal part of procursus, with simple retrolatero-ventral process, with complex and apparently partly hinged distal elements; bulb with only one process (weakly sclerotized embolus), distally with one small knob.

Legs. Without spines; with curved hairs on metatarsi 1-3; few vertical hairs; retrolateral trichobothrium on tibia 1 at 3\%; prolateral trichobothrium absent on tibia 1, present on other tibiae; tarsus 1 with 25 pseudosegments, distally fairly distinct.

Male (variation)

Tibia 1 in 7 other males: 8.2-9.4 (mean: 8.9).

\section{Female}

In general similar to male but clypeus unmodified and with pair of dark brown bands below ALE; eye triads much closer together (distance PME-PME $185 \mu \mathrm{m}$ ), without processes at ALE; with indistinct stridulatory apparatus between carapace and abdomen: modified area medially on carapace versus barely distinguishable hairless area on abdomen. Tibia 1 in 4 females: 6.6, 6.8, 7.1, 7.3; dark and light rings on legs mostly more distinct than in males. Epigynum as in Figs 232 and 240, anterior large plate pentagonal, with transversal anterior bulge bordered posteriorly by shallow indentation; area behind epigynum with pair of very indistinct membranous pockets in weakly modified cuticle (weak transversal ridges). Internal genitalia as in Figs 233 and 242, without sclerotized pockets.

\section{Natural history}

The spiders were found in domed sheet webs close to the ground, usually in well protected dark spaces under large rocks. Males and females were sometimes found together in one web. When disturbed, the spiders ran to the rock, vibrated only for a moment and then remained motionless, pressed against the rock surface.

\section{Distribution}

Known from the type locality only (Fig. 5).

\section{Discussion}

Our main objectives were to document the high diversity of Aetana in Southeast Asia, and to provide first data about ultrastructure, relationships, and ecology. However, while we added substantial new data about Philippine and Borneo species, individual records reaching as far east as Fiji suggest that a huge diversity remains to be discovered and described. Our cladistic analysis is certainly a step forward, but while some details are congruent with preliminary molecular data (A. Valdez-Mondragón, D. Dimitrov, B.A. Huber, unpublished data), others are in conflict and need further study. Both analyses agree on the monophyly of Aetana and on the four species groups proposed herein. However, the sister group of Aetana remains dubious: the present analysis suggests a group of three Southeast Asian genera as sister (Khorata, Savarna and an undescribed genus from northern Borneo), whereas the molecular analysis 
currently suggests Southeast Asian Spermophora as sister. Likewise, relationships among species groups within Aetana remain dubious and require further sampling and analysis.

Based on our field observations and the clear support for the four species groups in the cladistic analysis, we conclude that at least two microhabitat shifts have occurred in Aetana. Even if the four species groups are placed in a basal tetrachotomy, assuming a plesiomorphic microhabitat higher among the vegetation would require a minimum of three shifts toward the ground. On the other hand, assuming that the plesiomorphic microhabitat of Aetana is near the ground (as is the case in most species, including the cave-dwelling $A$. omayan) requires only two shifts, one in the Philippines (in the A. ocampoi group), and one on Borneo (in the $A$. kinabalu group). Further support for a shift from the ground towards higher vegetation comes from the outgroup taxa. Except for Zatavua griswoldi Huber, 2003 (for which no microhabitat data are available), all other species have been collected in the leaf litter or very close to the ground. The microhabitat of $A$. fiji has never been documented, but label data (Huber 2005a) suggest that it might represent a third independent case of microhabitat shift within Aetana.

Finally, we document a potential further case of genital dimorphism (in A. ocampoi Huber, sp. nov.), admitting that our data are not particularly strong. Genital dimorphism is a nuisance for invertebrate taxonomy, as it runs counter to one of the very central pillars of the discipline: species-specificity of genitalia (e.g., Huber \& Pérez-González 2001; Jocqué 2002; Mutanen \& Kaitala 2006). For this reason, any proposal for a new case should ideally be supported by convincing evidence, for example derived from rearing experiments such as in Huber \& Pérez-González (2001). We do not have this kind of data for A. ocampoi Huber, sp. nov., our sample size is small, and we have not so far succeeded in sequencing any of the two standard barcoding genes (16S, CO1) for this species. However, we document this potential case in the hope that it might stimulate further field work and research directed at this particular species. We also propose that only a change of paradigm might reveal the true abundance of species with polymorphic genitalia. Traditional invertebrate taxonomy has developed an almost absolute reliance on genital morphology to separate species, which is a major impediment for discovering genital polymorphism in the first place. If species are routinely distinguished by genital morphology, then different morphs will likely end up as different species, which in turn supports the original idea about species-specificity. This circle can only be broken if taxonomists routinely consider the possibility of genital polymorphism, even at the risk of being rebutted.

\section{Acknowledgements}

We thank our Philippine driver Vicente Bulongon for bringing us safely to all requested places. Samuel B. Huber, Mae A. Responte, Eddie P. Mondejar, and Philip N.O. Banaag II helped in the field and the latter three also contributed specimens from their own research. Permits were received from the Department of Environment and Natural Resources (DENR) CARAGA, DENR Region X, DENR Region XI and from the Forest Department, Sarawak (Permit No. NCCD.907.4.4(JLD.10)-211, Park Permit No. 174/2014). The German Research Foundation provided financial support (DFG Project HU 980/11-1).

\section{References}

Brown B.V. 1993. A further chemical alternative to critical-point-drying for preparing small (or large) flies. Fly Times 11: 10.

Dimitrov D., Astrin J.J. \& Huber B.A. 2013. Pholcid spider molecular systematics revisited, with new insights into the biogeography and the evolution of the group. Cladistics 29: 132-146. http://dx.doi. org/10.1111/j.1096-0031.2012.00419.x 
HUBER B.A. et al., Revision of Aetana spiders

Goloboff P.A. 1993. NONA (NO NAME) ver. 2. Published by the author, Tucumán, Argentina. Available from http://www.lillo.org.ar/phylogeny/ [accessed on 24 Nov. 2015]

Goloboff P.A. 1997. Pee-Wee, ver. 2.8. Published by the author. New York. Available from http://www. lillo.org.ar/phylogeny/ [accessed on 24 Nov. 2015]

Goloboff P.A., Farris J.S. \& Nixon K. 2004. TNT, tree analysis using new technology, version 1.1, sponsored by the Willi Hennig Society. Available from http://www.lillo.org.ar/phylogeny/ [accessed on 24 Nov. 2015]

Goloboff P.A., Farris J.S. \& Nixon K. 2008. TNT, a free program for phylogenetic analysis. Cladistics 24: 774-786. http://dx.doi.org/10.1111/j.1096-0031.2008.00217.x

Huber B.A. 2000. New World pholcid spiders (Araneae: Pholcidae): a revision at generic level. Bulletin of the American Museum of Natural History 254: 1-348. http://dx.doi.org/10.1206/00030090(2000)254\%3C0001:NWPSAP\%3E2.0.CO;2

Huber B.A. 2001. The pholcids of Australia (Araneae; Pholcidae): taxonomy, biogeography, and relationships. Bulletin of the American Museum of Natural History 260: 1-144. http://dx.doi. org/10.1206/0003-0090(2001)260\%3C0001:TPOAAP\%3E2.0.CO;2

Huber B.A. 2003a. Cladistic analysis of Malagasy pholcid spiders reveals generic level endemism: revision of Zatavua n. gen. and Paramicromerys Millot (Pholcidae, Araneae). Zoological Journal of the Linnean Society 137 (2): 261-318. http://dx.doi.org/10.1046/j.1096-3642.2003.00046.x

Huber B.A. 2003b. High species diversity in one of the dominant groups of spiders in East African montane forests (Araneae: Pholcidae: Buitinga n. gen., Spermophora Hentz). Zoological Journal of the Linnean Society 137 (4): 555-619. http://dx.doi.org/10.1046/j.1096-3642.2003.00053.x

Huber B.A. 2003c. Southern African pholcid spiders: revision and cladistic analysis of Quamtana gen. nov. and Spermophora Hentz (Araneae: Pholcidae), with notes on male-female covariation. Zoological Journal of the Linnean Society 139 (4): 477-527. http://dx.doi.org/10.1046/j.0024-4082.2003.00082.x

Huber B.A. 2005a. Revision of the genus Spermophora Hentz in Southeast Asia and on the Pacific Islands, with descriptions of three new genera (Araneae: Pholcidae). Zoologische Mededelingen 79-2 (4): 61-172.

Huber B.A. 2005b. High species diversity, male-female coevolution, and metaphyly in Southeast Asian pholcid spiders: the case of Belisana Thorell, 1898 (Araneae, Pholcidae). Zoologica 155: 1-126.

Huber B.A. 2011. Revision and cladistic analysis of Pholcus and closely related taxa (Araneae, Pholcidae). Bonner zoologische Monographien 58: 1-509.

Huber B.A. 2013. Revision and cladistic analysis of the Guineo-Congolian spider genus Smeringopina Kraus (Araneae, Pholcidae). Zootaxa 3713: 1-160. http://dx.doi.org/10.11646/zootaxa.3713.1.1

Huber B.A. \& Fleckenstein N. 2008. Comb-hairs on the fourth tarsi in pholcid spiders (Araneae, Pholcidae). Journal of Arachnology 36: 232-240. http://dx.doi.org/10.1636/CSh07-71.1

Huber B.A. \& Pérez-González A. 2001. Female genital dimorphism in a spider (Araneae: Pholcidae). Journal of Zoology, London 255: 301-304. http://dx.doi.org/10.1017/S095283690100139X

Jocqué R. 2002. Genitalic polymorphism - a challenge for taxonomy. Journal of Arachnology 30: 298306. http://dx.doi.org/10.1636/0161-8202(2002)030[0298:GPACFT]2.0.CO;2

Mitter C., Farrell B. \& Wiegmann B. 1988. The phylogenetic study of adaptive zones: has phytophagy promoted insect diversification? The American Naturalist 132: 107-128. http://dx.doi. org/10.1086/284840 
Mutanen M. \& Kaitala A. 2006. Genital variation in a dimorphic moth Selenia tetralunaria (Lepidoptera, Geometridae). Biological Journal of the Linnean Society 87: 297-307. http://dx.doi.org/10.1111/j.1095$\underline{8312.2006 .00578 . \mathrm{x}}$

Nixon K.C. 2002. Winclada, version 1.00.08. Program and documentation. Available online from http:// www.cladistics.com/wincDownload.htm [accessed on 24 Nov. 2015]

Manuscript received: 10 September 2015

Manuscript accepted: 14 October 2015

Published on: 14 December 2015

Topic editor: Rudy Jocqué

Desk editor: Kristiaan Hoedemakers

Printed versions of all papers are also deposited in the libraries of the institutes that are members of the EJT consortium: Muséum national d'Histoire naturelle, Paris, France; Botanic Garden Meise, Belgium; Royal Museum for Central Africa, Tervuren, Belgium; Natural History Museum, London, United Kingdom; Royal Belgian Institute of Natural Sciences, Brussels, Belgium; Natural History Museum of Denmark, Copenhagen, Denmark. 
HUBER B.A. et al., Revision of Aetana spiders

\section{Appendix 1}

Data matrix for cladistic analysis. Taxa are arranged as in the cladogram in Fig. 1. Terminals and characters are detailed in Appendices 2 and 3; "“" = non-applicable; "?" = unknown or coding ambiguous. This matrix is available online at www.pholcidae.de/matrices.html

Zatavua griswoldi Huber, 2003 Spermophora estebani Simon, 1892 Khorata khammouan Huber, 2005 Savarna thaleban Huber, 2005 Gen.n. Bor80 Gen.n. Bor20 Aetana ocampoi Huber, sp. nov. Aetana libjo Huber, sp. nov. Aetana baganihan Huber, sp. nov. Aetana kiukoki Huber, sp. nov. Aetana paragua Huber, sp. nov. Aetana loboc Huber, sp. nov. Aetana pasambai Huber, sp. nov. Aetana gaya Huber, sp. nov. Aetana kinabalu Huber, 2005 Aetana lambir Huber, sp. nov. Aetana poring Huber, sp. nov. Aetana indah Huber, sp. nov. Aetana fiji Huber, 2005 Aetana abadae Huber, sp. nov. Aetana omayan Huber, 2005 Aetana manansalai Huber, sp. nov. Aetana lozadae Huber, sp. nov. Aetana banahaw Huber, sp. nov.

$$
\begin{array}{rrrrrrrr}
5 & 10 & 15 & 20 & 25 & 30 & 35 & 40 \\
\downarrow & \downarrow & \downarrow & \downarrow & \downarrow & \downarrow & \downarrow & \downarrow
\end{array}
$$

$0005000000000100000000--400001000010100000-?$ $00000011000000000010010040000100000-100000-0$ $2000101100000000010000--00000101100-000000-0$ $200011--00100010000000--30001101100-000000-0$ $2004100001001000000000--001111011011000000-0$ $2000100001001000000000--001111011011000000-0$ $1000000010100010001100--1100001 ? ? 010000000-0$ $1000000010100000001100--210010101011001000-1$ $1000000010100000001100--2100101 ? ? 011001000-1$ $100301--00000000011000--100000101010000010-0$ $100301--00000000011000--1000001 ? ? 010000010-0$ $110301--00000010011000--1000001 ? ? 010000010-0$ $110301--00000010011000--1000001 ? ? ? ? ? ? ? ? ? ? 0$ $00000001000010101010110000000010100-010000-0$ $0000000100000011101011000000001 ? ? 00-010100-1$ $0000000100000010101010--0000001 ? ? 00-010000-1$ $0000000100001111101011010000001 ? ? 00-010000-0$ $00000001000011111010110100000010100-010100-0$ $10020011000000110010110000 ? ? ? 0 ? ? ? ? 0-000 ? 0 ? ? ?$ $1002001100010010001011020000001 ? ? 10-00010100$ $10020011000100110010110200000010110-00010100$ $1011001100000010001011100000001 ? ? 12-00000110$ $1011001100000010001011100000001 ? ? 12-00000110$ 1011001100000010001011100000001 ??12-00000110 


\section{Appendix 2}

Terminal taxa scored for the cladistic analysis, with origin and depository. Taxa are arranged as in the cladogram in Fig. 1.

\section{Outgroups}

Zatavua griswoldi Huber, 2003: data from Huber 2003a.

Spermophora estebani Simon, 1892: data from Huber 2005a.

Khorata khammouan Huber, 2005: data from Huber 2005a.

Savarna thaleban Huber, 2005: Thailand, Thale Ban N.P. (ZFMK).

Gen.n. Bor80 Huber, sp. nov.: Malaysia, Sarawak, Kapit (ZFMK).

Gen.n. Bor20 Huber, sp. nov.: Malaysia, Sarawak, Niah (ZFMK).

\section{Aetana}

A. ocampoi Huber, sp. nov.: Philippines, Luzon, Mt. Isarog (ZFMK).

A. libjo Huber, sp. nov.: Philippines, Dinagat Isl. (ZFMK).

A. baganihan Huber, sp. nov.: Philippines, Mindanao, Baganihan (ZFMK).

A. kiukoki Huber, sp. nov.: Philippines, Mindanao, Baganihan (ZFMK).

A. paragua Huber, sp. nov.: Philippines, Dinagat Isl. (ZFMK).

A. loboc Huber, sp. nov.: Philippines, Bohol, Loboc (ZFMK).

A. pasambai Huber, sp. nov.: Philippines, Negros, Casaroro Falls (ZFMK).

A. kinabalu Huber, 2005: Malaysia, Sabah, Mt. Kinabalu (ZFMK).

A. lambir Huber, sp. nov.: Malaysia, Sarawak, Lambir Hills (ZFMK).

A. gaya Huber, sp. nov.: Malaysia, Sabah, Gaya Isl. (ZFMK).

A. poring Huber, sp. nov.: Malaysia, Sabah, Poring (ZFMK).

A. indah Huber, sp. nov.: Malaysia, Sabah, Crocker Range (ZFMK).

A. fiji Huber, 2005: Data from Huber 2005a.

A. abadae Huber, sp. nov.: Philippines, Negros, Twin Lakes N.P. (ZFMK).

A. omayan Huber, 2005: Philippines, Luzon, Baguio (ZFMK).

A. manansalai Huber, sp. nov.: Philippines, Luzon, betw. Lucban and Tayabas (ZFMK).

A. lozadae Huber, sp. nov.: Philippines, Luzon, Mt. Isarog (ZFMK).

A. banahaw Huber, sp. nov.: Philippines, Luzon, Mt. Banahaw (ZFMK). 


\section{Appendix 3}

Characters scored for cladistic analysis.

\section{Prosoma}

1. Thoracic furrow: (0) absent (Fig. 135); (1) shallow, only anteriorly (Fig. 63); (2) distinct over entire length of carapace. The plesiomorphic condition in Pholcinae seems to be the absence of a thoracic furrow. However, most representatives of Aetana have a shallow furrow in the anterior part of the carapace. The absence in the Aetana kinabalu group is here considered secondary; the same is true for the distinct and long furrows in Khorata, Savarna, and 'Gen.n. Borneo'.

2. Male ocular area median process: (0) absent; (1) present. A median process (Figs 77, 96) is a unique synapomorphy of Aetana loboc Huber, sp. nov. + A. pasambai Huber, sp. nov..

3. Male ocular area, ventral processes near ALE: (0) absent; (1) present. These unique processes (Figs 221,226) unite three species of the Aetana omayan group: A. manansalai Huber, sp. nov., A. lozadae Huber, sp. nov., and A. banahaw Huber, sp. nov..

4. Male clypeus: (0) unmodified or slightly bulging; (1) with pair of lateral ridges (Figs 221, 226); (2) with pair of apophyses (Fig. 191); (3) with large sclerotized process at clypeus margin (Figs 59, 77); (4) with small median process between eyes and clypeus margin; (5) with pair of bulges at rim. An unmodified clypeus seems to be plesiomorphic for Aetana. A large sclerotized process at the clypeus rim is a synapomorphy of the Aetana kiukoki group; a pair of rather small apophyses unites the Aetana omayan group but is modified into a pair of ridges in $A$. manansalai sp. nov., A. lozadae Huber, sp. nov., and $A$. banahaw Huber, sp. nov.. Character states 4 and 5 are autapomorphic for outgroup taxa (Zatavua griswoldi; 'Gen.n. Bor 80 Huber, sp. nov.').

5. Sternum color: (0) at least partly light; (1) entirely dark. A dark (usually black) sternum unites several outgroup taxa (Savarna; Khorata; 'Gen.n. Borneo'). All Aetana species have a light or mostly light sternum.

\section{Male chelicerae}

6. Chelicerae distal apophyses: (0) present; (1) absent or indistinct hump. The presence of distal apophyses (e.g., Figs 15, 115, 221) is interpreted to be plesiomorphic for Aetana. A reduction occurred twice in the present matrix, once in Savarna, and once as a synapomorphy of the Aetana kiukoki group (Figs 59, 72, 77, 96).

7. Chelicerae distal apophyses, length: (0) short; (1) long. Short distal apophyses seem to be plesiomorphic for Aetana. Long apophyses have evolved convergently in Spermophora estebani, Khorata khammouan, and as a synapomorphy of the Aetana omayan group (Figs 191, 221, 226).

8. Chelicerae distal apophyses, position: (0) frontal; (1) lateral. The plesiomorphic position is ambiguous. A lateral position may unite the Aetana kinabalu and A. omayan groups, but occurs independently in Spermophora estebani and Khorata khammouan.

9. Chelicerae proximal apophyses: (0) present; (1) absent. Proximal cheliceral apophyses (Figs 59, $115,221)$ are a synapomorphy of Pholcinae. In the present matrix, the reduction of these apophyses (Figs 15, 40) is a synapomorphy of the Aetana ocampoi group.

\section{Male pedipalp}

10. Coxa ventral apophysis or rim: (0) absent or indistinct; (1) present and distinct. A ventral apophysis is a synapomorphy of Modisiminae but is rare in other subfamilies. In the present matrix, it is an autapomorphy of 'Gen.n. Borneo'.

11. Trochanter-femur connection: (0) normal hinge; (1) segments partly fused (Figs 14, 27). A partial fusion between trochanter and femur occurs both in Savarna and in the Aetana ocampoi group, but is not known in any other Pholcidae. The cladistic analysis suggests that these are two independent origins. 
12. Trochanter prolateral apophysis: (0) absent; (1) present. In most Pholcinae, the palpal trochanter has one (retrolateral to ventral) apophysis. Additional apophyses (usually retrolateral or dorsal) have evolved frequently. In the present matrix, two species of the Aetana omayan group are united by a unique prolateral apophysis in addition to the usual ventral apophysis (Fig. 189).

13. Trochanter apophysis: (0) smooth; (1) with small teeth or scales (Fig. 158). The retrolatero-ventral apophysis of the trochanter is usually smooth. Teeth or scales have evolved independently in 'Gen.n. Borneo' and in three species of the Aetana kinabalu group.

14. Femur apophysis near prolateral joint to trochanter: (0) absent; (1) present. This small but distinct apophysis (Figs 145, 150) is a synapomorphy of two species within the Aetana kinabalu group. A similar process evolved independently in the outgroup species Zatavua griswoldi.

15. Femur distal retrolatero-ventral process: (0) absent; (1) present. The Aetana kinabalu and A. omayan groups are united by this process, which is large and round in the $A$. kinabalu group (Figs 114, 151) but smaller and more slender in the $A$. omayan group (Figs 190, 220). A similar structure occurs in Aetana ocampoi Huber, sp. nov. (Fig. 14), in A. loboc Huber, sp. nov. + A. pasambai Huber, sp. nov., and in Savarna thaleban.

16. Femur prolateral process: (0) absent; (1) present. A prolateral process (not close to the femurtrochanter hinge as char. 14; e.g., Fig. 145) has apparently evolved several times independently in the Aetana kinabalu and A. omayan groups.

17. Femur distal prolatero-ventral process: (0) absent; (1) present. All species of the A. kinabalu group share this sometimes large process on the femur (Figs 113, 126, 150).

18. Femur retrolateral apophysis: (0) absent or indistinct; (1) present/long (Figs 58, 71, 76, 98). A distinct long apophysis is a synapomorphy of the A. kiukoki group.

19. Tibia retrolateral trichobothrium, position: ( 0 ) normal (i.e., at about $60-90 \%$ of tibia length); (1) very distal ( $>90 \%$ of tibia length). All species of Aetana share a very distal position of the retrolateral trichobothrium on the male palpal tibia (e.g., Figs 27, 71, 114). This is shared by Spermophora estebani (and other species of Spermophora; see Huber 2005a). The present analysis interprets this as a convergence, but preliminary molecular data resolve Aetana and Southeast Asian Spermophora as sister groups (A. Valdez-Mondragón, D. Dimitrov, B.A. Huber, unpublished data).

20. Procursus: (0) complex, with sclerotized elements; (1) simple semi-transparent, ribbon-shaped process (Figs 14,27). A highly reduced procursus is a unique synapomorphy of the Aetana ocampoi group.

21. Procursus ventral lamina: (0) absent; (1) present. This distinctive process (e.g., Figs 127, 190, 229 231) unites the Aetana kinabalu and A. omayan groups.

22. Procursus retrolatero-ventral process: (0) absent; (1) present. This sclerite (e.g., Figs 127, 190, 229 231) unites the Aetana kinabalu and A. omayan groups, but occurs independently in Spermophora estebani (and other species of Spermophora; see Huber 2005a).

23. Procursus retrolatero-ventral process, position: (0) transversal; (1) pointing toward distal. In the outgroup taxon Spermophora estebani (and even more clearly in other species of Spermophora; see Huber 2005a) this sclerite has a transversal position on the procursus. This is thus considered plesiomorphic for Aetana. In three species of the A. omayan group, the sclerite points toward distal (Figs 229-231).

24. Procursus retrolatero-ventral process tip: (0) simple; (1) bifid; (2) bipartite. A simple tip seems to be plesiomorphic. Two species of the A. kinabalu group share a bifid tip (Figs 146, 151), while in two species of the A. omayan group the sclerite is deeply split in two parts (Fig. 190).

25. Genital bulb distal processes: (0) only embolus; (1) embolus plus short membranous process (Figs $58,75)$; (2) embolus plus two partly sclerotized processes (Figs 38-39, 41-42); (3) single complex, sclerotized process containing sperm duct; (4) embolus plus one partly sclerotized process. A single sclerotized process ('appendix') in addition to a slightly sclerotized embolus (char. state 4) is plesiomorphic for Aetana and probably for Pholcinae. The present analysis suggests a loss of the appendix in the ancestor of Aetana + some outgroup taxa, and many species of Aetana retain 
this character state (char. state 0). Most species of the Aetana kiukoki and A. ocampoi groups have developed a short membranous process (char. state 1), and A. libjo Huber, sp. nov. and A. baganihan Huber, sp. nov. share even two additional processes (char. state 2). A single complex, sclerotized process containing the sperm duct (char. state 3 ) is a putative autapomorphy of Savarna (B.A. Huber \& B. Petcharad, unpubl. data).

26. Genital bulb proximal retrolateral process: (0) absent; (1) present. This indistinct process (Figs 14, 27) occurs in all species of the Aetana ocampoi group.

\section{Legs}

27. Male femur 1 spines: (0) absent; (1) present. Spines on the legs are very rare in Pholcinae. In the present matrix, they only occur in 'Gen.n. Bor 80 Huber, sp. nov.' and 'Gen.n. Bor 20 Huber, sp. nov.'. They also occur in two species of Savarna (B.A. Huber \& B. Petcharad, unpubl. data) but not in $S$. thaleban.

28. Male femora vertical hairs: (0) absent (or very few); (1) present in high density. Short vertical hairs in high density on the femora are rare in Pholcidae (known in some Modisiminae genera; see Huber 2000). In the present matrix, they only occur in 'Gen.n. Bor 80 Huber, sp. nov.' and 'Gen.n. Bor 20 Huber, sp. nov.'.

29. Tibia vertical hairs: (0) absent (or very few); (1) present in high density. Short vertical hairs on the tibiae are slightly more widespread than on the femora (especially in Modisiminae), but rare in Pholcinae. According to the present analysis, they evolved independently in Savarna + ('Gen.n. Bor 80 Huber, sp. nov.' + 'Gen.n. Bor 20 Huber, sp. nov.') and in Aetana libjo Huber, sp. nov. $+A$. baganihan Huber, sp. nov..

30. Tibia 1 retrolateral trichobothrium position: (0) proximal (at $<5 \%$ of tibia 1 length); (1) distal (at $>5 \%$ of tibia 1 length). In the present matrix, only Aetana is characterized by a very proximal position of the retrolateral trichobothrium.

31. Curved hairs on tibiae and/or metatarsi: (0) absent; (1) present (Fig. 133). In the present matrix, only Aetana is characterized by curved hairs on tibiae and/or metatarsi.

\section{Abdomen}

32. Epiandrous spigots: (0) present; (1) absent. The presence of epiandrous spigots is plesiomorphic for Pholcinae and for Aetana. In the present matrix, the loss of these spigots unites several outgroup taxa, i.e. Savarna, Khorata (Figs 243, 245, 247), and 'Gen.n. Borneo'.

33. ALS spigots: (0) eight; (1) two. The plesiomorphic condition in Pholcinae is seven to eight spigots: one very wide spigot, one pointed spigot, and five to six smaller cylindrically-shaped spigots. In the present matrix, Aetana and several outgroup taxa are united by the loss of the smaller cylindricallyshaped spigots (Figs 68, 142, 210, 244, 246, 248).

34. Female stridulatory apparatus between prosoma and abdomen: (0) absent; (1) present. A modified median plate on the carapace (Figs 186-188) acting against an indistinct hairless field on the abdomen characterizes all species of the Aetana omayan group (not verified in A. fiji).

35. Epigynum posterior margin: (0) more or less straight; (1) with scape; (2) deeply indented. A straight epigynal margin is plesiomorphic for Aetana. A scape is here interpreted to have evolved convergently in 'Gen.n. Borneo' and within Aetana, uniting the Aetana ocampoi and A. kiukoki groups. A deeply indented posterior margin is a synapomorphy of three species within the A. omayan group.

36. Epigynum scape, shape: (0) wide; (1) narrow. In the Aetana ocampoi and A. kiukoki groups, a wide scape (Figs 16, 60,78) is plesiomorphic, and a narrow scape (Figs 28, 43) unites $A$. libjo Huber, sp. nov. and $A$. baganihan Huber, sp. nov.. In 'Gen.n. Borneo' the scape originated as a narrow scape.

37. Epigynum external pair of pockets: (0) absent; (1) present. A pair of pockets on the epigynal plate occurs in the outgroup taxa Zatavua and Spermophora, but not in Aetana or other outgroup taxa. 
38. Female internal genitalia, lateral membranous pockets: (0) absent; (1) present. This pair of pockets, that is only visible in cleared preparations (Figs 112, 117, 129, 149, 154), is a synapomorphy of the Aetana kinabalu group.

39. Female internal genitalia, median membranous structure: (0) absent; (1) present. This unique structure (Figs 29,44) unites two species of the Aetana ocampoi group: A. libjo Huber, sp. nov. + A. baganihan Huber, sp. nov..

40. Female internal genitalia, sclerotized pockets: (0) absent; (1) present. Sclerotized internal pockets originating from the ventral wall of the uterus externus (Figs 111, 153, 192, 194) occur in the Aetana kinabalu group and in the A. omayan group, but are here interpreted to have evolved three times convergently.

41. Female internal genitalia, serrated ridges: (0) absent; (1) present. These highly distinctive and unique ridges (Figs 61,73,79) are a synapomorphy of the Aetana kiukoki group.

42. Pair of pockets behind epigynum: (0) absent; (1) present. A membranous and poorly visible pair of pockets in the area behind the epigynum (Figs 192-194, 222, 227, 232) is a synapomorphy of the Aetana omayan group.

43. Pair of pockets behind epigynum, distance: (0) wide apart; (1) close together. Within the Aetana omayan group, two species are characterized by pockets that are far apart (292-294), and three species by pockets that are close together $(222,227,232)$. The plesiomorphic condition is unclear, as is the condition in $A$. fiji.

\section{Ecology}

44. Microhabitat: (0) close to ground; (1) higher among the vegetation. Most Aetana species live well protected in dark spaces under rocks and logs. A few species occur higher among the vegetation, with their webs among twigs and leaves and often reached by direct sun. This has apparently evolved at least twice, once in A. libjo Huber, sp. nov. + A. baganihan Huber, sp. nov., and once in A. kinabalu + A. lambir Huber, sp. nov.. A third independent case might occur in A. fiji, but the available data (sparse label information) are not conclusive. 